\title{
Improving the simulation of a waterflooding recovery process using artificial neural networks
}

\author{
Edison Gil \\ West Virginia University
}

Follow this and additional works at: https://researchrepository.wvu.edu/etd

\section{Recommended Citation}

Gil, Edison, "Improving the simulation of a waterflooding recovery process using artificial neural networks" (2000). Graduate Theses, Dissertations, and Problem Reports. 1071.

https://researchrepository.wvu.edu/etd/1071

This Thesis is protected by copyright and/or related rights. It has been brought to you by the The Research Repository @ WVU with permission from the rights-holder(s). You are free to use this Thesis in any way that is permitted by the copyright and related rights legislation that applies to your use. For other uses you must obtain permission from the rights-holder(s) directly, unless additional rights are indicated by a Creative Commons license in the record and/ or on the work itself. This Thesis has been accepted for inclusion in WVU Graduate Theses, Dissertations, and Problem Reports collection by an authorized administrator of The Research Repository @ WVU. For more information, please contact researchrepository@mail.wvu.edu. 


\title{
IMPROVING THE SIMULATION OF A WATERFLOODING RECOVERY
} PROCESS USING ARTIFICIAL NEURAL NETWORKS

\section{Edison Gil}

\author{
Thesis Submitted to the \\ College of Engineering and Mineral Resources \\ At West Virginia University \\ In partial fulfillments of the requirements \\ For the degree of
}

\author{
Master of Science \\ In \\ Petroleum and Natural Gas Engineering
}

Kashayar Aminian, Ph.D., Chair

Samuel Ameri, M.S.

Ilkin Bilgesu, Ph.D.

Shahab Mohaghegh, Ph.D.

Department of Petroleum and Natural Gas Engineering

\section{Morgantown, West Virginia}

2000

Keywords: Petroleum and Natural Gas Engineering, Reservoir Simulation, Artificial Neural Networks, Reservoir Characterization, Waterflooding Copyright 2000 Edison Gil 


\section{ABSTRACT \\ IMPROVING THE SIMULATION OF A WATERFLOODING RECOVERY PROCESS USING ARTIFICIAL NEURAL NETWORKS

\author{
Edison Gil
}

The waterflood performance of the dual five-spot pilot project in the Stringtown oil field, situated in West Virginia, has been studied. A numerical simulator, called BOAST98, was used for the simulation purposes, after developing a reservoir description.

The producing horizon in the field is the Upper Devonian Gordon sandstone, which is characterized by severe heterogeneity due to the depositional environment. Using available core and log data and geological analysis, a reservoir characterization study was done. A preliminary reservoir description based on log porosity - core permeability correlation was improved by developing Artificial Neural Networks (A.N.N.), which incorporates geophysical well log information. These A.N.N.'s were utilized to predict porosity and permeability for five wells in the pilot area.

A reservoir model for simulation purposes was constructed after identifying the principal flow units within the formation. Results from the simulation were compared with five years of actual field data. A close history matching for the cumulative oil and water production in the pilot project was achieved after scheduling $10-15 \%$ of the total water injection volume into the pilot area. 


\section{ACKNOWLEDGEMENTS}

I would like to take this opportunity to express my gratitude and appreciation to Dr. Khashayar Aminian, my academic and research advisor, for his invaluable guidance, support and dedication that made possible the completion of the study.

My appreciation to Dr. Sam Ameri, Chairman of the Petroleum and Natural Gas Engineering Department, for his friendship and continuous advice during my stay at West Virginia University.

Special thanks to Dr. H. Ilkin Bilgesu, for his encouragement and permanent assistance during my research, and Dr. Shahab Mohaghegh for their participation in the examining committee.

I would also like to extend my appreciation to the staff at the WV Geological and Economic Survey, for their collaboration throughout the duration of the project.

My gratitude also to my friends at WVU, especially Alexander Chamorro and Jonathan Diazgranados, who were a great moral and educational support the last 2 years. Good fellows.

Finally, I dedicate this work to my beloved family, from whom I have been learning the most important lesson in life, to be a better human being. 


\section{TABLE OF CONTENTS}

Page

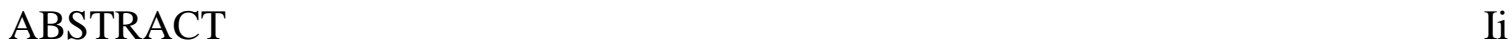

ACKNOWLEDGEMENTS

TABLE OF CONTENTS $\quad$ iv

LIST OF FIGURES

LIST OF TABLES viii

NOMENCLATURE $\quad x$

CHAPTER 1. INTRODUCTION 1

CHAPTER 2. BACKGROUND AND THEORY 4

$2.1 \quad$ Description of the field 4

$\begin{array}{lll}2.2 & \text { Reservoir Characterization } & 7\end{array}$

$\begin{array}{llr}2.3 & \text { Artificial Neural Networks } & 9\end{array}$

$\begin{array}{lll}\text { 2.3.1 Types of Artificial Neural Networks } & 10\end{array}$

$\begin{array}{lll}\text { 2.3.1.1 Supervised Networks } & 10\end{array}$

$\begin{array}{lll}\text { 2.3.1.2 Unsupervised Networks } & 12\end{array}$

$\begin{array}{lll}\text { 2.3.2 Neural Network Structure } & 13\end{array}$

$\begin{array}{lll}\text { 2.3.3 Learning Process } & 14\end{array}$

$\begin{array}{lll}\text { 2.3.4 Activation Functions } & 18\end{array}$ 
$\begin{array}{lll}2.4 & \text { Numerical Simulation } & 19\end{array}$

$\begin{array}{ll}2.4 .1 & \text { Types of Simulators }\end{array}$

2.4.2 BOAST98 Simulator Overview 21

CHAPTER 3. METHODOLOGY 26

3.1 Data Collection and Analysis 26

3.1.1 Description of the Gordon Sandstone 26

3.1.2 Waterflood Pilot Area 29

3.2 Prediction of Petrophysical Parameters 35

3.2.1 Conventional Permeability Prediction 35

3.2.2 Porosity Prediction with A.N.N.s 35

3.2.3 Permeability Prediction using Artificial Neural Networks 36

3.3 Definition of Flow Units 37

3.4 Simulation Model $\quad 37$

3.4.1 Input Data for the Simulator $\quad 38$

3.4.1.1 Reservoir Parameters 38

3.4.1.2 Fluid Parameters 39

3.4.2 Recurrent Data for the Simulator 43 
4.1 Permeability Prediction using Conventional Approach $\quad 47$

4.2 Porosity Predicted with A.N.N. $\quad 49$

4.3 Effect of Lithology on Permeability 49

4.4 Permeability Predicted with A.N.N. $\quad 52$

4.5 Petrophysical Parameters for the Pilot Wells 53

4.6 Definition of Flow Units in Pilot Area 55

4.7 History Matching $\quad 55$

CHAPTER 5. CONCLUSIONS 60

CHAPTER 6. RECOMMENDATIONS 62

$\begin{array}{ll}\text { REFERENCES } & 63\end{array}$

Appendix A. Porosity, permeability and lithology distribution in cored wells. 65

Appendix B. Porosity predictions in cored wells. $\quad 69$

Appendix C. Permeability predictions in cored wells. 73

Appendix D. Porosity and permeability predictions with A.N.N. for wells in pilot 77 area.

Appendix E. Description of Edboast and Boast98. 81

Appendix F. History matching using lithologic zones as Flow units 91 


\section{LIST OF FIGURES}

Page

Figure 2.1 Stringtown Oilfield Location 4

Figure 2.2 Daily Oil Production in the Stringtown Field. 1896-1991 6

Figure 2.3 Cumulative Oil Production in the Stringtown field. 1896-1991 6

Figure 2.4 Arquitecture of a Backpropagation Neural Network. 12

$\begin{array}{lll}\text { Figure 2.5 Structure of an A.N.N. } & 14\end{array}$

Figure 3.1 Location of the cored wells in the Stringtown field. 27

Figure 3.2 Distribution of the Wells in the Pilot Area 31

Figure 3.3 Total water injection rates in the pilot. 32

Figure 3.4 Wellhead injection pressures in the pilot. 32

Figure 3.5 Cumulative oil production in the pilot wells. 34

Figure 3.6 Cumulative water production in the pilot wells. 34

Figure $3.7 \quad$ Shape of the Pay Sand in the Pilot 39

Figure 3.8 Comparison of relative permeabilities. 42

Figure 4.1 Correlation between core porosity and core permeability. 47

Figure 4.2 Correlation between core porosity and log-derived porosity. 48

Figure 4.3 Correlation between Log-derived porosity and core permeability. 48

Figure 4.4 Correlation between core porosity and porosity from A.N.N. 50

Figure 4.5 Correlation between Log-derived porosity and core permeability. $\quad 50$

Figure 4.6 Correlation between core porosity - permeability for conglomerate 51

Figure 4.7 Correlation between core porosity - permeability for sandstone 52

Figure 4.8 Comparison of cumulative oil production from the pilot. Both 57 
producers

Figure 4.9 Comparison of cumulative water production from the pilot. Both producers

Figure 4.10 Comparison of cumulative oil production. Well M-1 58

Figure 4.11 Comparison of cumulative water production. Well M-1 58

Figure 4.12 Comparison of cumulative oil production. Well H-12 59

Figure 4.13 Comparison of cumulative water production. Well H-12 59

Figure A.1 Porosity, lithology and permeability from core data. Well H-11 66

Figure A.2 Porosity, lithology and permeability from core data. Well H-9 66

Figure A.3 Porosity, lithology and permeability from core data. Well B-19 67

Figure A.4 Porosity, lithology and permeability from core data. Well T-8 67

Figure A.5 Porosity, lithology and permeability from core data. Well L-13 68

Figure A.6 Porosity, lithology and permeability from core data. Well B-18 68

$\begin{array}{lll}\text { Figure B.1 Porosity Prediction with A.N.N. Well H-11 } & 70\end{array}$

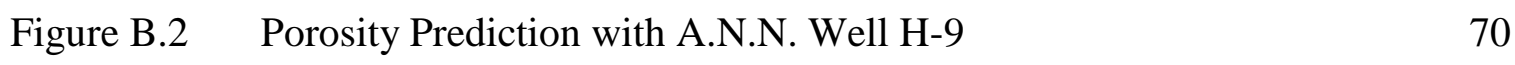

Figure B.3 Porosity Prediction with A.N.N. Well B-19 71

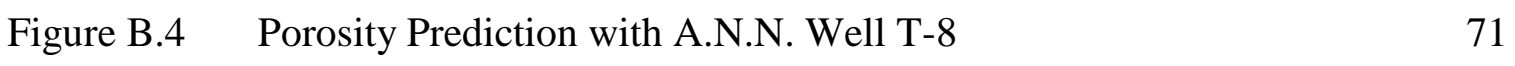

$\begin{array}{lll}\text { Figure B.5 Porosity Prediction with A.N.N. Well L-13 } & 72\end{array}$

Figure B.6 Porosity Prediction with A.N.N. Well B-18 72

Figure C.1 Permeability Prediction with A.N.N. Well H-11

Figure C.2 Permeability Prediction with A.N.N. Well H-9

Figure C.3 Permeability Prediction with A.N.N. Well B-19 75

Figure C.4 Permeability Prediction with A.N.N. Well T-8 75 
Figure C.5 Permeability Prediction with A.N.N. Well L-13 76

Figure C.6 Permeability Prediction with A.N.N. Well B-18 76

Figure D.1 Porosity and permeability distribution from A.N.N. Well P-7 78

Figure D.2 Porosity and permeability distribution from A.N.N. Well L- 9

Figure D.3 Porosity and permeability distribution from A.N.N. Well H-10 79

Figure D.4 Porosity and permeability distribution from A.N.N. Well A-5 79

Figure D.5 Porosity and permeability distribution from A.N.N. Well H-12 80

$\begin{array}{lll}\text { Figure E.1 Boast98 main menu Window. } & 82\end{array}$

Figure E.2 Main input data menu in EdBoast. 83

Figure E.3 Primary menu display of BOAST98. 87

Figure E.4 Boast98 secondary menu shown during simulation. 90

Figure F.1 Cumulative oil production for both producers. Lithologic zones 92 taken as flow units.

Figure F.2 Cumulative water production for both producers. Lithologic zones 92 taken as flow units.

Figure F.3 Cumulative oil production, well M-1. Lithologic zones taken as 93 flow units.

Figure F.4 Cumulative water production, well M-1. Lithologic zones taken as 93 flow units.

Figure F.5 Cumulative oil production, well H-12. Lithologic zones taken as flow units.

Figure F.6 Comparison of cumulative water production. Well H-12. Lithologic zones taken as flow units. 


\section{LIST OF TABLES}

Pag.

Table 3.1 Core Analysis, Stringtown Oilfield. 28

Table 2.2 Well data for pilot area. 30

Table 2.3 Average pressure and water injection rates in the pilot. 31

Table 3.1 Activation functions used in the A.N.N. for porosity prediction. 35

$\begin{array}{lll}\text { Table } 3.2 & \text { Crude Oil Analysis. } & 40\end{array}$

Table 3.3 Gas Analysis. $\quad 40$

$\begin{array}{lll}\text { Table } 3.4 & \text { Produced Water Analysis. } & 40\end{array}$

Table 3.5 Relative permeabilities from well H-9. 41

Table 3.6 Capillary pressure air-brine from well L-13. 42

$\begin{array}{lll}\text { Table } 3.7 & \text { Oil PVT properties. } & 44\end{array}$

$\begin{array}{lll}\text { Table } 3.8 \quad \text { Water PVT properties. } & 44\end{array}$

$\begin{array}{lll}\text { Table } 3.9 & \text { Gas PVT properties. } & 44\end{array}$

Table 3.10 Well treatments in pilot wells 45

Table 3.11 Average water injection rates per well 46

Table 4.1 $\mathrm{R}^{2}$ values for porosity prediction. $\quad 49$

Table 4.2 $\mathrm{R}^{2}$ values for permeability prediction. 53

Table 4.3 Average reservoir properties for the pilot wells. 53

Table 4.4 Contribution factors for porosity prediction in pilot wells. 54

Table 4.5 Contribution factors for permeability prediction in pilot wells. 54

Table 4.6 Average properties in the pilot wells per layer. 56 


\section{NOMENCLATURE}

\section{A.N.N.: Artificial Neural Network}

Bo: Oil Formation Volume Factor, RB/STB

BOPD: Barrels of oil per day

$B g$ : Gas Formation Volume Factor, $\mathrm{RCF} / \mathrm{SCF}$

$D X: \quad \mathrm{x}$-direction grid block dimension, $\mathrm{ft}$.

$D Y: \quad$ y-direction grid block dimension, $\mathrm{ft}$.

GR: Gamma Ray

GRNN: General Regression Neural Network

$h$ : Thickness, $\mathrm{ft}$

$K$ : Permeability, $\mathrm{mD}$

Kr: Relative Permeability

Pc corr: Capillary pressure corrected for an oil-water system, psia.

Pc exp: Capillary pressure obtained for a water-air system, psia.

$P I D$ Flow index per layer, for rates in STB/D.

$P N N$ : Probabilistic Neural Network

Rs: Gas-Oil ratio, $\mathrm{SCF} / \mathrm{STB}$

$r w$ : Wellbore radius, $\mathrm{ft}$

$S: \quad$ Layer skin factor

Sw: Water saturation, $\%$

$\sigma_{\mathrm{w}-\mathrm{o}}$ Interfacial tension for water-oil, $\mathrm{dyn} / \mathrm{cm}$.

$\sigma_{\mathrm{w}-\mathrm{a}:}$ Interfacial tension for air-water, $\mathrm{dyn} / \mathrm{cm}$.

$\varphi$ : Porosity, $\%$ 


\section{CHAPTER 1}

\section{INTRODUCTION}

During the life of a water injection project, the field performance is evaluated using past response data, primarily oil production and injection pressures. Different techniques have been proposed and used for this purpose, ranging from empirical correlation to analytical models. ${ }^{1}$ Numerical reservoir simulation models are widely used to analyze the production history of an oil field and to forecast future performance under different operation methods. Nevertheless, the success of any numerical simulation will depend on an accurate reservoir description.

The objective of the reservoir characterization process is to define the main petrophysical parameters needed to predict the flow of fluids within the porous formation. Among these parameters, permeability is one of the most important, since it influences the flow and sweep efficiency in any recovery process involving fluid injection, especially when lateral and vertical variations are present. Connected paths of high or low permeability values will condition the flow, therefore a reservoir description must be focused on identifying these different units that can be used later in a numerical simulation study.

The paths of different flow characteristics are called flow units. A flow unit is defined as a volume of rock subdivided according to geological and petrophysical properties that influence the flow of fluids through it. ${ }^{2}$ The integration of as many of 
these properties as possible into a reservoir description enhance the understanding of the reservoir and provide the best input to build a simulation model.

In order to define the flow units appropriately, permeability and porosity must be predicted with accuracy. Since few wells are cored, these parameters are evaluated using well log information, which is available for almost all the wells in a field. Porosity is generally evaluated using density log data. Permeability is then evaluated developing permeability-porosity correlations, but these do not provide good results in heterogeneous reservoirs. In this case a different technique must be utilized to define the permeability distribution throughout the field. One way to accomplish this is using Artificial Neural Networks, which have been used successfully in previous studies to obtain reliable permeability values from geophysical log data. ${ }^{3}$

Inspired by the biological neural system, artificial neural network technology is being used to solve a wide variety of complex scientific, engineering and business problems. Neural networks are ideally suited for such problems because like the biological neural system, an artificial neural network can learn, and therefore can be trained to find solutions, recognize patterns, classify data, and forecast future events. In the present study, two back propagation networks were developed using the core analysis information for six cored-wells, two of them injectors in the pilot project.

In this project, a numerical simulation study has been conducted to evaluate the Waterflood performance of the dual five-spot pilot project in the Stringtown oil field, 
located in West Virginia. The producing formation in this field is the Upper Devonian Gordon sandstone, which is characterized by severe heterogeneity due to a complex interplay of stratigraphic, structural and diagenetic factors. 


\section{CHAPTER 2.}

\section{BACKGROUND AND THEORY}

\subsection{Description of the field ${ }^{4}$}

The Stringtown Oil Field was discovered in 1895. It is located in the northwestern part of West Virginia, in Tyler, Wetzel and Doddridge Counties (Fig. 2.1). The primary producing formation is the Upper Devonian Gordon Sandstone. The pay thickness in the field ranges from 4 to $15 \mathrm{ft}$. This variation is primarily a result of the topography of the pre-Gordon depositional surface and secondarily by post-depositional erosion. A secondary producing interval is the Mississippian Big Injun sand, approximately 800 feet above the Gordon, but it was not completed for primary production in the Stringtown field.

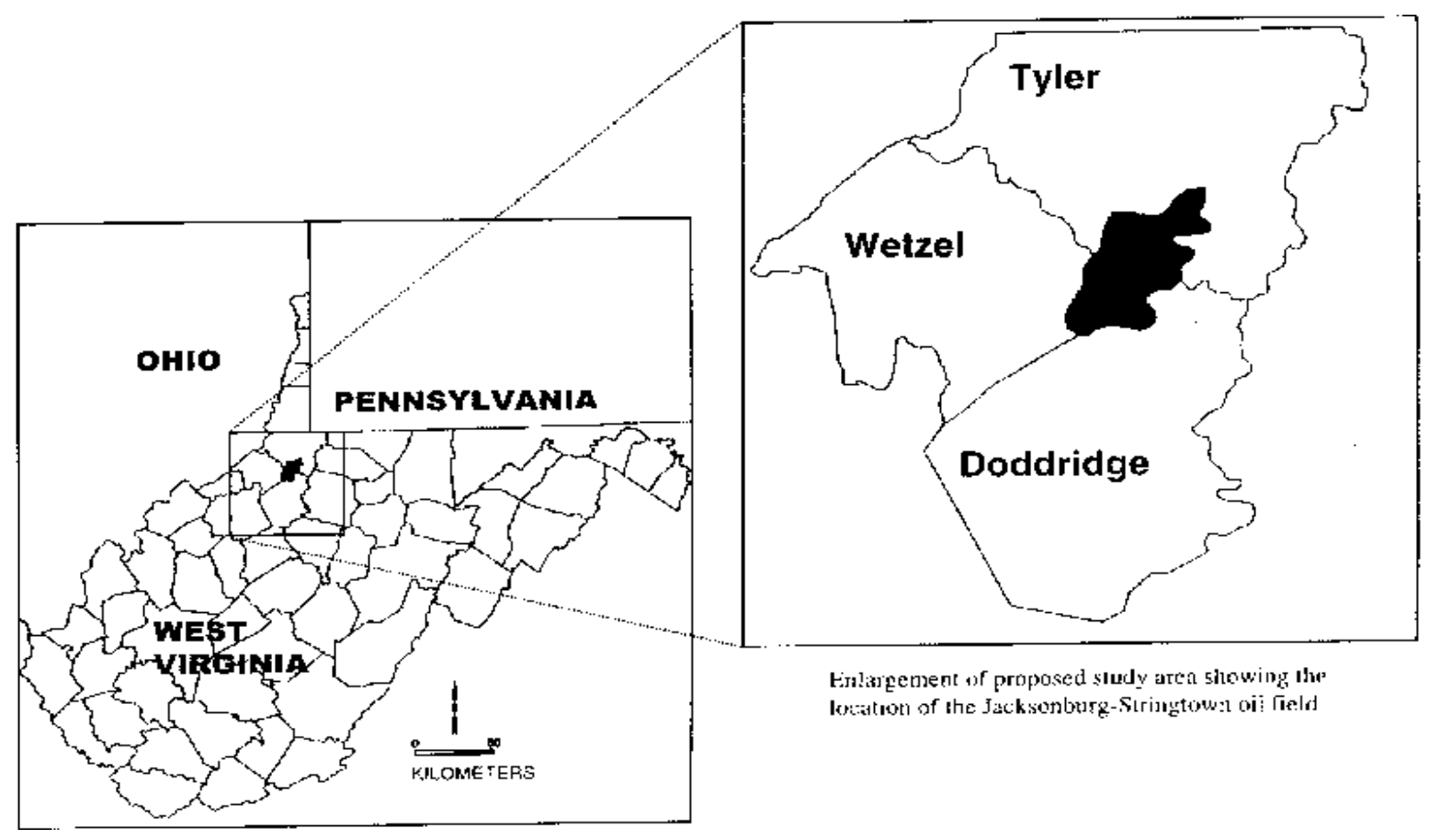

Figure 2.1. Stringtown Oil Field Location 
The 8500 acres field is roughly six miles long (north-south trend) and its width is approximately 2.5 miles. The reservoir area shape is like an inverted cone, wider in the north, narrower in the south. Encountered at an average depth of $3000 \mathrm{ft}$, the entire Gordon section is approximately $50 \mathrm{ft}$. thick and is bound at top and bottom by a series of interbedded sandstones and shales that have been proved to be correlative throughout the field. This sand is interpreted as shallow marine, shoreline deposits, which trends in a northeast-southwest direction. Analysis revealed that it is made up of $71 \%$ quartz, $13 \%$ cementing material, $4 \%$ feldspar and $12 \%$ minor rock fragments. It is a lightly gray, fine to very fine grain size, well sorted, massive to planar bedding with occasional shale laminations. The pay zone lies beneath a low-porosity, conglomeratic zone. Conglomerates are found to have generally unpredictable permeability, which can range from 0 to $500 \mathrm{md}$. As a result, this conglomerate section may act as a permeability barrier, as a reservoir, or even as a thief zone for injected fluids.

Over 500 wells were drilled in the field between 1897 and 1901, with most of them being plugged by 1910 . Average well spacing was 13 acres, and the average initial production potential per well was 72 barrels of oil per day (BOPD), with a range of 0 to 300 BOPD. The typical well was completed open hole and then stimulated with a nitroglycerine shot. The primary production mechanisms were solution gas drive and gravity drainage, which lasted until mid the 1920's. A gas re-injection program was initiated in 1936 and continued through the 1950's, and accounted for about $10 \%$ of the field cumulative production. The daily and cumulative oil productions from 1897 to 1991 are shown in Figures 2.2 and 2.3. 


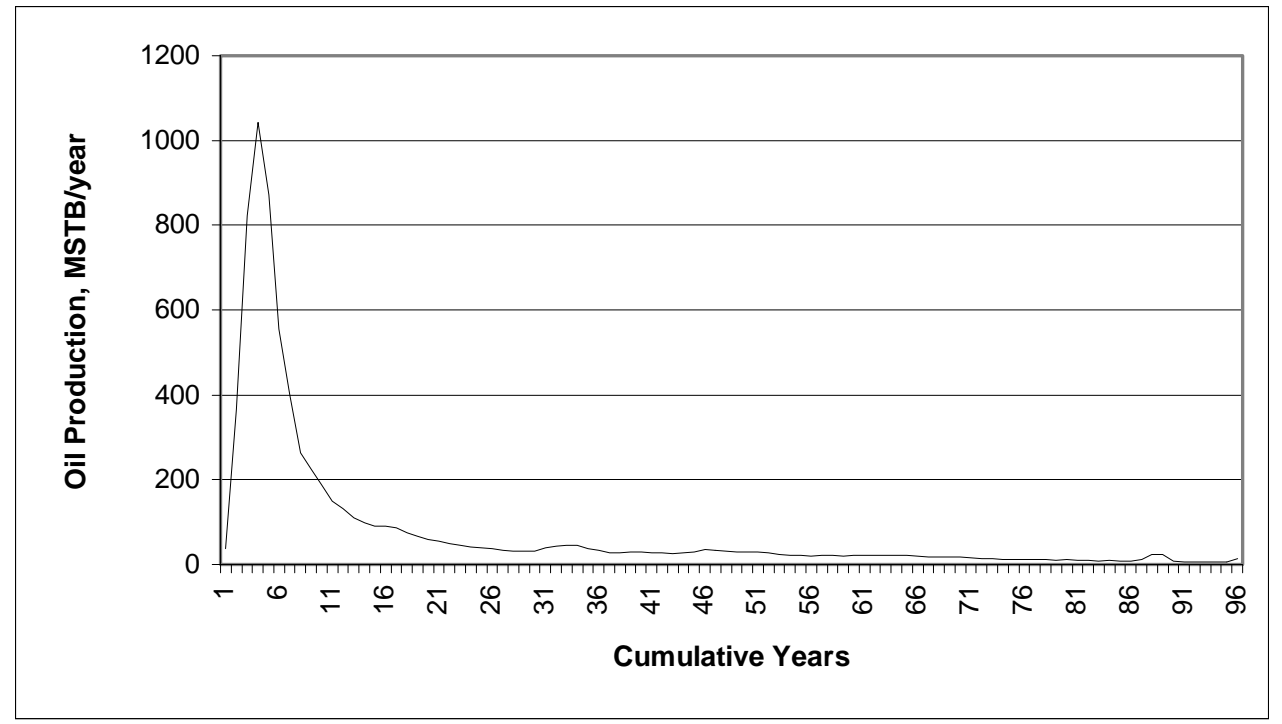

Figure 2.2. Daily Oil Production in the Stringtown field. 1896-1991

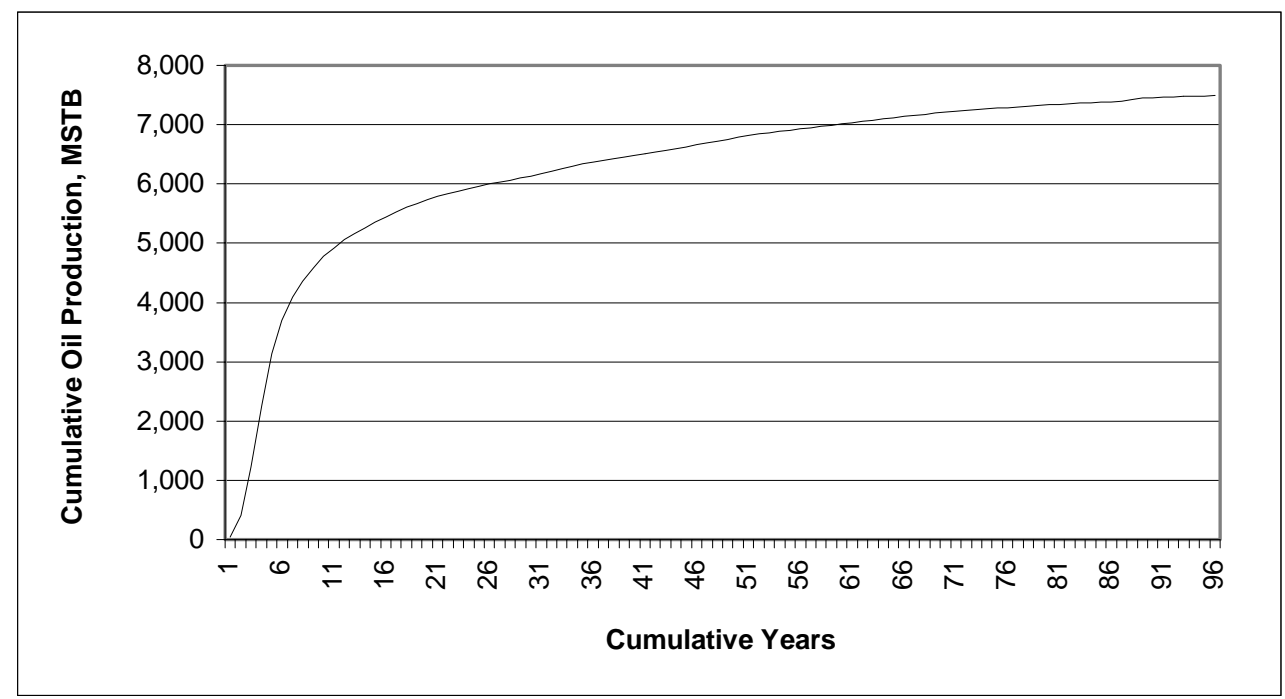

Figure 2.3. Cumulative Oil Production in the Stringtown field. 1896-1991 


\subsection{Reservoir Characterization. ${ }^{5,6}$}

Reservoir description is the key factor for designing, operating and evaluating the performance of a waterflood as well as other enhanced recovery projects. The main goal is to find the variation of properties such us porosity, permeability, thickness and saturations in the pore space between wells, and the vertical and lateral continuity of the formation.

A team of engineers and geologists generally conducts the reservoir description study. Four major steps have been defined in this process and are widely used as a guide. ${ }^{5}$ These are:

- Rock studies. The objective of this first step is to define lithology, depositional environment and develop correlations of rock properties, such us porosity and permeability. This is achieved by studying the cores. Since these are available for a limited number of wells in the field, well logs must be used to estimate porosity and saturations and later correlate other properties.

- Framework Studies. These are done to determine the distribution of reservoir and non-reservoir zones, basically shales, and their areal and vertical continuity. The correlation between wells is performed by the integration of the depositional model with core description graphs and well logs.

- Reservoir Quality Studies. At this point, a qualitative description of the variation of rock properties and fluid saturations throughout the reservoir is done. Contour maps are constructed to define net pay sand thickness, porosity, permeability and 
fluid saturations. For the net pay thickness, a cut-off value for porosity or permeability must be defined.

- Integration Studies. The main objective is to evaluate the consistency of the reservoir description with known production performance. The results from previous steps are integrated to build a 3D model for the reservoir, which is the basis for the simulation study. During this stage, the reservoir model is validated matching the pressure and/or production history with the results from the simulator.

Generally a small percentage of wells are cored, but electric well log records like Gamma Ray, Density, SP or Induction are available for most of them. The correlation of core data with log data becomes essential in order to gain a better understanding of the reservoir.

In flow simulations, the single most important input reservoir parameter is the permeability spatial distribution, which governs the fluid flow within the formation. The first attempt to define this distribution is done by finding a relationship between permeability and porosity, another reservoir parameter commonly available. This process starts by developing a correlation between log porosity and core porosity. To do this, the porosities from both sources are compared foot by foot, and the values from cores may be shifted a few feet to obtain a good correlation. The permeability is then correlated with the $\log$ porosity in order to be used in other non-cored wells field-wide. This correlation may be improved if different facies are recognized within the formation. 
Once the permeability distribution is determined for a reservoir, a further subdivision for simulation purposes may be necessary, especially when there is considerable variation in permeability and different lithological units are present. When variations in permeability are found, both vertically and laterally, primarily connected paths of high or low permeability values will condition the flow and thus the sweep efficiency and final recovery. The reservoir description must be then focused on identifying these different units that will be used later in the numerical simulator.

The paths of different flow characteristics are called Flow Units. These are regions in the formation that are believed to control the movement of injected and produced fluids within the reservoir. They are generally selected based on observed ranges of porosity, permeability and general geological properties determined by core description. Thus, they serve to separate contiguous regions of the reservoir by their capability to transmit fluids laterally and vertically. The flow units are more complex than a depositional model, but they are more realistic because incorporate a variety of geological and petrophysical properties characteristics of the reservoir. ${ }^{2}$

\subsection{Artificial Neural Networks. ${ }^{7-9}$}

Artificial Neural Networks (A.N.N.) mimic the brain process to solve problems. They are information-processing systems that have certain functional characteristics with the biological neural system. Researchers have hypothesized that millions of neurons in the biological brain work together in parallel, each trying to solve a tiny bit of a big problem. Just as humans apply knowledge gained from past experience to new problems 
or situations, an A.N.N. takes previously solved examples to build a system of "neurons" that makes decisions, classifications, and forecasts.

The A.N.N. learns by examples. Based on these examples, the net builds a model for the problem. They look for patterns in training sets of data, learn these patterns, and develop the ability to correctly classify new patterns or to make forecasts and predictions. Neural networks excel at problem diagnosis, decision-making, prediction, and other classifying problems where pattern recognition is important and precise computational answers are not required. They have been used in different areas such us financial markets, medical diagnosis and many more. In the oil industry, the A.N.N. can be applied to deal with problems related to pressure-transient analysis, well-log interpretation, and reservoir characterization and well stimulation, among others.

\subsubsection{Types of Neural Networks.}

The architecture of the neural network defines the connectivity pattern among neurons and how much knowledge is stored in it. It also determines the algorithm to be used in updating the weights of each connection. There are two basic types of neural networks: supervised and unsupervised:

\subsubsection{Supervised networks.}

These build models that classify patterns, make predictions, or make decisions according to other patterns of inputs and outputs they have "learned." They give the most reasonable answer based upon the variety of learned patterns. The supervised network 
makes predictions, classifications or decisions by giving it a large number of correct classifications or predictions from which it can learn. Backpropagation, PNN and GRNN networks are supervised network types.

a. Backpropagation. In this model, the network output is compared with the desired (known) output and the difference (error) is propagated backwards to the network and the weights of the connections (links) between neurons are adjusted. The process is continued until a small error between the outputs is attained.

These networks are known for their prediction capabilities and ability to generalize well on a wide variety of problems. These models are trained with both inputs and target outputs. Many variations of these nets are encountered in the literature. One of these is the Ward network with multiple slabs in the middle layer. They are very powerful when each hidden slab is given a different activation function from the other slabs because they detect different features of the input vectors. This gives the output layer different viewpoints of the data. This A.N.N. arquitecture is depicted in Figure 2.4

b. Probabilistic Neural Network (PNN). This network is known for its ability to train quickly on sparse data sets. PNN also separates data into a specified number of output categories.

c. General Regression Neural Network (GRNN). Like PNN networks, GRNN also trains quickly on sparse data sets but, rather than categorizing it, GRNN applications are 


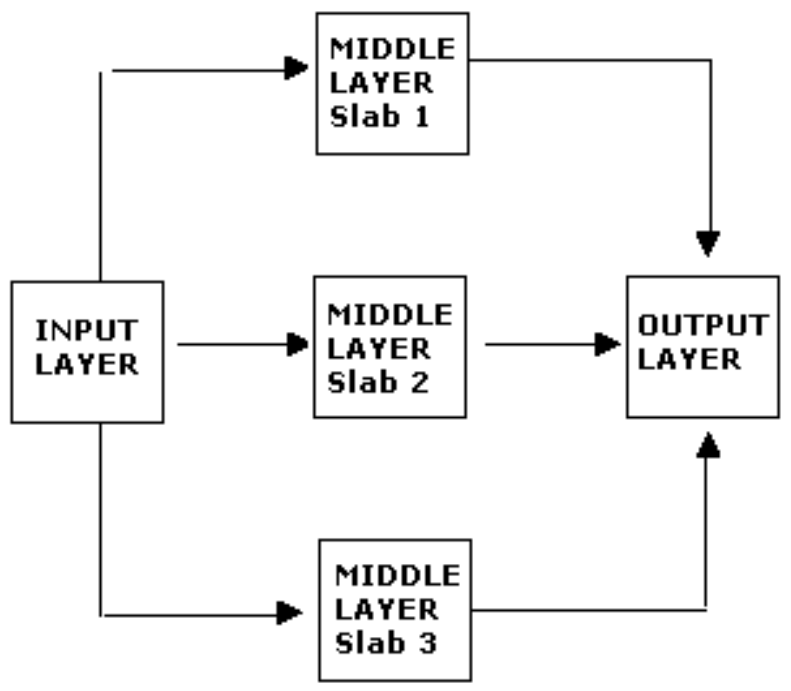

Figure 2.4 Arquitecture of a Backpropagation Neural Network.

able to produce continuous valued outputs. GRNN can have multidimensional input, and it will fit multidimensional surfaces through data. Because GRNN networks evaluate each output independently of the other outputs, GRNN networks may be more accurate than Backpropagation networks when there are multiple outputs. Its architecture is similar to that of a standard network.

\subsubsection{Unsupervised networks.}

They can classify a set of training patterns into a specified number of categories without being shown in advance how to categorize. The network does this by clustering patterns. The user tells the network the maximum number of categories and it usually clusters the data into that number of categories. One of them is the Kohonen network. The architecture is the simplest of all with only two layers: input and output. This network has the ability to learn without being shown correct outputs in sample patterns. 
Neither type of network is guaranteed to always give an absolutely "correct" answer, especially if patterns are in some way incomplete or conflicting. Results should be evaluated in terms of the percentage of correct answers that result from the model. Some problems are well suited for the pattern recognition capabilities of a neural network and others are better solved with more traditional methods.

\subsubsection{Neural Network Structure.}

The main components of a neural network are shown in Figure 2.5. The basic building block of neural network technology is the simulated neuron (depicted as a circle). Independent neurons are of little use, however, unless they are interconnected in a network of neurons. The network processes a number of inputs from the outside world to produce an output, the network's classifications or predictions. The neurons are connected by weights, (depicted as lines) which are applied to values passed from one neuron to the next.

A group of neurons is called a slab. Neurons are also grouped into layers by their connection to the outside world. For example, if a neuron receives data from outside of the network, it is considered to be in the input layer. If a neuron contains the network's predictions or classifications, it is in the output layer. Neurons in between the input and output layers are in the hidden layer(s). A layer may contain one or more slabs of neurons. 


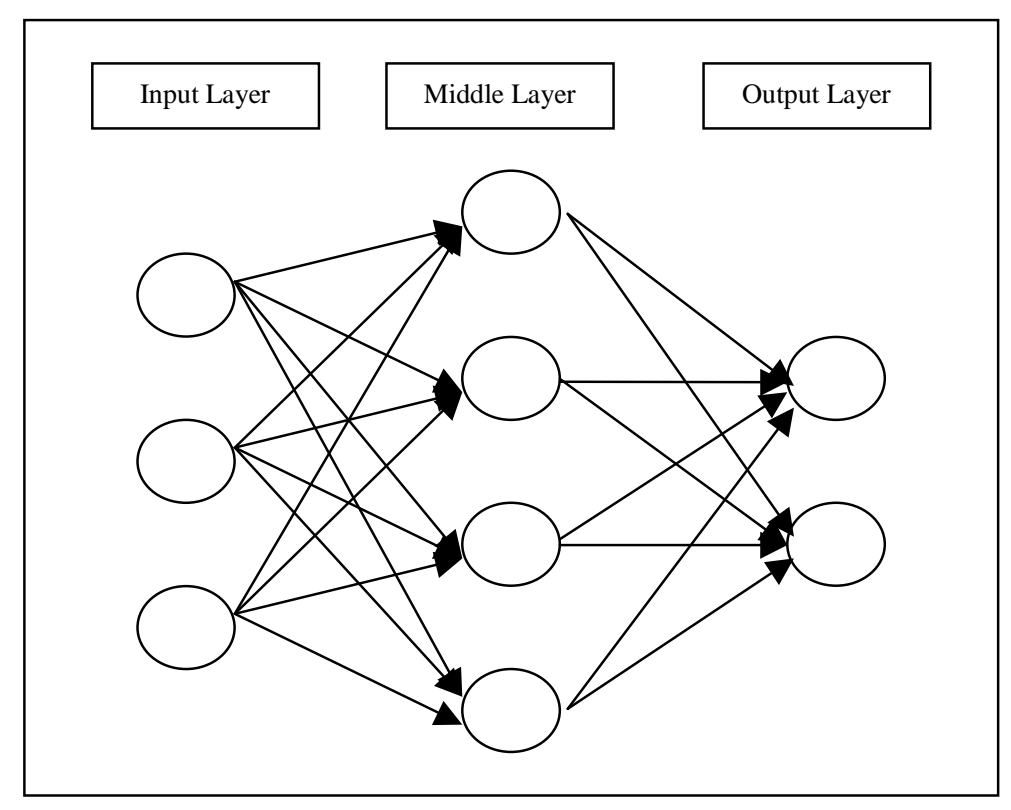

Figure 2.5 Structure of an A.N.N.

\subsubsection{Learning Process.}

A typical neural network is a Backpropagation network, which usually has three layers of neurons. Neurons in the input layer produce "intermediate" outputs by applying an activation function to the sum of the weighted input values. The "intermediate" outputs then become the inputs for the middle or hidden layer. The hidden layer passes values to the output layer in the same fashion, and the output layer generates the desired results (predictions or classifications) also by applying an activation function to the sum of its weighted input neurons.

The network "learns" by adjusting the interconnection weights between layers. The outputs the network is generating are repeatedly compared with the correct answers, and each time the connecting weights are adjusted slightly in the direction of the correct 
answers. Eventually, if the problem can be learned, a stable set of weights is reached and will produce good answers. The real power of the A.N.N. is evident when the trained network is able to produce good results for data that the network has never "seen" before.

The main objective when applying an A.N.N. is to achieve a balance between correct responses to training patterns and good responses to new input patterns, in other words the network must seek a balance between memorization and generalization. To accomplish this goal, all the data are divided in two groups, the training and the test set.

The training set is used to develop the A.N.N. In this process, the known output is used to help the A.N.N. adjust the weights between its neurons. So, training is accomplished by modification of the weights until a small difference between "known" and "predicted" outputs is reached.

The test set is a data pattern consisting of input variables (and correct output variables for supervised networks) used to test the network. The test patterns are used to verify how well the network is working. A test set is important because it provides a set of data not included in the training set.

Weight adjustments are based on the training set, however, at intervals during training, the error is computed using the test set. As long as the error on the test set decreases, training continues. The A.N.N. is saved based on the best performance on the test set. When the error begins to increase, the A.N.N. starts to memorize the training data 
set too specifically and begins to lose its ability to generalize as well. At this point, training should be concluded.

The most important feature to consider for building a successful neural network is to know when to stop training. If training is limited, the A.N.N. will not learn the patterns. On the contrary, if too much training is done, the A.N.N. will learn the noise or memorize the training patterns and will not generalize well with new patterns.

The parameter used to tell the network when to stop training is called Calibration. It finds the optimum network for the data in the test set, which means that the network is able to generalize well and give good results on new data. Calibration does this by computing the mean squared error between actual and predicted for all outputs over all patterns. The mean squared error is the standard statistical technique for determining closeness of fit. Calibration computes the squared error for each output in a pattern, totals them and then computes the mean of that number over all patterns in the test set. The Calibration interval decides the number of events after which the network temporarily halts training and tests its performance on the test set. If the error on the test set reaches a new minimum, the weights are saved and training is resumed.

For Backpropagation models, the network is saved every time a new minimum average error (or mean squared error) is reached. For GRNN networks, Calibration optimizes the smoothing factor based upon the values in the test set. Calibration does this by trying different smoothing factors and choosing the one that generates the least mean 
squared error between the actual and predicted answers. For PNN, Calibration also optimizes the smoothing factor, but does so by minimizing the probabilistic error.

When training an A.N.N. by backpropagation, there are several parameters that must be set before training actually begins. Two of the most important settings are the Learning Rate and Momentum. These two parameters work together and help to define how fast and how stable the learning process is.

Each time a pattern is presented to the network, the weights leading to an output node are modified slightly during learning in the direction required to produce a smaller error the next time the same pattern is presented. The amount of weight modification is the learning rate times the error. For example, if the learning rate is .5 , the weight change is one half the error. The larger the learning rate, the larger the weight changes, and the faster the learning will proceed. Oscillation or no convergence can occur if the learning rate is too large.

Large learning rates often lead to oscillation of weight changes and learning never completes, or the model converges to a solution that is not optimum. One way to allow faster learning without oscillation is to make the weight change a function of the previous weight change to provide a smoothing effect. The momentum factor determines the proportion of the last weight change that is added into the new weight change. 


\subsubsection{Activation Functions.}

For the input layer, this function is the linear or identity function. Generally, the same activation function is used for all neurons in any particular slab. In order to obtain the benefits of parallel-distributed processing system that ANN's offer a non-linear activation function is generally used.

Activation functions may be divided into four categories: linear, binary, sigmoid and probabilistic. The most common functions are: ${ }^{9,10}$

a. Linear Functions:

- Identity: $f(x)=x$

- Linear Scaled: $f(x)=m x+b$

These functions are used primarily in the input layer so that the input pattern data set is passed just as is to the middle layer.

b. Binary Functions:

- Step: $f(x)=1$ if $\mathrm{x} \geq \mathrm{b}$ or $f(x)=0$ if $\mathrm{x}<\mathrm{b}$

This function is utilized to convert continuo data into a binary unit. This feature is very helpful when building net to establish classes or categories

c. Sigmoid Functions:

- Logistic: $f(x)=\frac{1}{\left(1+e^{-\sigma x}\right)}$

- Hyperbolic Tangent: $f(x)=\tanh (x)$

- Hyperbolic Tangent 1.5: $f(x)=\tanh (1.5 x)$ 
- Symmetric Logistic: $f(x)=\frac{2}{\left(1+e^{-\sigma x}\right)}-1$

\section{d. Probabilistic Functions:}

- Gaussian: $f(x)=e^{-x^{2}}$

- Gaussian Complement: $f(x)=1-e^{-x^{2}}$

The probabilistic functions are unique in A.N.N.'s applications, because unlike the others, they are not increasing functions. The Gaussian function is the classic bell shaped curve, which maps high values into low ones, and maps mid-range values into high ones. The Gaussian Complement function tends to reveal meaningful characteristics in the extremes of the data. Both functions are very useful in Ward networks.

\subsection{Numerical Simulation. ${ }^{10-12}$}

Reservoir simulators are complex programs that simulate multiphase displacement process in two or three dimensions. They are widely used to study reservoir performance and to determine methods for enhancing the ultimate recovery of hydrocarbons. Numerical simulation is based on material balance principles, considering reservoir heterogeneity and direction of flow. Calculations are carried out using material balance and fluid flow equations to estimate saturation distribution, pressure and flow of gas, oil and water for each cell at discrete time steps. Other techniques developed to model the waterflood performance have limitations, especially when there are important changes in rock properties, in saturations across the reservoir or when cross-flow and gravity segregation are important mechanisms of fluid flow. Another important 
advantage of the simulator is that it takes into account the location of injection and producing wells and their operating conditions, such us changes in flow rates, injection pressures and formation damage.

The simulation process consists basically of three phases: collection of input data, history matching and performance prediction. The input data comprises rock and fluid data, geological data and production/injection and well completion data. The reservoir is divided into small cells or blocks to account for heterogeneity. When this first step is over, a simulation model is built.

History matching of past production and pressure performance consists of adjusting the reservoir parameters in the model until the simulated performance matches the observed behavior. After a satisfactory matching is achieved, the model can be utilized to predict future performance of the reservoir under existing operating conditions or some alternative development plan.

2.4.1 Types of Simulators. Depending upon fluid flow, mass and heat transfer, these are classified as:

- Black Oil. These are frequently used to simulate isothermal, simultaneous flow of oil, gas and water as a result of viscous, gravitational and capillary forces. Black oil means that the phase composition is constant. 
- Compositional Simulators. In this case, the variation of phase composition with pressure is considered in the calculations. These are mainly used when dealing with volatile-oil and gas-condensate reservoirs.

- Thermal Simulators. This type accounts for both fluid flow, heat transfer and chemical reactions. They are used to study enhance recovery processes such us insitu combustion.

- Chemical Simulators. These group accounts for fluid flow and mass transfer due to dispersion, absorption and complex phase behavior. They are useful for surfactant, polymer and alkaline flooding evaluation.

Simulators are also characterized by the:

- Number of phases flowing in the system. So, the simulator is categorized as single phase, two-phase or three-phase.

- Number of directions of flow. It may be a 1-dimensional linear or radial, 2dimensional areal or cross-sectional, or 3-dimensional simulator.

- Type of solution used for the finite difference equations. The simulator is called implicit, impes or fully implicit.

\subsubsection{BOAST98 Simulator Overview. ${ }^{12}$}

In this study, a black-oil, three-phase, 3-D simulator called BOAST98 was used. This program was developed by the U.S. Department of Energy, and is available to the public via the Internet. (www.npto.doe.gov) 
The BOAST98 program simulates isothermal, darcy flow in three dimensions. It assumes reservoir fluids can be described by three fluid phases (oil, gas, and water) of constant composition with physical properties that depend on pressure only. Some of the typical field production problems that can be handled by BOAST98 include: primary depletion studies, pressure maintenance by water and/or gas injection, and evaluation of secondary recovery waterflooding operations.

BOAST98 is a finite-difference, implicit pressure/explicit saturation (IMPES) numerical simulator. It contains both direct and iterative solution techniques for solving systems of algebraic equations. The well model allows specification of rate or pressure constraints on well performance, and wells can be added or recompleted during the simulation. Multiple rock and PVT regions may be defined, and three aquifer models are available as options. BOAST98 contains flexible initialization capabilities, a bubble point tracking scheme, an automatic time step control method, and a material balance check on solution stability.

The data input section is divided into two parts: an initialization data section and a recurrent data section. The initialization data include reservoir model grid dimensions and geometry, the distribution of porosity and permeability within the reservoir, fluid PVT data, rock relative permeability and capillary pressure data, initial pressure and saturation distributions within the reservoir, specification of solution method, and various run control parameters. The recurrent data include the location and initial specifications of wells in the model, time step control information for advancing the simulation through 
time, a schedule of individual well rate and/or pressure performance, changes in well completions and operations over time, and controls on the type and frequency of printout information provided by the simulator.

Some of the simulator features handled by Boast 98 are listed below.

Reservoir features:

- Optional three-phase relative permeability algorithm.

- Multiple rock and PVT regions allowed.

- Bubble point pressure can vary with depth and PVT region.

- Several different analytic aquifer models.

- Direct input of noncontiguous layers.

- Net and gross thickness allowed.

\section{Well Model Features:}

- Individual well gas/oil ratio (GOR) and water/oil ratio (WOR) constraints.

- Minimum oil production and maximum liquid withdrawal well constraints.

- Multiple wells per grid block.

- Gas well model using a laminar-inertial-turbulent analysis.

- Maximum water/gas injection rates.

Numerical Features:

- Two new iterative matrix solution methods: $y$ and $\mathrm{z}$ direction line successive overrelaxation (LSOR) methods. 
- Zero pore volume (inactive) grid blocks allowed.

- Optional two-point upstream weighting for reducing numerical dispersion.

Some of the Boast98 limitations are:

- A large grid size of $\mathrm{x}$-direction blocks, $\mathrm{y}$-direction blocks, and z-direction blocks or layers will force the use of virtual memory and drastically slow down the array iteration processes.

- Maximum well blocks of 200.

- Maximum time steps of 8000 .

- Maximum data sets of 200 .

- Maximum wells of 150.

- Maximum nodes per well of 10.

- Maximum modifications to permeability, porosity, and transmissibility of 55 each.

- Maximum rock regions and PVT regions of 5.

- Maximum table entries for relative permeability curves and for capillary pressure curves of 25 .

This simulator consists of two basic components, Edboast, used to edit the input data, and Boast98, used to make the calculations. A simulation run can be started from either the Edboast or the Boast98 application. However, beginning with the Edboast program, the user will be able to review the input data file first and locate any mistakes that apply 
to the BOAST98 application. More information about these applications is presented in Appendix E. 


\section{CHAPTER 3.}

\section{METHODOLOGY}

The main objective of the study was to use a reservoir simulator to determine if the production behavior in the pilot area could be duplicated using the reservoir description obtained from core and log data analysis and the results of predicted porosity and permeability from the neural network models. This chapter presents a description of the main steps followed throughout the project. These steps included: data collection and analysis, prediction of petrophysical parameters (permeability and porosity), definition of flow units and development of the simulation model.

\subsection{Data Collection and Analysis.}

\subsubsection{Description of the Gordon Sandstone.}

The reservoir description for the Gordon Sandstone was based on the available core data for six wells. The location of the cored wells in the field is illustrated in Figure 3.1, as wells as the units I, II and III in which the company divided the field for the implementation of the waterflooding operations. These three zones were selected according to average porosity-permeability-thickness values in a given area:

- Unit I: good porosity and permeability, this area was first developed and is located in the middle of the field.

- Unit II: porosity and permeability values are less than those of Unit I, but was still considered a good productive area. It is located from the middle toward the north of the field. 


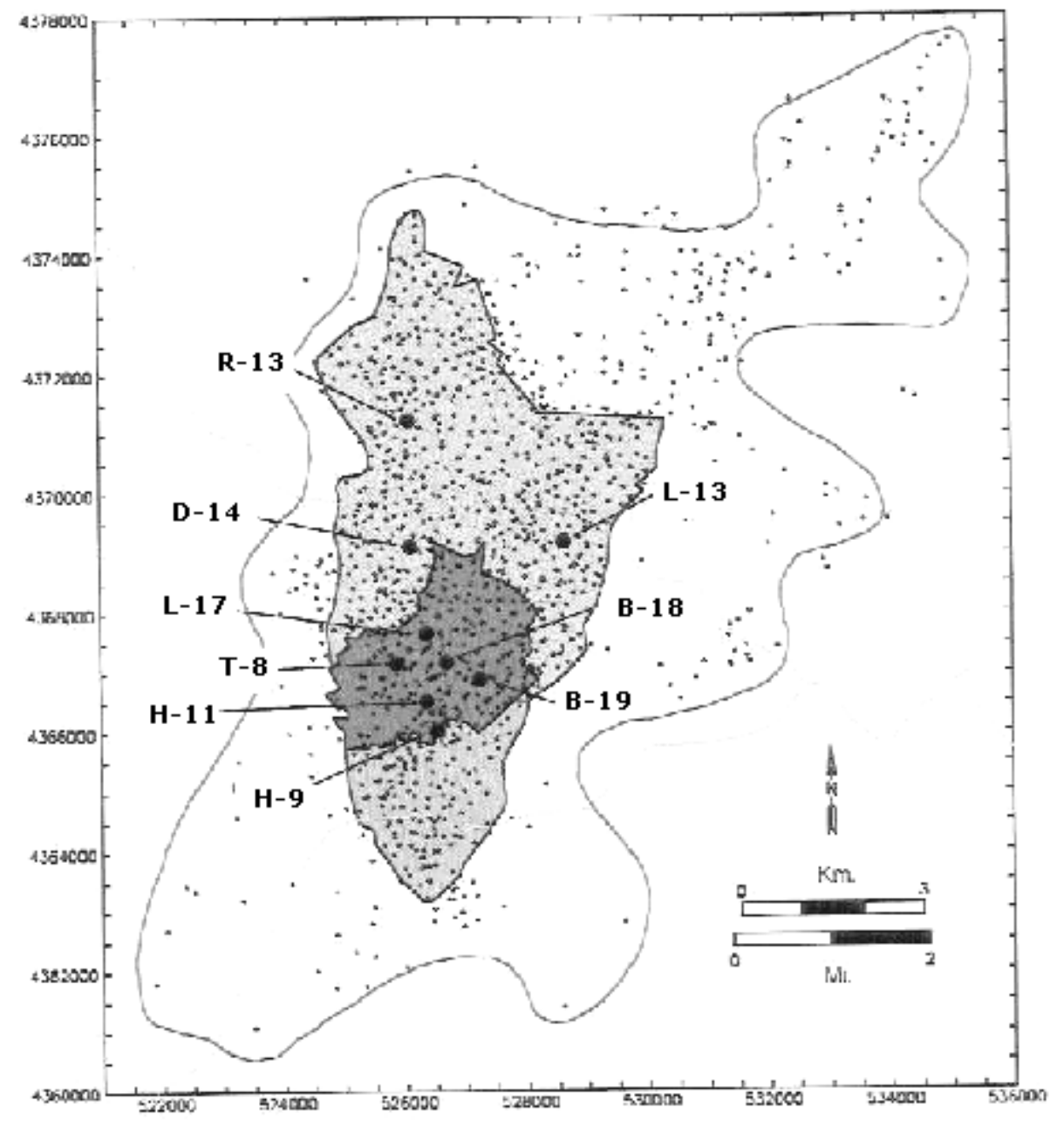

Figure 3.1. Location of the cored wells in the Stringtown field.

- Unit III: values for porosity and permeability are poor. This unit is the most southerly area and is of less interest. It is the last area where Waterflood operations were implemented.

Some basic information about these six wells and the average petrophysical properties is presented in Table 3.1. Two of these wells, H-11 and H-9, were injectors in the pilot 
waterflood. The plots showing porosity and permeability versus depth are presented in Appendix 1.

Table 3.1 Core Analysis, Stringtown Oilfield.

\begin{tabular}{|c|c|c|c|c|}
\hline Well & \multirow{2}{*}{$\begin{array}{c}\text { Cored } \\
\text { Interval, ft }\end{array}$} & $\begin{array}{c}\text { Avg. porosity, } \\
\text { \% }\end{array}$ & \multicolumn{2}{|c|}{ Permeability averages mD } \\
\cline { 4 - 5 } & & Arithmetic & Geometric \\
\hline B-18 & $2988.5-3014$ & 14.7 & 52 & 2.7 \\
\hline B-19 & $3086-3115$ & 14.9 & 41 & 6.2 \\
\hline H-9 & $2980-2908$ & 18.2 & 106 & 57 \\
\hline H-11 & $3083.4-3093.4$ & 18.8 & 72 & 19 \\
\hline T-8 & $2781-2797$ & 12.4 & 6.5 & 0.75 \\
\hline L-13 & $3032.4-3061.5$ & 8.4 & 2.5 & 0.2 \\
\hline
\end{tabular}

The well R-13 was not used in this study because a detailed core analysis core showed that it was core in a zone above the sandstone, showing very low permeabilities. The core data for the well D-14 was missing, and the other well, L-17, was not considered because the log records were not available.

A detailed geologic interpretation of the Gordon strata was carried out by the West Virginia Geologic and Economic Survey, based on three approaches: core description; $\log$ analysis and measurement of permeability with a Minipermeameter. ${ }^{4}$

The TEMCO MP-401 minipermeameter was used in the study. Based on log interpretations, three stratigraphic units were observed in the Gordon formation, defined 
as $\mathrm{A}, \mathrm{B}$ and $\mathrm{C}$. Then, based on core descriptions and permeability values from the minipermeameter, a sedimentary sequence was defined.

The lithology sequence showed 3 zones: conglomerate, sandstone and shale. The conglomeratic zone was found only in Unit A, formed by well-rounded pebbles ranging from 1 to $4 \mathrm{~cm}$ in diameter. It was generally found on the top of the sandstone and exhibiting permeabilities varying from 0 to $500 \mathrm{mD}$. This means that this section may act like a barrier to flow in some areas of the reservoir or even as a "thief" zone in other sections. This thief zone is the most critical when studying the Waterflood performance in any field, since some wells might be completed in this zone and the water injected may be moving outside the pattern.

The pay zone generally lies beneath the conglomerate zone, and shows high porosity. This section was further classified as "pay" sandstone for minipermeameter values ranging from 10 to $200 \mathrm{md}$, and as "nonpay" sandstone for minipermeameter values ranging from 0 (below the level of instrumental detection) to less than $5 \mathrm{md}$. The lithology groups identified with the cores were correlated with the Gamma Ray and Density logs to identify these zones in the rest of the field and have a better picture of the reservoir.

\subsubsection{Waterflood Pilot Area.}

Waterflood operations began in a dual five-spot pilot located in the center of the field, from 1981 to mid 1985. Seven new wells were drilled during 1980, six injectors 
and one producer. The other producer was an existing well drilled in 1897. The new wells were completed with a $4.5 \mathrm{OD}$ casing and subjected to acid fracturing to remove damage. Some features about these wells are presented in Table 3.2. The distribution of the wells in the pilot is shown in Figure 3.2.

Table 3.2 Well data for pilot area.

\begin{tabular}{|c|c|c|c|}
\hline $\begin{array}{c}\text { Well } \\
\text { Type }\end{array}$ & $\begin{array}{c}\text { Gordon Formation } \\
\text { Gross Thickness }\end{array}$ & $\begin{array}{c}\text { Perforated } \\
\text { Interval, ft }\end{array}$ & $\begin{array}{c}\text { Elevation (G.L.), } \\
\text { ft. }\end{array}$ \\
\hline P-7 & 15 & $2840-2846$ & 963.22 \\
\hline L-9 & 75 & $2794-2798$ & 927.52 \\
\hline H-11 & 85 & $3084-3092$ & 1189.9 \\
\hline H-10 & 84 & $2954-2962$ & 1050.54 \\
\hline A-5 & 100 & $2870-2878$ & 976.89 \\
\hline H-9 & 18 & $2896-2904$ & 1008.94 \\
\hline M-1 & 13 & $3023-3027$ & 1142.47 \\
\hline H-12 & 84 & $2944-2948$ & 1063.95 \\
\hline
\end{tabular}

The producers and some injectors experienced a number of problems during the pilot operation. The producers were affected by paraffin deposition, and some injectors by perforation and/or formation plugging caused by iron deposits and bacteria growth. The daily water injection rates and injection pressures varied throughout the life of the project. Water injection rates were higher for the wells located in the eastern part of the pattern, where the permeability was higher. Likewise, injection pressures were lower for the same wells. The history of water injection rates and pressures are shown in Figures 3.3 and 3.4. Also, the average pressure and injection rates are presented in Table 3.3. 


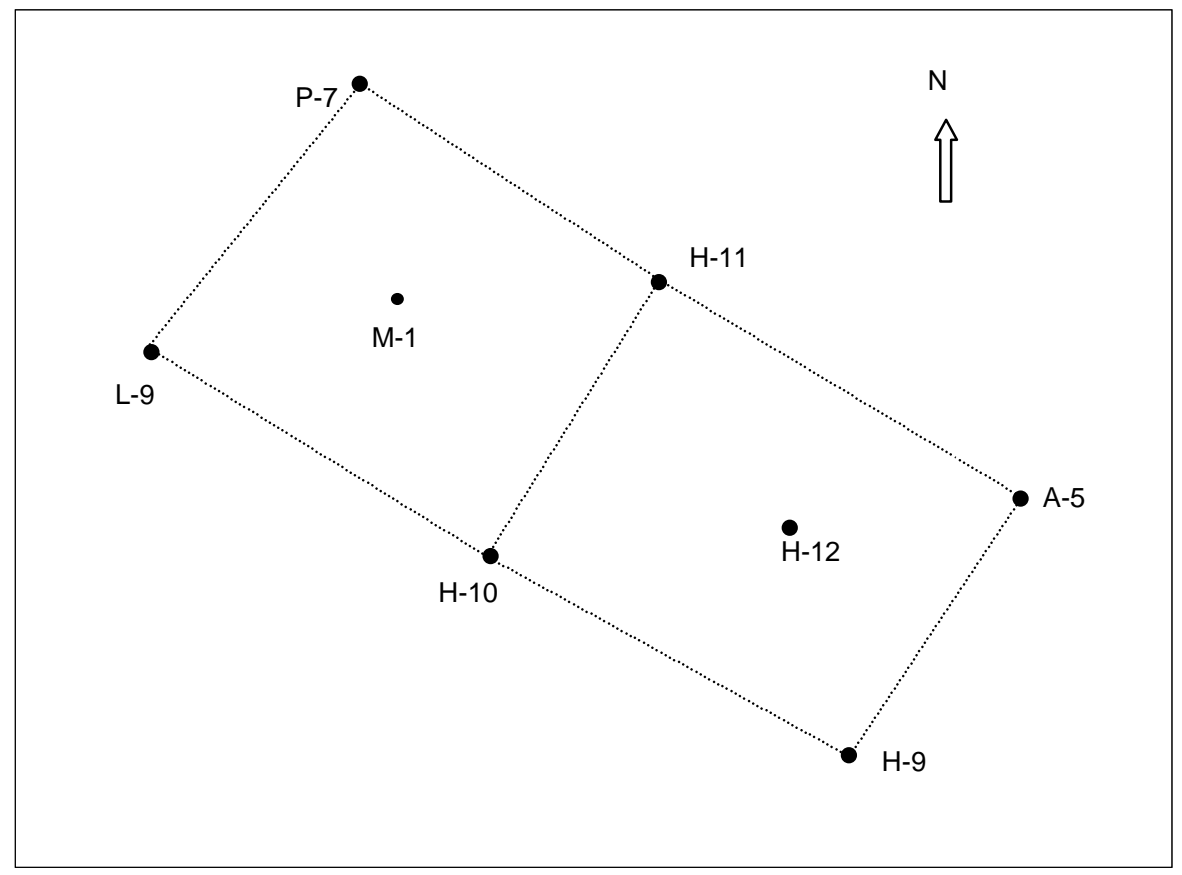

Figure 3.2. Distribution of the Wells in the Pilot Area.

Table 3.3. Average pressure and water injection rates in the pilot.

\begin{tabular}{|c|c|c|}
\hline Year & $\begin{array}{c}\text { Avg. Injection Rate } \\
(\text { STB/well })\end{array}$ & Avg. pressure (psia) \\
\hline 1 & 119 & 615 \\
\hline 2 & 70 & 636 \\
\hline 3 & 73 & 975 \\
\hline 4 & 75 & 953 \\
\hline 5 (5 months) & 51 & \\
\hline
\end{tabular}




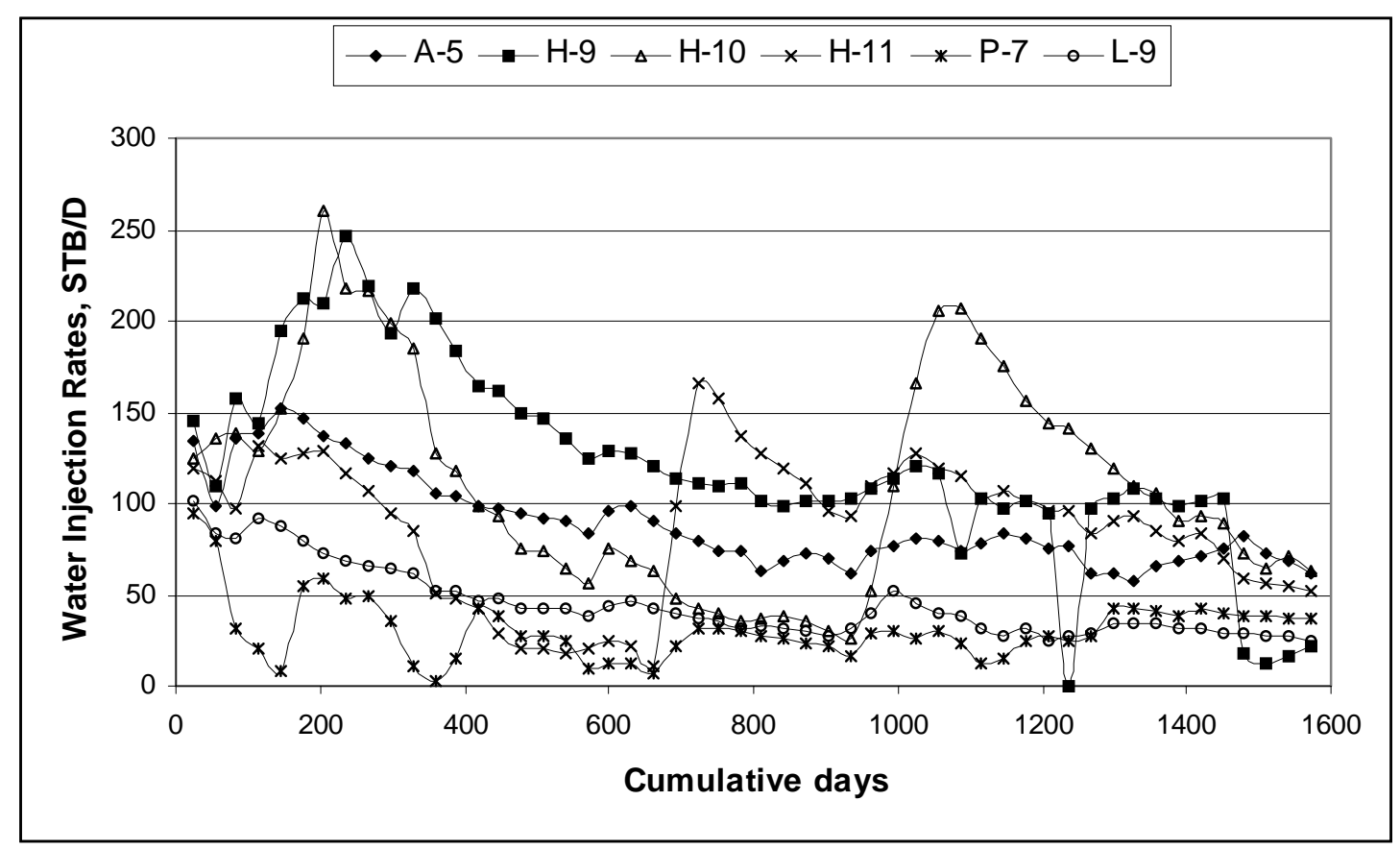

Figure 3.3. Total water injection rates in the pilot.

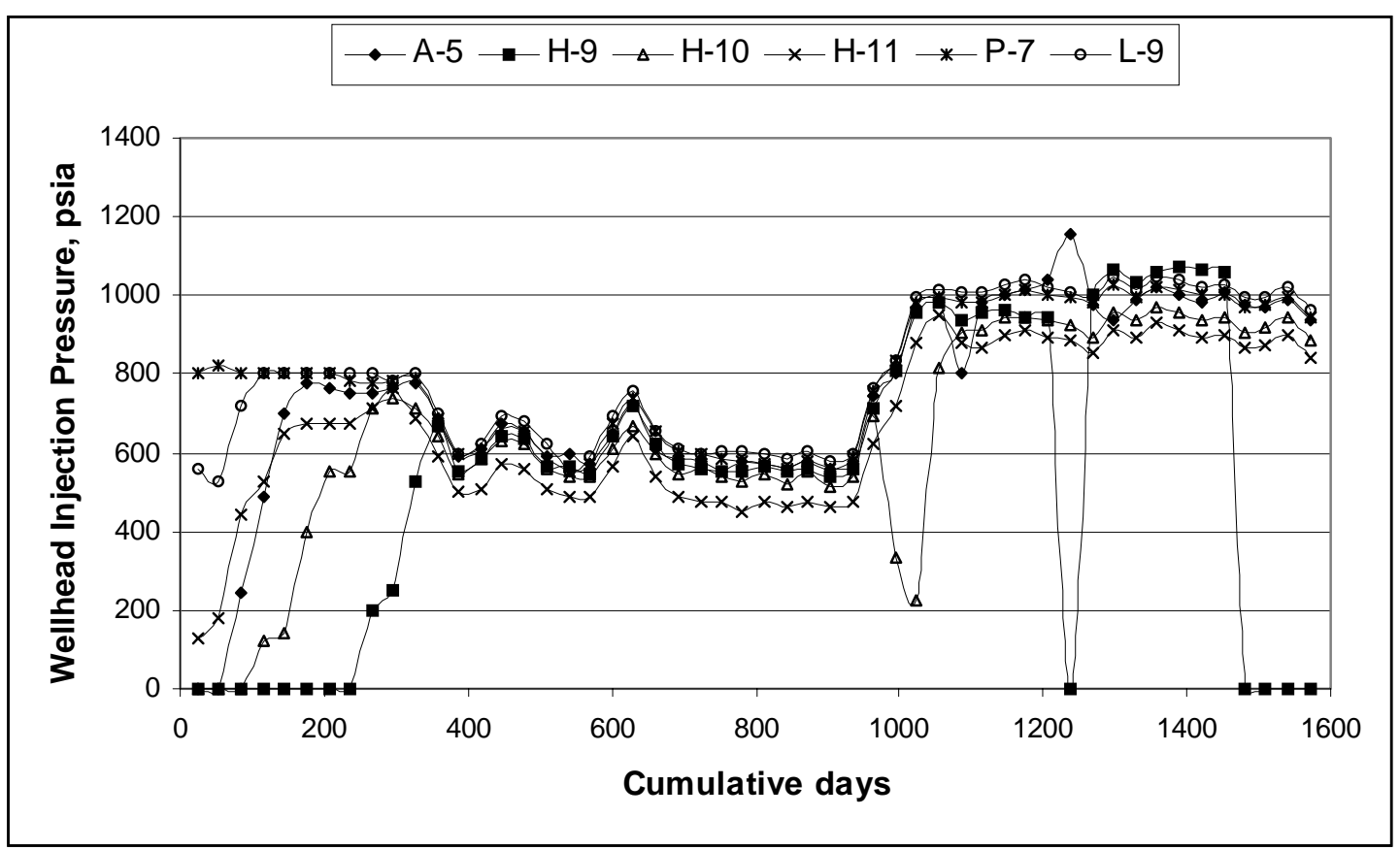

Figure 3.4. Wellhead injection pressures in the pilot. 
As can be seen in the previous plots, some wells showed a steeply decreasing injection rate after injection commenced. This was caused by plugging of the perforations and the formation near the wellbore. To solve this, the wells were treated using acid fracturing with $\mathrm{HCl}$. Some problems related with bacteria growth were also reported for the injection wells.

Three injectors were treated with acid to removed plugging caused by iron deposits, caused by interaction of injected water and the formation; and carbonate deposits originated by mixing fresh with produced water and use it as injection water. A fluid sensitivity analysis revealed that it was necessary to de-oxygenate the water and increase its $\mathrm{pH}$ to avoid these problems.

Paraffin deposition also presented problems in the producers, due basically to paraffin deposition. Well $\mathrm{H}-12$ presented a sharp drop in production during the second year of operations. It was hydraulically fractured after an ineffective paraffin treatment. The other producer, M-1, showed a decrease in production at the third year, but the treatment failed.

The cumulative oil and water production in both wells are compared in Figures 3.5 and 3.6. As can be observed, the production was very different in each well, perhaps caused by the distribution of formation properties within the pilot. 


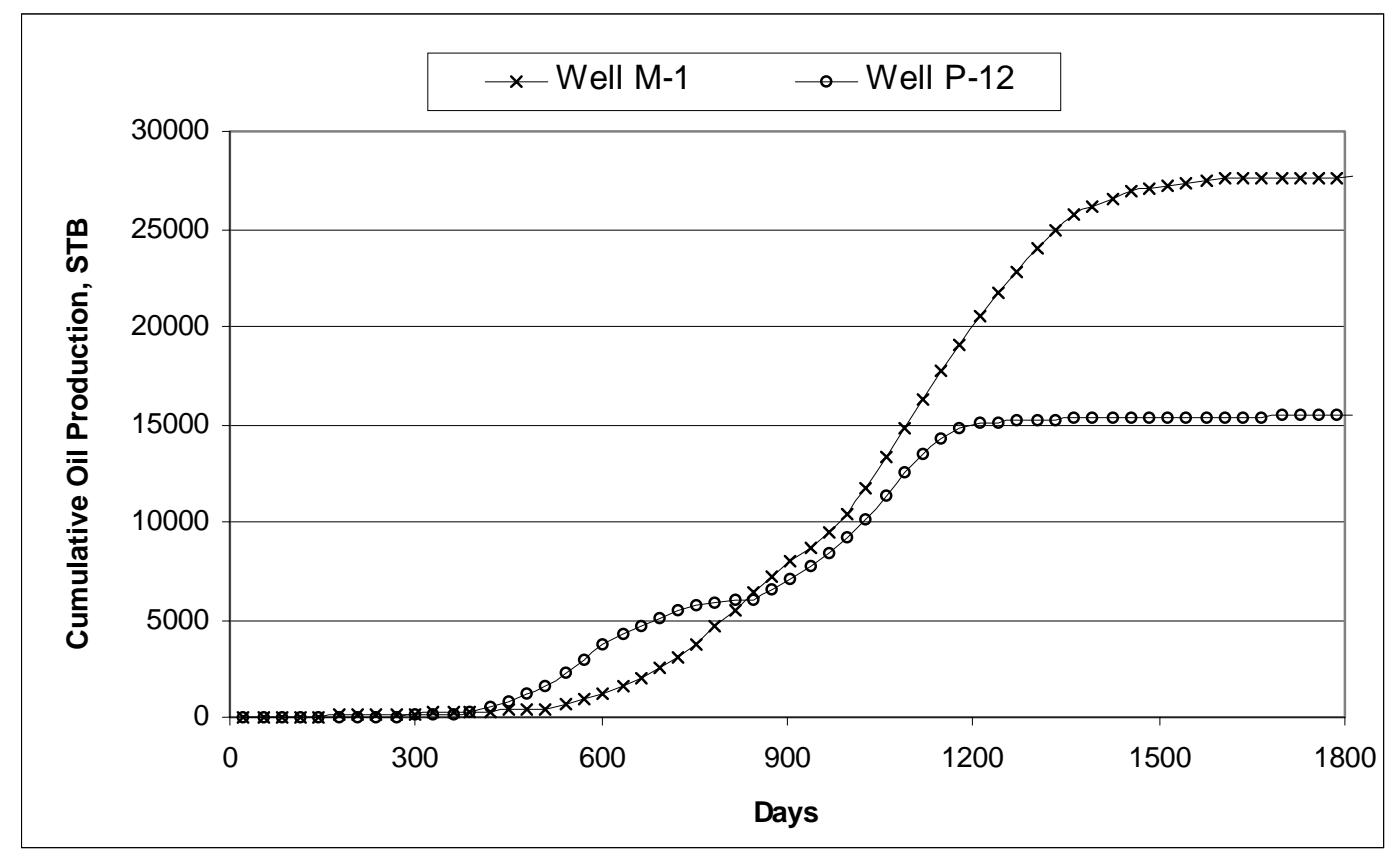

Figure 3.5. Cumulative oil production in the pilot wells.

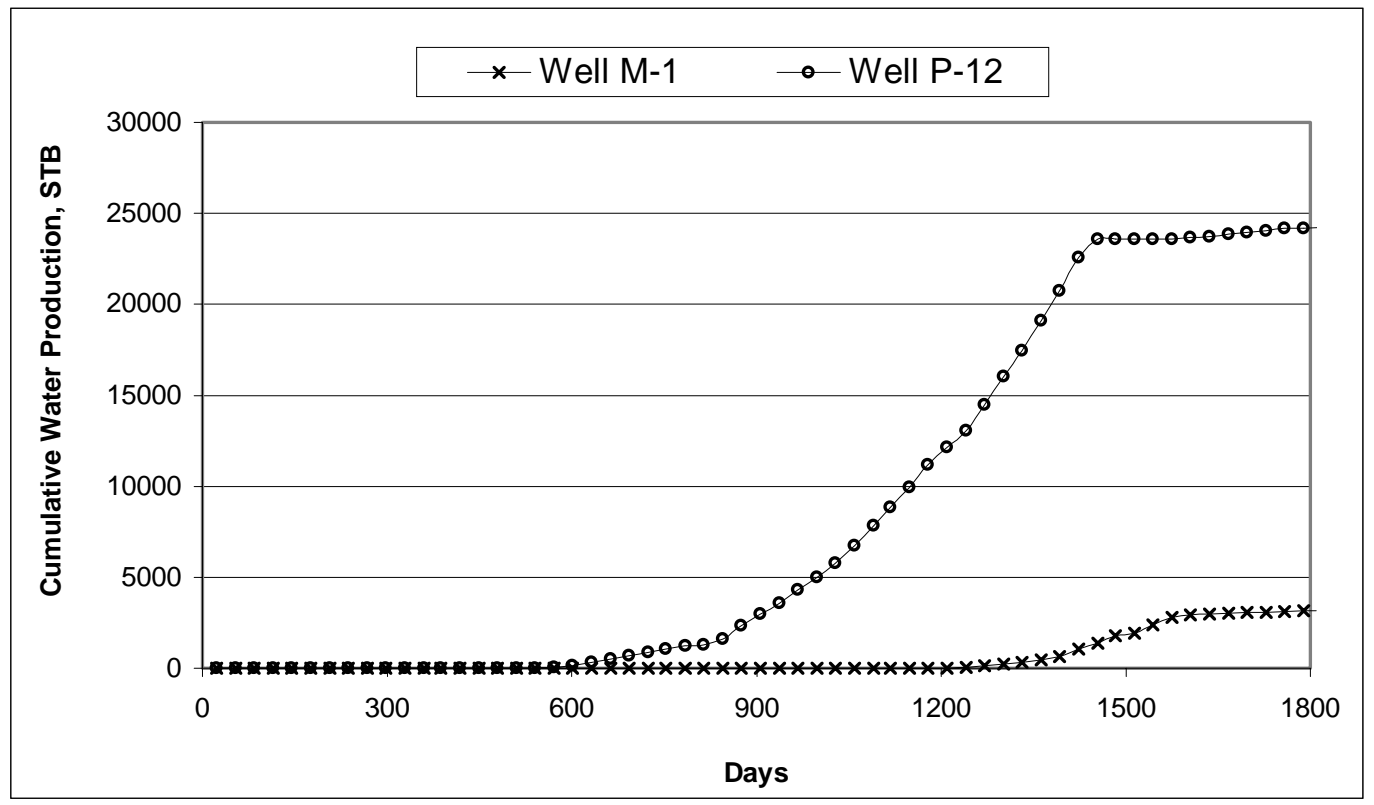

Figure 3.6. Cumulative water production in the pilot wells. 


\subsection{Prediction of Petrophysical Parameters.}

\subsubsection{Conventional Permeability Prediction.}

The first attempt utilized to determine the permeability distribution in the reservoir consisted of establishing a mathematical relationship between the measured porosity and permeability from the cores, in order to find out if a good correlation existed between these two parameters. Then, the procedure was repeated using porosity calculated from bulk density logs since the previous correlation cannot be used for other wells in the field where core porosity data are not available. Results are shown in chapter 4.

\subsubsection{Porosity prediction with A.N.N.s}

An A.N.N. was used to improve the low $\mathrm{R}^{2}$ coefficient obtained when correlating core porosity with log-derived porosity. A backpropagation network, with three slabs in the middle layer, was trained to predict porosity using 11 inputs from logs and well information, such us depth and location (X, Y coordinates). Table 3.1 shows the inputs selected and the activation functions used in each slab. The inputs included Gamma Ray and Density Logs (digitized values, first and second derivatives, base lines), depth and well coordinates.

Table 3.1. Activation functions used in the A.N.N. for porosity prediction.

\begin{tabular}{|c|c|c|c|c|}
\hline \multicolumn{4}{|c|}{ Activation functions } \\
\hline \multirow{2}{*}{ Input Layer } & \multicolumn{3}{|c|}{ Middle Layer } & \multirow{2}{*}{ Output Layer } \\
\cline { 2 - 5 } & Slab1 & Slab 2 & Slab 3 & \\
\hline Linear & Gaussian & Tanh & Gaussian compl. & Logistic \\
\hline
\end{tabular}


Core porosity and well log data from the six cored wells were used to develop the A.N.N. A test set, randomly chosen from the input file, was used for calibration and stop criteria. In order to prove the accuracy of the model and its ability to generalize and predict porosity from data not seen in training, the A.N.N. was trained using data from 5 wells and one of them was used as the verification set. So, the network was trained six times.

\subsubsection{Permeability Prediction using Artificial Neural Networks.}

In order to improve the correlation developed for permeability based on log porosity, an artificial neural network (A.N.N.) was modeled to refine the prediction of the permeability. An A.N.N. can identify the complex relationships between permeability and well log data without any assumption or predefined model.

Several A.N.N.'s were trained using data from the six previously described cored wells to predict permeability. A three-layer backpropagation A.N.N. with three slabs in the middle layer, each slab with a different activation function, was used.

The A.N.N.'s were tested varying the input selection. Finally, the chosen input group that gave the best results consisted of formation depth, location of the well ( $\mathrm{X}$ and Y coordinates), GR and bulk density logs, first derivatives of these logs with depth and the $\log$ baselines. The output was the core permeability. Only GR and bulk density logs were selected because they are available for most of the wells in the field. This A.N.N. was utilized to predict the permeability for the pilot wells not cored. 
The accuracy of the A.N.N. was verified in a similar manner as explained for the porosity network, using each of the wells separately as verification set.

\subsection{Definition of Flow Units.}

The simulation was started with a one-layer model, built based on the average predicted porosities and permeabilities, but poor results were achieved. Then, a model with two layers corresponding to the main flow units was prepared.

The formation was divided in two flow units to account for permeability, porosity and lithology variations in the vertical direction. The first criterion to choose the flow units was lithology, taking conglomerate as one layer and sandstone as the second layer, even though conglomerate was not present in some wells, but the simulation did not give satisfactory results. Again, the sandstone zone was characterized by important permeability and porosity variations that may impact the flow behavior. Therefore, the criteria followed to select the flow units were permeability and porosity breaks.

\subsection{Simulation Model.}

In order to run the simulator, it was necessary to collect information regarding reservoir and fluid properties, well completion and treatments and production and injection history. The A.N.N.'s developed for porosity and permeability were applied to the pilot wells to predict these properties. After that, an early model was constructed using one layer, but this did not provided a good match with the cumulative oil 
production. The formation was then divided into two layers, corresponding to the flow units. The process to collect the necessary input data for the simulator is explained below.

\subsubsection{Input Data for the Simulator.}

\subsubsection{Reservoir Parameters.}

The porosity and permeability for each block were assigned averaging the predicted values in the injectors and the producer H-12, as indicated in chapter 4, Results. The program code, listed in Appendix F, contains all the input data used in the simulation. Other parameters for the reservoir model were:

- Initial reservoir pressure $=120 \mathrm{psia}$

- Initial oil saturation $=0.69$

- $\quad$ Irreducible water saturation $=0.15$

- Irreducible gas saturation $=0.08$

- Vertical permeability $=1 \mathrm{mD}$ in layer $1,5 \mathrm{mD}$ in layer two. (See program list)

The depth to the top of the first layer in each well was taken as the total depth minus the elevation, read from logs, to show the actual inclination of the formation and evaluate the impact of gravity drainage on the recovery process. These values, presented in the program list, range from $1877 \mathrm{ft}$. in the well P-7 to 1904 in well $\mathrm{H}-10$, which means that the formation is practically horizontal in this part of the field. The known depths were averaged to assign depths for the rest of the blocks. Figure 3.7 shows the resulting shape of the reservoir in the pilot area. 


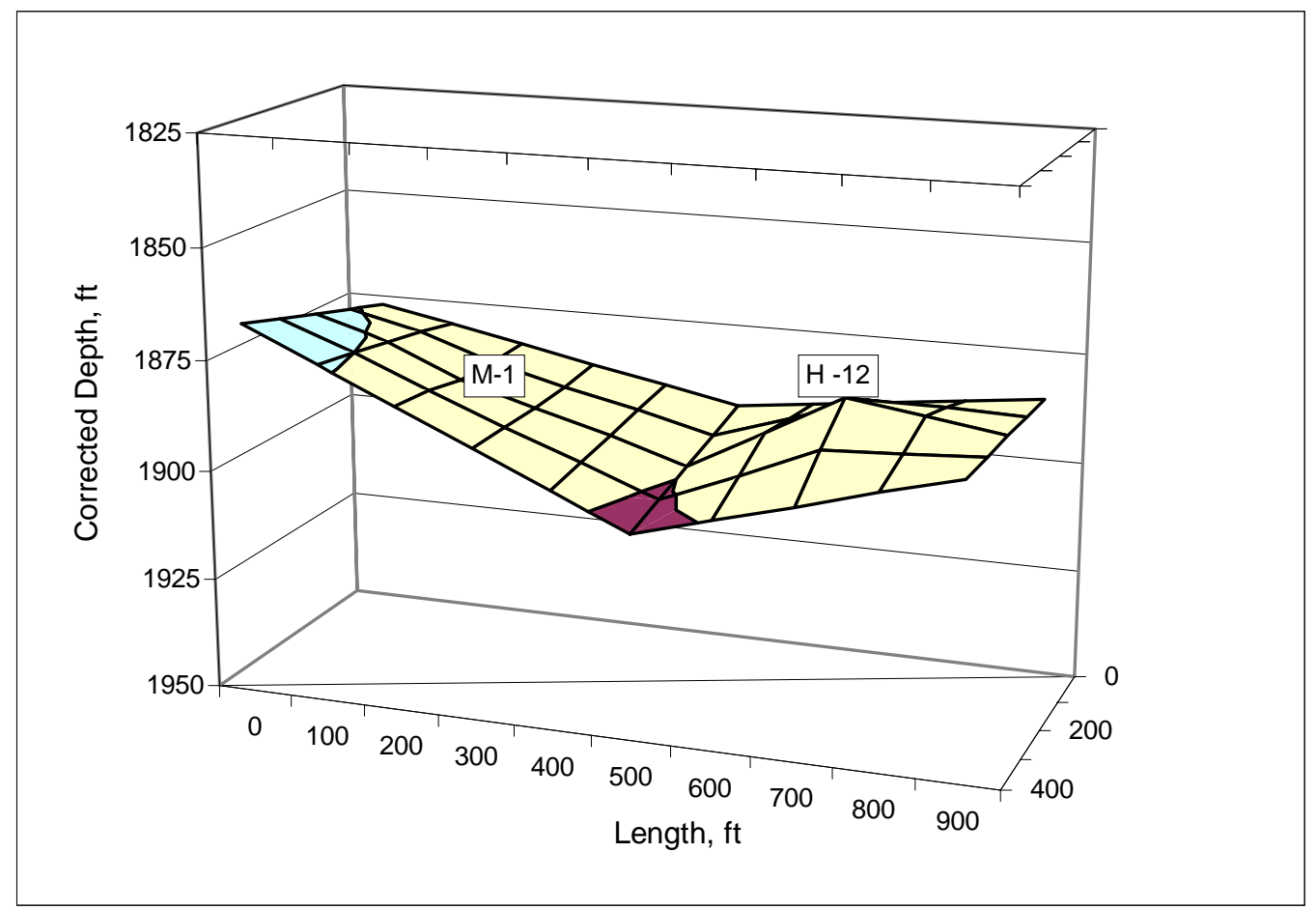

Figure 3.7. Shape of the Pay Sand in the Pilot.

Grid dimensions. The pilot area, as previously shown in Figure 3.2, consisted of a dual five-spot pattern with a northwest - southeast orientation. A grid system of $10 \times 5 \times 2$ blocks was built parallel to pattern, with the following size:

- X- orientation: $90,95,100,105,105,100,100,100,100$ and $100 \mathrm{ft}$.

- Y-orientation: $100 \mathrm{ft}$ all blocks.

- Z- orientation: variable size, as shown in the program list, appendix F.

\subsubsection{Fluid Properties.}

Some physical properties for oil, gas and produced water are presented in tables 3.2 through 3.4. The gas analysis is from a producing well outside the pattern. 
Table 3.2 Crude Oil Analysis.

\begin{tabular}{|l|c|}
\hline \multicolumn{1}{|c|}{ Property } & \\
\hline Crude Gravity, $^{\circ}$ API & 45.3 \\
\hline IBF, $^{\circ} \mathrm{F}$ & 96 \\
\hline${\text { Viscosity at } 85^{\circ} \mathrm{F}}^{\circ}$ & $3.5 \mathrm{cp}$ \\
\hline Density at $85^{\circ} \mathrm{F}$ & $0.7903 \mathrm{~g} / \mathrm{ml}$ \\
\hline$\%$ Tar & 1 \\
\hline
\end{tabular}

Table 3.3. Gas Analysis.

\begin{tabular}{|l|c|}
\hline \multicolumn{1}{|c|}{ Property } & \\
\hline Specific Gravity & 0.628 \\
\hline BTU/cu. Ft. at 14.73 psia & \\
Dry basis & 989.8 \\
Wet basis & 972.6 \\
\hline Molecular weight & 18.2 \\
\hline Compressibility factor & 0.998 \\
\hline
\end{tabular}

Table 3.4. Produced Water Analysis.

\begin{tabular}{|l|c|c|}
\hline \multicolumn{1}{|c|}{ Property } & M-1 & H-12 \\
\hline Specific Gravity @ $75^{\circ} \mathrm{F}$ & 1.089 & 1.002 \\
\hline PH & 4.3 & 7.46 \\
\hline Total Dissolved solids, mg/l & 129116 & 7006 \\
\hline
\end{tabular}

Relative Permeabilities. Relative permeability data were available for one injector in the pilot, H-9. Table 3.5 summarizes the report. Other important relevant information for the core is:

- Core depth: $2905 \mathrm{ft}$.

- Core description: sandstone, fine grain. 
- Initial water saturation: $19 \%$

- Porosity: $25.3 \%$

- Oil permeability at initial water saturation: $34 \mathrm{mD}$.

Table 3.5. Relative permeabilities from well $\mathrm{H}-9$

\begin{tabular}{|c|c|c|c|}
\hline Sw & Krw & Kro & Kro/Krw \\
\hline 19 & 0 & 1 & \\
\hline 32.7 & 0.0077 & 0.51 & 66.234 \\
\hline 37.7 & 0.012 & 0.436 & 36.333 \\
\hline 41.6 & 0.016 & 0.37 & 23.125 \\
\hline 46.2 & 0.024 & 0.283 & 11.792 \\
\hline 48.5 & 0.029 & 0.235 & 8.103 \\
\hline 50.8 & 0.037 & 0.19 & 5.135 \\
\hline 52.7 & 0.045 & 0.148 & 3.289 \\
\hline 54.1 & 0.052 & 0.114 & 2.192 \\
\hline 55 & 0.06 & 0.098 & 1.633 \\
\hline 55.6 & 0.066 & 0.089 & 1.348 \\
\hline 56.2 & 0.074 & 0.076 & 1.027 \\
\hline 57.3 & 0.08 & 0.05 & 0.625 \\
\hline 58.2 & 0.096 & 0.033 & 0.344 \\
\hline 59.5 & 0.107 & 0.0086 & 0.080 \\
\hline 60.1 & 0.119 & 0.0039 & 0.033 \\
\hline 60.8 & 0.135 & 0 & 0.000 \\
\hline & & & \\
\hline
\end{tabular}

These values were changed in the simulation during the history matching. Figure 3.8 compares the relative permeability from the well $\mathrm{H}-9$ with those used in the program.

Capillary pressures. Air-brine capillary pressure test were made in the well L-13. The reported values are listed in Table 3.6. Core data are: 


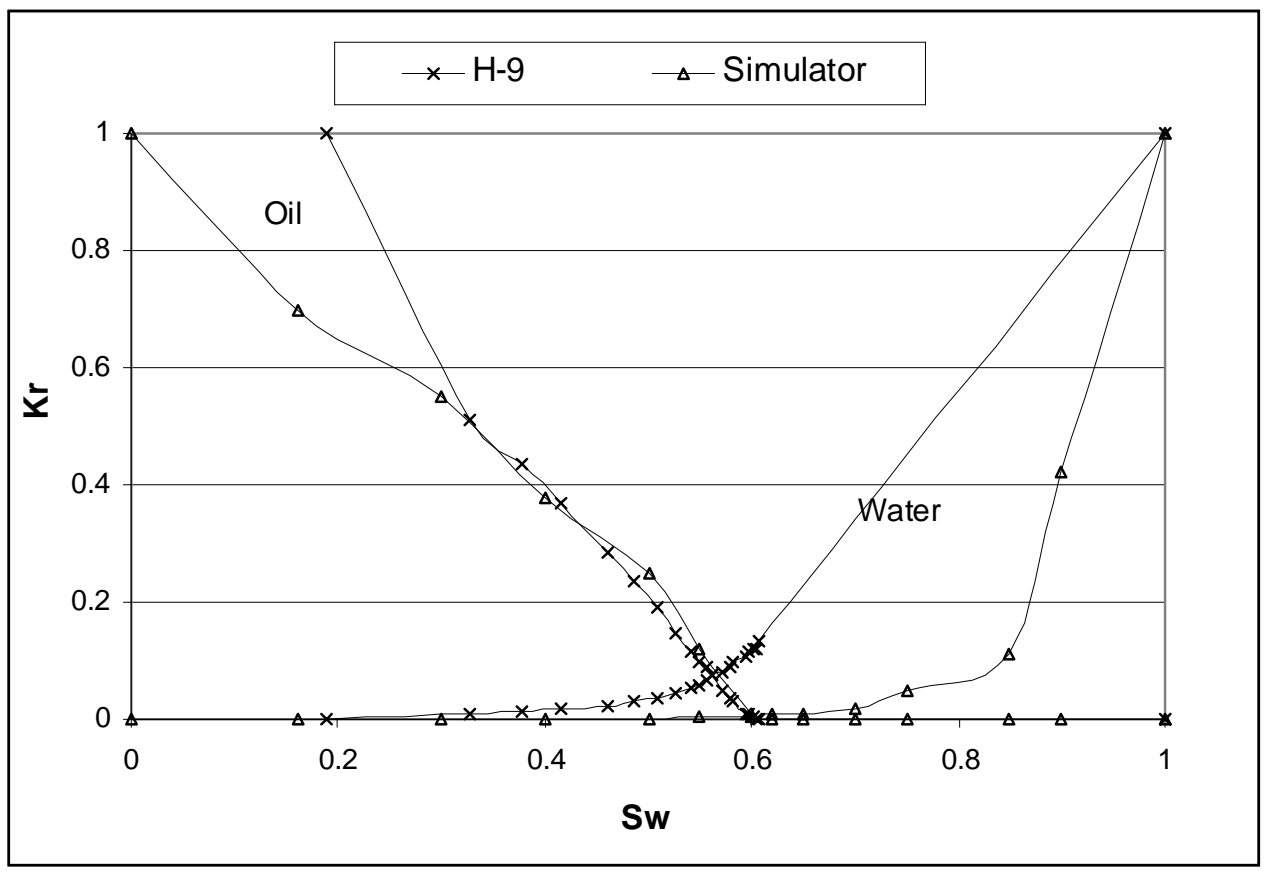

Figure 3.8. Comparison of relative permeabilities.

Table 3.6. Capillary pressure air-brine from well L-13

\begin{tabular}{|c|c|}
\hline Water Saturation & Capillary pressure, $\mathrm{psi}$ \\
\hline 100 & 0 \\
\hline 99.53 & 1 \\
\hline 97.69 & 2 \\
\hline 71.43 & 4 \\
\hline 62.28 & 8 \\
\hline 55.21 & 17 \\
\hline 52.58 & 30 \\
\hline 47.94 & 70 \\
\hline
\end{tabular}

- Depth: $3050.5 \mathrm{ft}$.

- Porosity: $19.4 \%$

- Permeability: $37 \mathrm{mD}$ 
- Grain density: $2.67 \mathrm{~g} / \mathrm{cc}$.

These experimental values of capillary pressure were adjusted to account for the

presence of oil instead of air, using the following expression: ${ }^{13}$

$$
\mathrm{Pc} \text { corr }=\operatorname{Pcexp} x\left(\sigma_{\mathrm{w}-\mathrm{o}} / \sigma_{\mathrm{w}-\mathrm{a}}\right)
$$

Where:

$\mathrm{Pc}_{\text {corr }}=$ Capillary pressure corrected for an oil-water system, psia.

$\mathrm{Pc}_{\mathrm{exp}}=$ Capillary pressure obtained for a water-air system, psia.

$\sigma_{\mathrm{w}-\mathrm{o}}=$ Interfacial tension for water-oil, dyn $/ \mathrm{cm}$

$\sigma_{\mathrm{w}-\mathrm{a}}=$ Interfacial tension for air-water, dyn $/ \mathrm{cm}$

In the program, $\sigma_{\mathrm{w}-\mathrm{a}}$ was taken equal to $72 \mathrm{dyn} / \mathrm{cm}$, and $\sigma_{\mathrm{w}-\mathrm{o}}$ equal to $20 \mathrm{dyn} / \mathrm{cm} .{ }^{6}$ The capillary pressure values used in the simulator are presented in Appendix F.

PVT Data. Since no PVT data were available for the field, these were computed using correlations. ${ }^{13}$ The known quantities for the field were the oil API gravity and viscosity, the formation temperature, the water viscosity. The PVT properties used in the program are summarized in tables 3.7 through 3.9 for oil, water and gas.

\subsubsection{Recurrent data for the simulator.}

The recurrent data include information about location and initial specifications of wells in the model such us, number of layers completed and a schedule of individual well 
rate and/or pressure performance, changes in well completions and stimulation or damage that occurred over time.

Table 3.7. Oil PVT properties.

\begin{tabular}{|c|c|c|c|}
\hline Pressure, psia & Viscosity, cp & Bo, RB/STB & $\begin{array}{c}\text { Rs, SCF, } \\
\text { STB }\end{array}$ \\
\hline 14.7 & 3.600 & 1.0000 & 0.0 \\
\hline 80.0 & 3.229 & 1.0254 & 14.5 \\
\hline 100.0 & 3.132 & 1.0275 & 18.9 \\
\hline 120.0 & 3.038 & 1.0296 & 23.5 \\
\hline 2500.0 & 0.6100 & 1.4234 & 862.5 \\
\hline Slope $(\mathrm{P}>\mathrm{Pb})$ & $\begin{array}{c}0.125 \mathrm{E}-02 \\
\mathrm{cp} / \mathrm{psia}\end{array}$ & $\begin{array}{c}-0.800 \mathrm{E}-06 \\
\mathrm{RB} / \mathrm{STB} / \mathrm{psia}\end{array}$ & 0.0 \\
& \multicolumn{3}{|c}{} \\
\hline
\end{tabular}

Table 3.8. Water PVT properties.

\begin{tabular}{|c|c|c|}
\hline Pressure & Viscosity, $\mathrm{cp}$ & Bo, RB/STB \\
\hline 14.7 & 1.4527 & 0.9911 \\
\hline 120.0 & 1.4585 & 0.9909 \\
\hline 2500.0 & 1.465 & 0.9880 \\
\hline
\end{tabular}

Table 3. 9. Gas PVT properties.

\begin{tabular}{|c|c|c|c|c|}
\hline $\begin{array}{c}\text { Pressure, } \\
\text { Psia }\end{array}$ & $\begin{array}{c}\text { Viscosity, } \\
\mathrm{cp}\end{array}$ & Bg, RCF/SCF & $\begin{array}{c}\text { Pseudo PRS, } \\
\mathrm{psia}^{2} / \mathrm{cp}\end{array}$ & $\begin{array}{c}\text { Rock Comp. } \\
1 / \mathrm{psia}\end{array}$ \\
\hline 14.7 & 0.0112 & $0.1048 \mathrm{E}+01$ & $0.00 \mathrm{E}+00$ & $0.380 \mathrm{E}-05$ \\
\hline 120. & 0.0114 & $0.7446 \mathrm{E}-01$ & $0.3592 \mathrm{E}+07$ & $0.380 \mathrm{E}-05$ \\
\hline 2500. & 0.0196 & $0.4800 \mathrm{E}-02$ & $0.4800 \mathrm{E}+09$ & $0.380 \mathrm{E}-05$ \\
\hline
\end{tabular}

Productivity Index (PID). This function is used to account for changes in the well condition, basically changes in the skin factor, S, after damage or any stimulation is performed in the well. The layer flow index can be estimated as follows: 


$$
\mathrm{PID}=\left[\frac{0.00708 \mathrm{Kh}}{\ln \left(\frac{0.121 \sqrt{\mathrm{DX}{ }^{*} \mathrm{DY}}}{r_{\mathrm{w}}}\right)+\mathrm{S}}\right]
$$

Where:

PID: Flow index per layer, for rates in STB/D.

$\mathrm{K}$ = layer absolute permeability, $\mathrm{mD}$.

$\mathrm{h}=$ layer thickness, $\mathrm{ft}$.

$\mathrm{DX}=\mathrm{x}$-direction grid block dimension, $\mathrm{ft}$.

$\mathrm{DY}=\mathrm{y}$-direction grid block dimension, $\mathrm{ft}$.

$\mathrm{r}_{\mathrm{w}}=$ wellbore radius, $\mathrm{ft}$.

$\mathrm{S}=$ layer skin factor.

Several wells had treatments throughout the project's life. This information was used to assign different skin factor values at different times. Table 3.10 summarizes the different treatments reported for the pilot wells, as well as the time elapsed since the beginning of the flooding project.

Table 3.10. Well treatments in pilot wells.

\begin{tabular}{|c|c|c|}
\hline Well & Treatment & Elapsed days \\
\hline P-7 & Acid fracturing, 3 times & $147,387,660$ \\
\hline H-11 & Acid fracturing & 662 \\
\hline H-10 & Acid fracturing & 965 \\
\hline M-1 & $\begin{array}{c}\text { Chemical injection to } \\
\text { remove paraffin deposit }\end{array}$ \\
\hline H-12 & $\begin{array}{c}\text { Acid fracturing to remove } \\
\text { paraffin deposit }\end{array}$ \\
\hline
\end{tabular}


At some stage during the pilot life, produced water was mixed with fresh water to be injected. Analysis showed that these waters were incompatible and should not be mixed because carbonate precipitation was likely to occur. This mixing could have been the cause of plugging in some wells.

Injection rates. The water injection rates assigned to the injectors were chosen between 10 and $15 \%$ of the total rate, as shown in Table 3.11. Only with those low percentages an acceptable match between actual and simulated water production was achieved.

Table 3.11. Average water injection rates per well.

\begin{tabular}{|c|c|}
\hline Injection well & $\begin{array}{c}\text { Average water injection } \\
\text { rate, \% of total }\end{array}$ \\
\hline P-7 & 11.7 \\
\hline L-9 & 14.0 \\
\hline H-11 & 15.5 \\
\hline H-10 & 12.0 \\
\hline A-5 & 15.0 \\
\hline H-9 & 15.2 \\
\hline
\end{tabular}




\section{CHAPTER 4.}

\section{RESULTS AND DISCUSSION}

\subsection{Permeability Prediction using Conventional Approach.}

Core data from six wells were used to find the core porosity - core permeability correlation, which is depicted in Figure 4.1. The correlation between core porosity and permeability is good for permeability prediction; nevertheless it cannot be used for other wells in the field where core porosity data are not available. For this reason, the procedure was repeated using porosity calculated from bulk density logs. A correlation for $\log$ porosity and core was developed, presented in Figure 4.2, after adjusting the core data for depth with the logs. The results for the correlation between this log porosity and core permeability is shown in Figure 4.3. As can be seen, the $\mathrm{R}^{2}$ coefficient was lower than that obtained using core porosity.

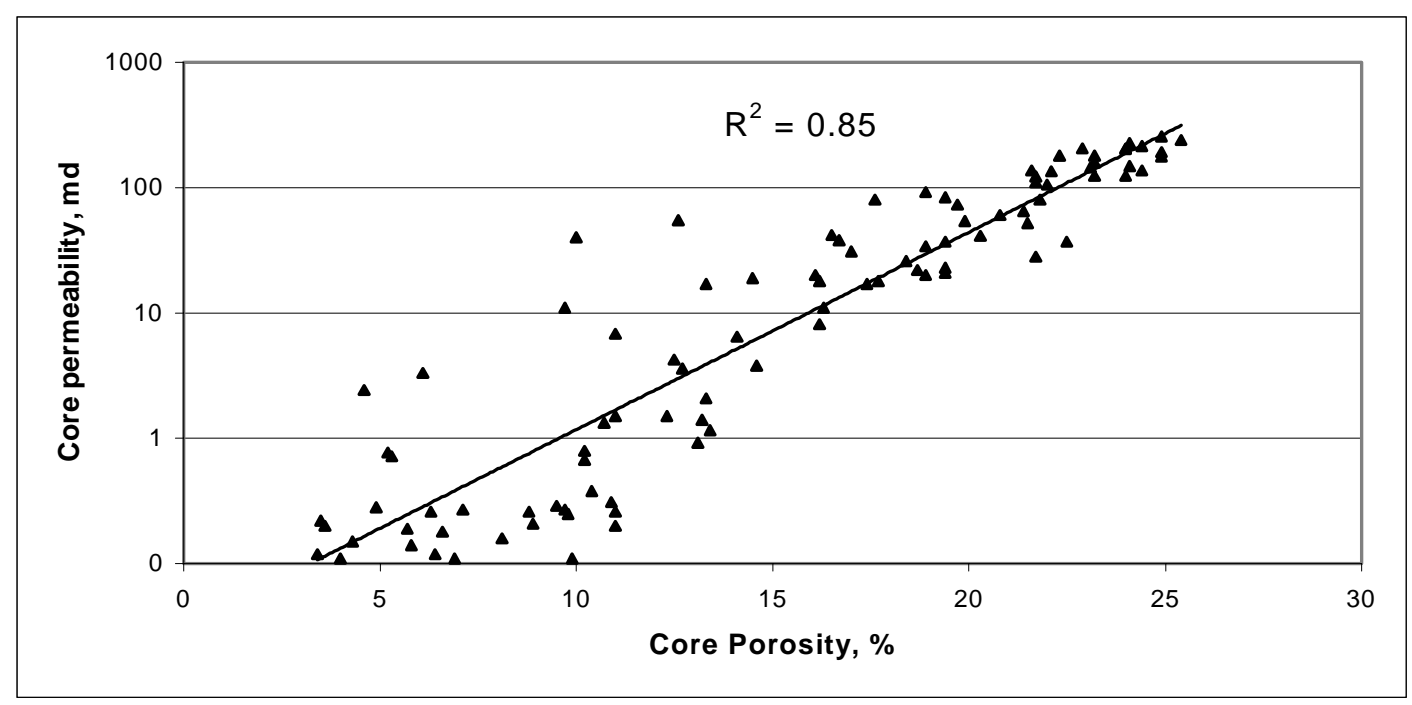

Figure 4.1. Correlation between core porosity and core permeability. 


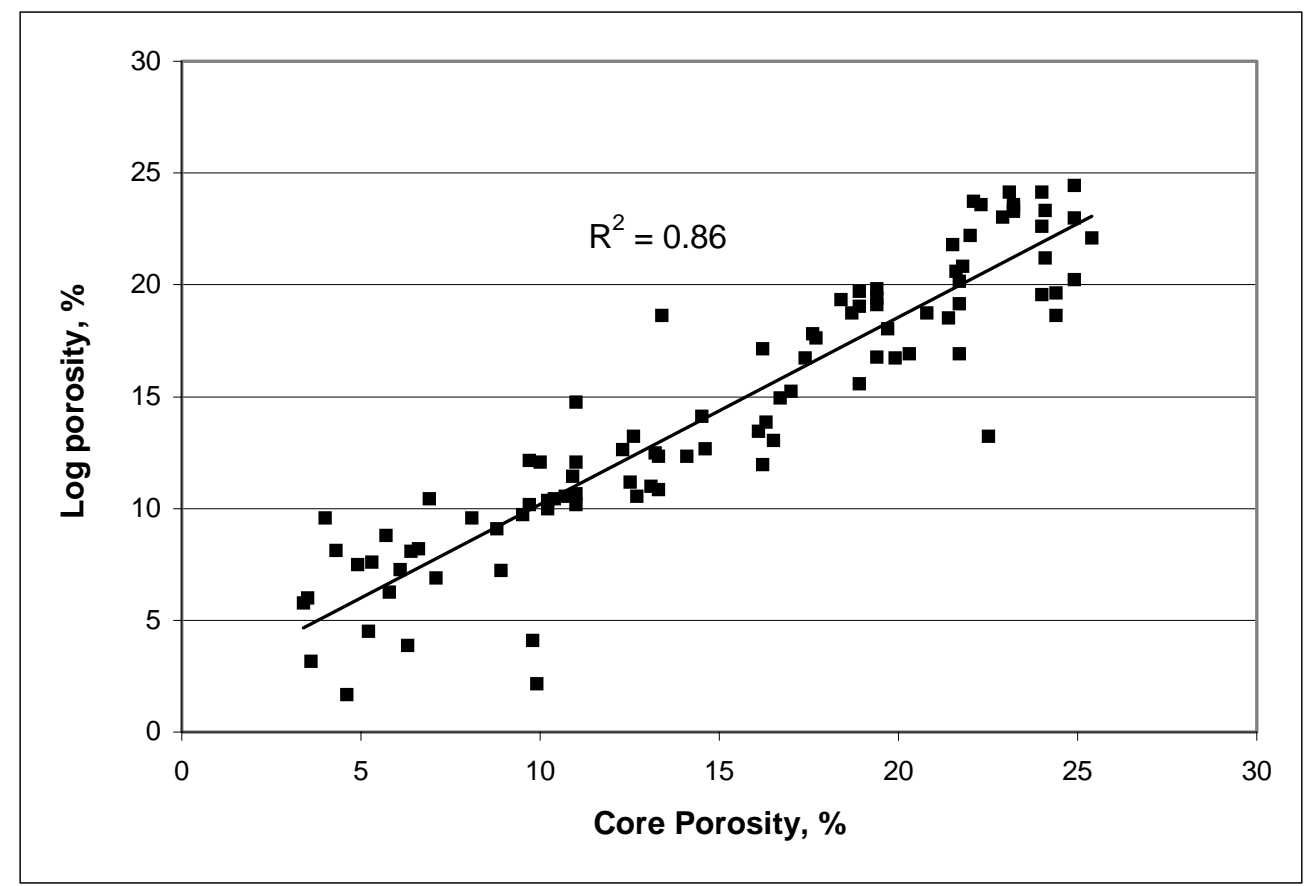

Figure 4.2. Correlation between core porosity and log-derived porosity.

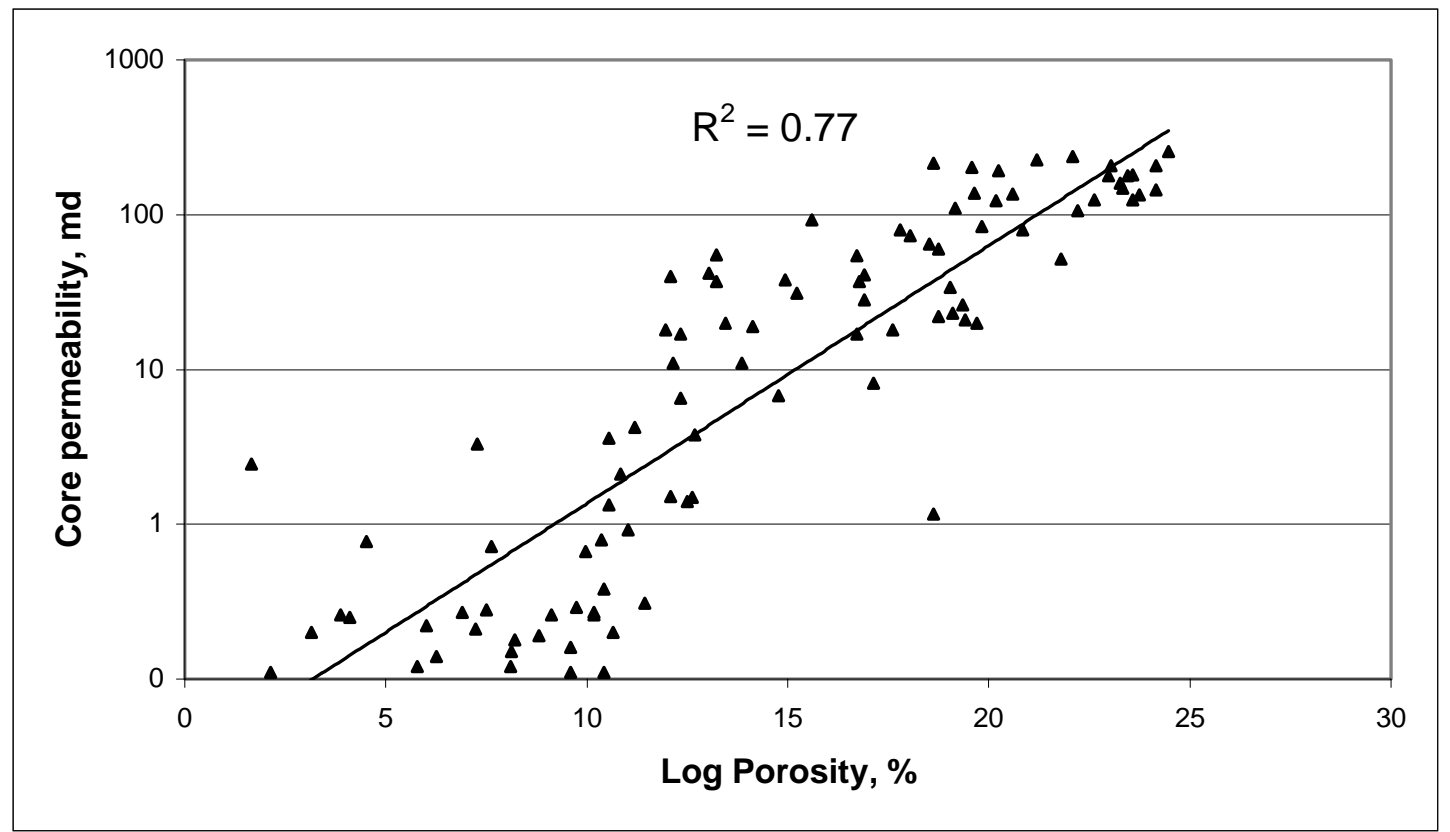

Figure 4.3. Correlation between Log-derived porosity and core permeability. 


\subsection{Porosity Predicted with A.N.N.}

A backpropagation network, with three slabs in the middle layer, was trained to predict porosity using 11 inputs from logs and well information. The $\mathrm{R}^{2}$ values for both training and test and for the verification well are shown in Table 4.1.

Table 4.1. $\mathbf{R}^{2}$ values for porosity prediction

\begin{tabular}{|c|c|c|}
\hline Verification Well & $\begin{array}{c}\mathbf{R}^{2} \text { for training }+ \\
\text { test }\end{array}$ & $\mathbf{R}^{2}$ for verification \\
\hline B-18 & 0.92 & 0.90 \\
\hline B-19 & 0.94 & 0.82 \\
\hline H-9 & 0.91 & 0.96 \\
\hline H-11 & 0.92 & 0.89 \\
\hline T-8 & 0.94 & 0.83 \\
\hline L-13 & 0.95 & 0.82 \\
\hline
\end{tabular}

The correlations for core porosity-A.N.N. porosity and A.N.N. porositypermeability are depicted in Figures 4.4 and 4.5. Both correlations present an improvement compared with the ones developed from logs.

\subsection{Effect of Lithology on Permeability.}

The lithology groups identified with the cores were correlated with the Gamma Ray and Density logs to identify these zones in the rest of the field. Then, the porosity and permeability values from the core analysis were grouped according to conglomerate and sandstone in order to evaluate the impact of lithology on the correlation and the reservoir quality. 


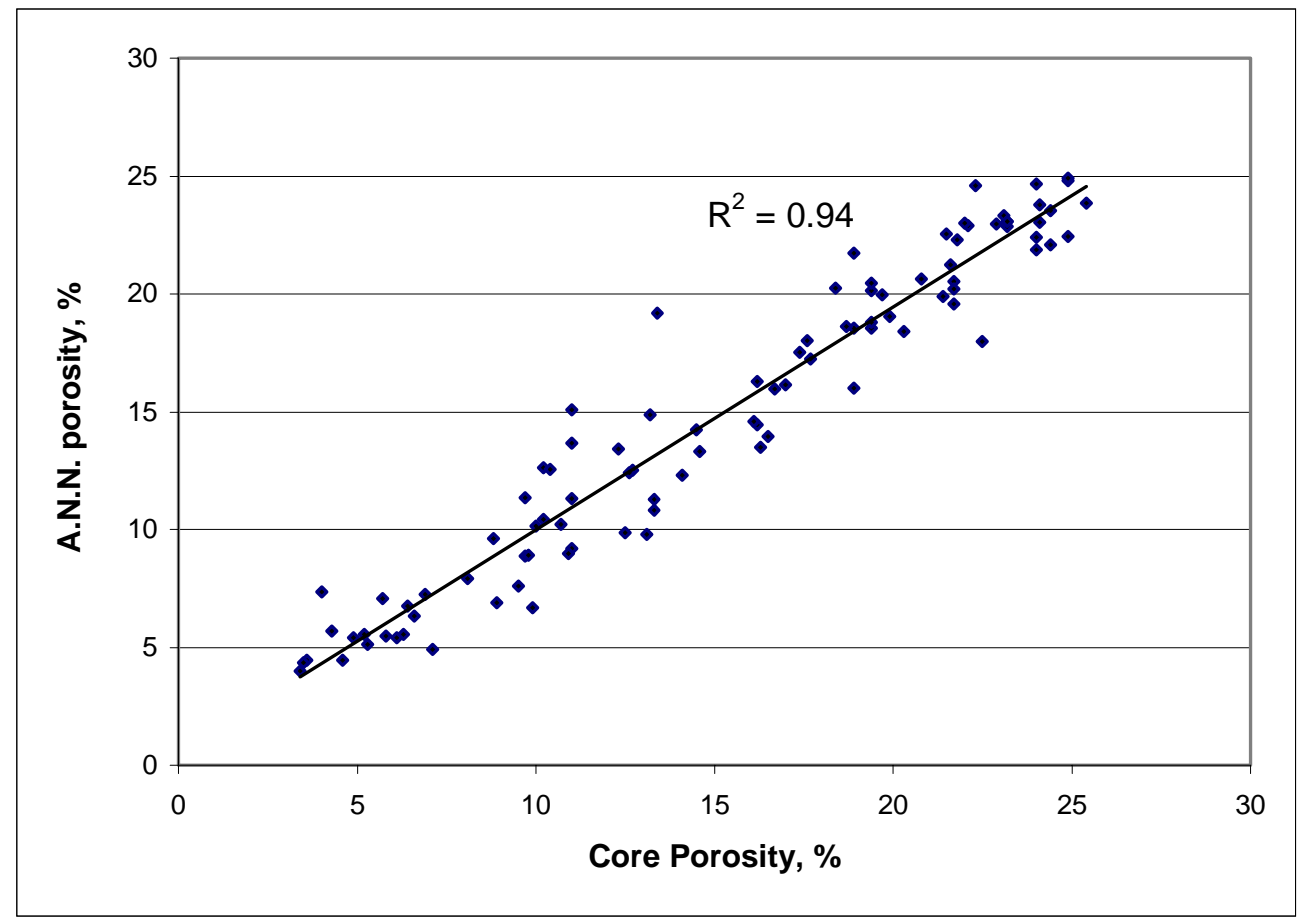

Figure 4.4. Correlation between core porosity and porosity from A.N.N.

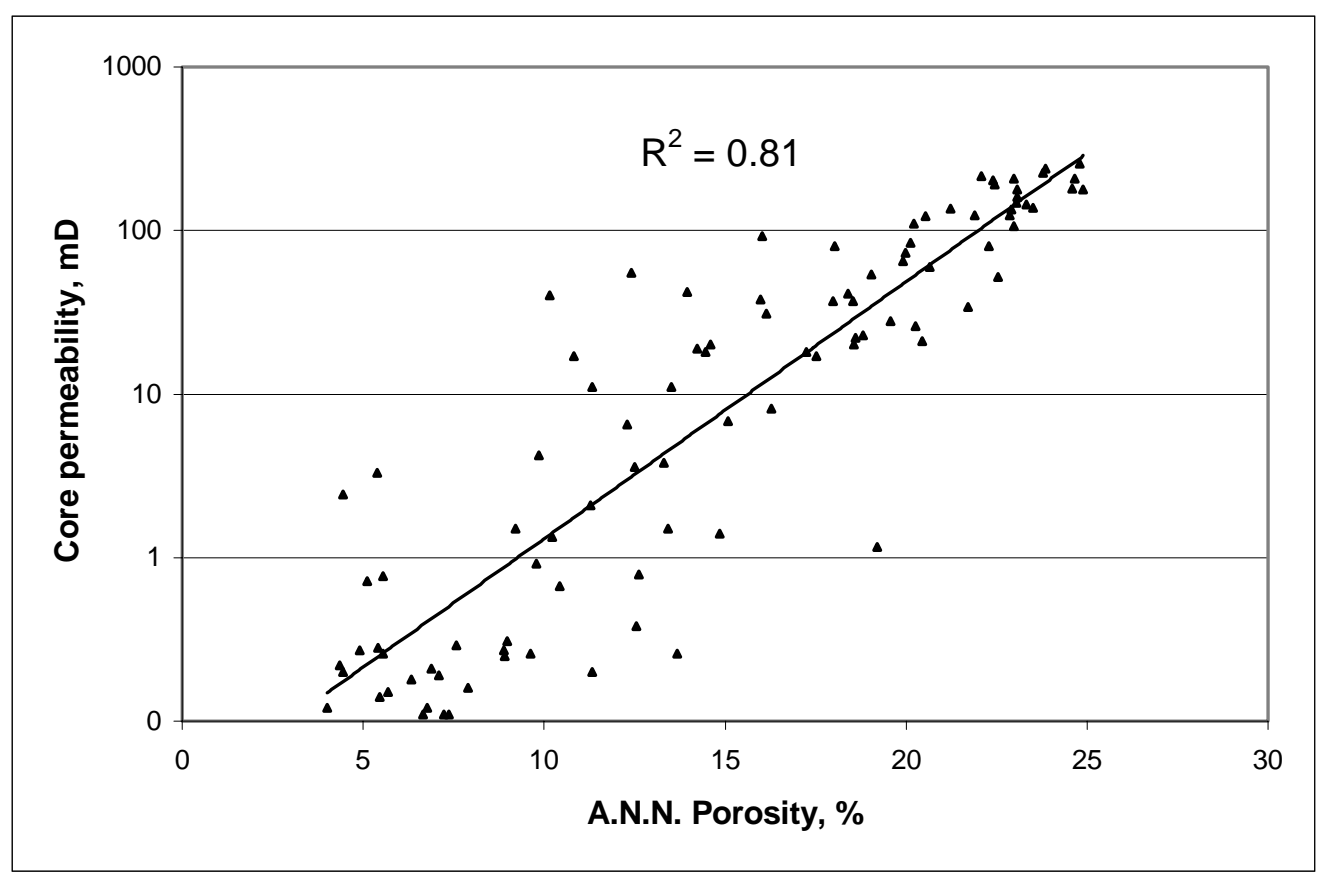

Figure 4.5. Correlation between Log-derived porosity and core permeability. 
The development of such correlations allowed the recognition of the different behavior of permeability between these zones and an improvement in the correlation for the sandstone. As is illustrated in Figure 4.6, the correlation coefficient for the conglomerate is low, 0.60, whereas for sandstone is high, 0.93 (Figure 4.7). This confirms the heterogeneity of the formation and also shows the need to develop a better method for permeability prediction.

The different lithologies found in the cores are shown in Appendix 1, as well as the porosity and the permeability.

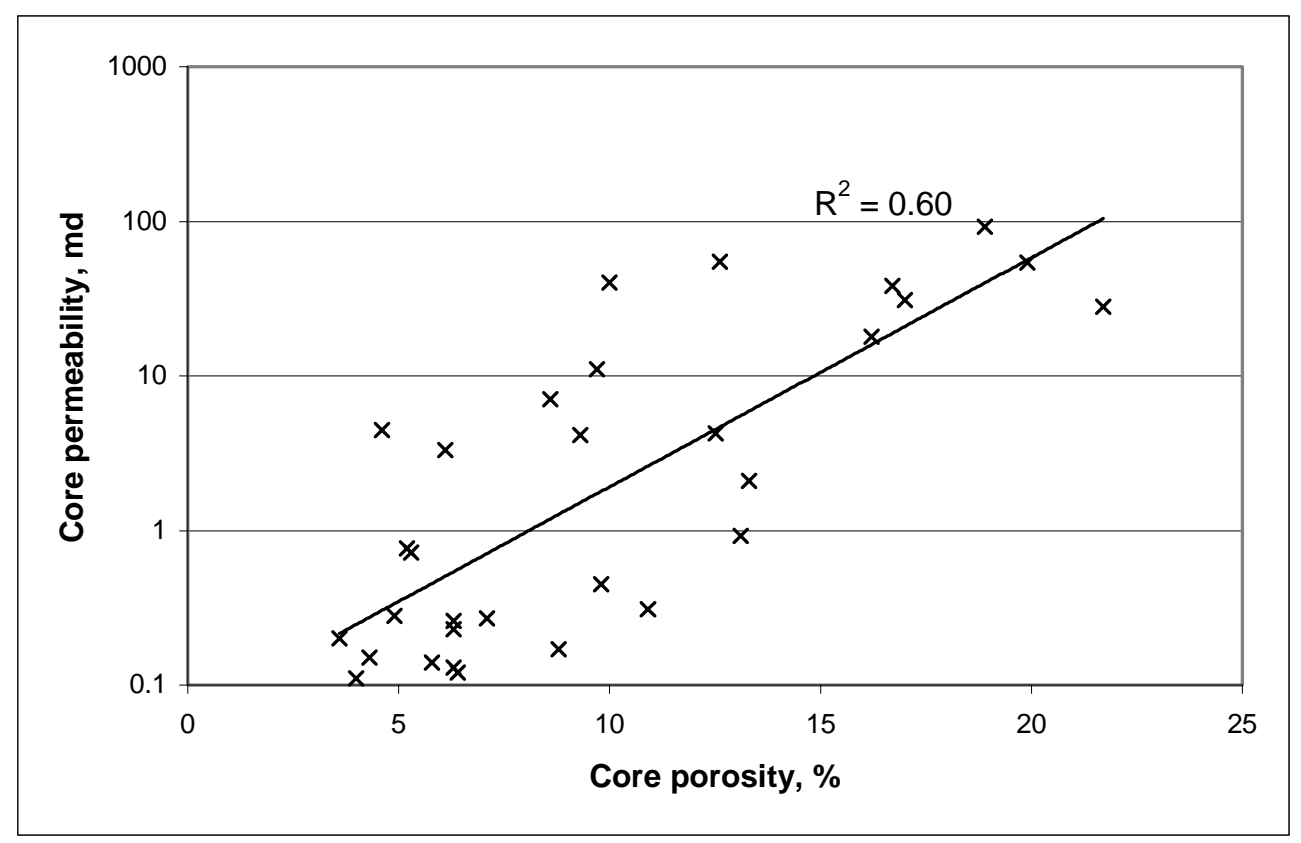

Figure 4.6. Correlation between core porosity and core permeability for conglomerate. 


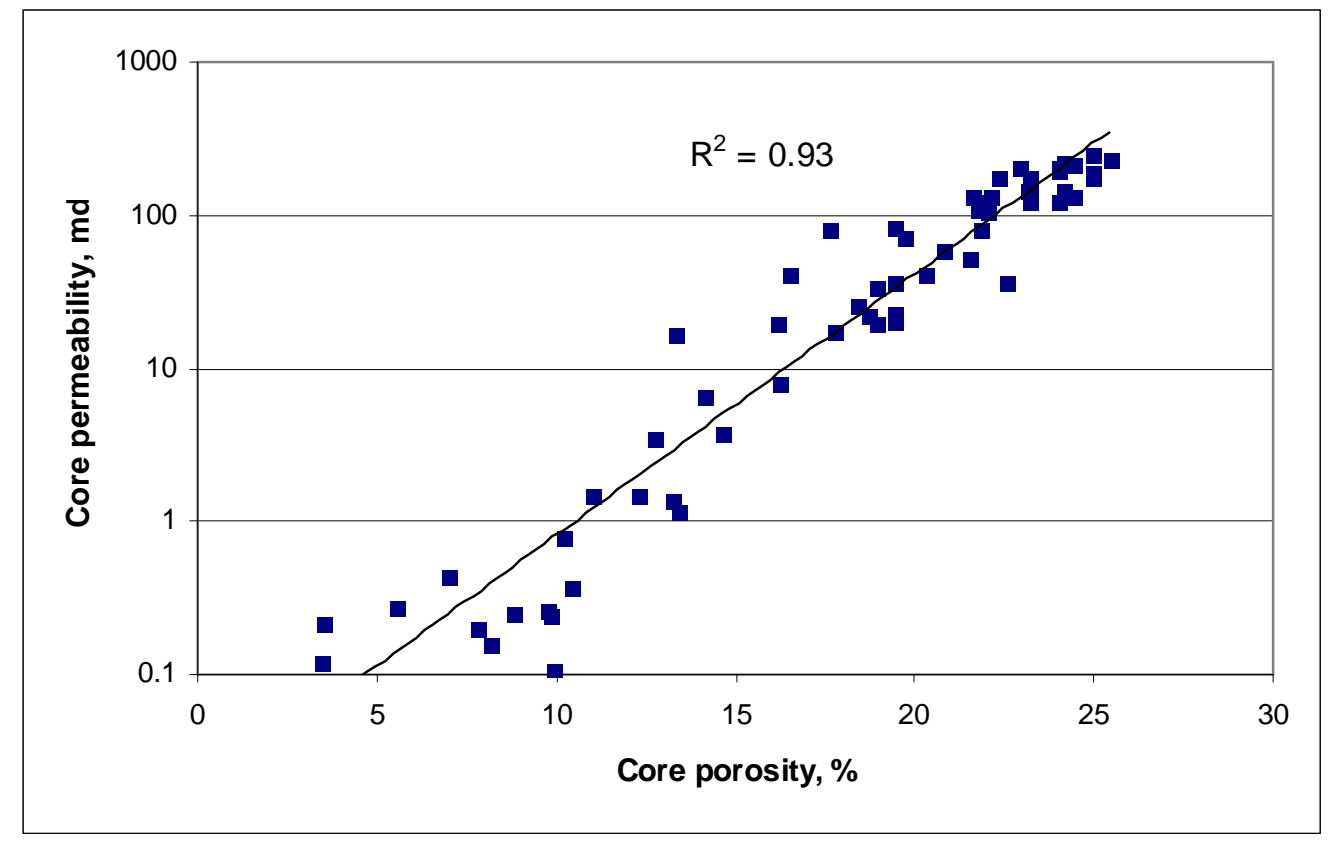

Figure 4.7. Correlation between core porosity and core permeability for sandstone.

\subsection{Permeability Predicted with A.N.N.}

A three-layer backpropagation A.N.N. with three slabs in the middle layer, each slab with a different activation function, was used. Input data included formation depth, location of the well (X and Y coordinates), GR and bulk density logs, first derivatives of these logs with depth and the log baselines. The corresponding correlation coefficients for both training and test sets and for the verification well are shown in Table 4.2. The comparison between core and predicted permeabilities for each well are presented in Appendix B.

When comparing predicted with core permeabilities for all the wells, the $\mathrm{R}^{2}$ coefficient is 0.78 (if the well $\mathrm{H}-11$ is not included, this coefficient would be 0.85 ). 
Table 4.2. $\mathbf{R}^{2}$ values for permeability prediction.

\begin{tabular}{|c|c|c|}
\hline Verification Well & $\mathbf{R}^{2}$ for training + test & $\mathbf{R}^{2}$ for verification \\
\hline B-18 & 0.97 & 0.96 \\
\hline B-19 & 0.99 & 0.75 \\
\hline H-9 & 0.80 & 0.91 \\
\hline H-11 & 0.95 & 0.30 \\
\hline T-8 & 0.90 & 0.80 \\
\hline L-13 & 0.95 & 0.83 \\
\hline
\end{tabular}

\subsection{Petrophysical Parameters for the Pilot Wells.}

The A.N.N. models developed for porosity and permeability were applied to the pilot area. The results are summarized in Table 4.3. These properties are plotted against depth from Figures D.1 to D.5, Appendix D. The lithological zones, as described by the geologic correlation developed between core interpretation and well logs, are also shown. The properties for two of the injectors, that were cored, were summarized in Table 2.1.

Table 4.3. Average reservoir properties for the pilot wells.

\begin{tabular}{|c|c|c|c|}
\hline Well & Avg. porosity & \multicolumn{2}{|c|}{ Permeability from A.N.N., avg. mD } \\
\cline { 3 - 4 } & from A.N.N., \% & Arithmetic & Geometric \\
\hline P-7 & 19.2 & 112.3 & 102.6 \\
\hline L-9 & 19.7 & 66.6 & 41.9 \\
\hline H-10 & 20.1 & 67.5 & 48.8 \\
\hline A-5 & 19.5 & 177.0 & 161.9 \\
\hline H-12 & 17.4 & 29.4 & 25.3 \\
\hline
\end{tabular}

The contribution factors for the inputs in both A.N.N. for porosity and permeability when applied to the pilot wells are presented in tables 4.4 and 4.5 . In order to build the most 
successful A.N.N., several inputs variables were tried. For instance, using only log data as input for the model, the A.N.N. did not give good predictions. The first and second derivatives were used in the input file to help the model recognize the changes in the shape of the log responses and reduce the inherent noise.

Table 4.4. Contribution factors for porosity prediction in pilot wells.

\begin{tabular}{|l|c|}
\hline \multicolumn{1}{|c|}{ Inputs } & Contribution Factors \\
\hline Density & 0.203 \\
\hline Gamma Ray slope & 0.111 \\
\hline Gamma Ray & 0.108 \\
\hline Density 2 ${ }^{\text {nd }}$ slope & 0.092 \\
\hline Gamma Ray 2 ${ }^{\text {nd }}$ slope & 0.091 \\
\hline Gamma Ray Baseline & 0.080 \\
\hline Density slope & 0.075 \\
\hline Depth & 0.069 \\
\hline X coordinate & 0.060 \\
\hline Density Baseline & 0.059 \\
\hline Y coordinate & 0.052 \\
\hline
\end{tabular}

Table 4.5. Contribution factors for permeability prediction in pilot wells.

\begin{tabular}{|l|c|}
\hline \multicolumn{1}{|c|}{ Inputs } & Contribution Factors \\
\hline Density & 0.158 \\
\hline Gamma Ray slope & 0.132 \\
\hline Density slope & 0.126 \\
\hline X coordinate & 0.116 \\
\hline Depth & 0.109 \\
\hline Density Baseline & 0.104 \\
\hline Gamma Ray & 0.095 \\
\hline Gamma Ray Baseline & 0.81 \\
\hline Y coordinate & 0.08 \\
\hline
\end{tabular}




\subsection{Definition of Flow Units in Pilot Area.}

The formation was divided in two flow units to account for permeability, porosity and lithology variations in the vertical direction. The first criterion to choose the flow units was lithology, taking conglomerate as one layer and sandstone as the second layer, even though conglomerate was not present in some wells, but the simulation did not give satisfactory results. Again, the sandstone zone was characterized by important permeability and porosity variations that may impact the flow behavior. The history matching for this case is presented in appendix $\mathrm{F}$.

The final criteria followed to select the flow units were permeability and porosity breaks. The average properties of the selected flow units are displayed in Table 4.6. As shown, the first layer is generally of low porosity and permeability, while in the second one these values are higher.

\subsection{History Matching.}

The cumulative production from the simulator, using one and two layers, was plotted in conjunction with the actual production and shown in Figures 4.8 through 4.13 for both oil and water. Figures 4.8 and 4.9 depict the cumulative production of oil and water from both producing wells. As can be seen, the cumulative production is the same when using one or two layers in the model. These results can be misleading when interpreting the difference between one or two layers, because the real effect of these two models is best understood when the production is plotted for each producing well separately. 
Table 4.6. Average properties in the pilot wells per layer.

\begin{tabular}{|c|c|c|c|c|c|c|}
\cline { 2 - 7 } \multicolumn{1}{c|}{} & \multicolumn{5}{c|}{ Average properties } \\
\cline { 2 - 7 } \multicolumn{1}{c|}{} & \multicolumn{5}{c|}{ Layer 1 } & \multicolumn{3}{c|}{ Layer 2 } \\
\hline Well & Thickness & $\phi$ & K, geom.. & Thickness & $\phi$ & K, geom.. \\
\hline P-7 & 3.0 & 17.7 & 81.2 & 4.0 & 19.2 & 119.8 \\
\hline L-9 & 3.0 & 18.4 & 24.9 & 3.0 & 19.7 & 84.1 \\
\hline H-11 & 4.5 & 16.2 & 9.1 & 5 & 21.3 & 117.4 \\
\hline H-10 & 5.5 & 21.5 & 83.2 & 3.5 & 20.1 & 35.5 \\
\hline A-5 & 6.0 & 12.5 & 94.8 & 12.0 & 19.5 & 215.1 \\
\hline H-9 & 4 & 15.7 & 67.1 & 9 & 22.8 & 144.9 \\
\hline H-12 & 3.5 & 18.0 & 33.8 & 2.0 & 17.4 & 16.1 \\
\hline
\end{tabular}

Figure 4.10 and 4.11 show the cumulative oil and water production for the well M-1. Now the effect of using one and two layers is more noticeable, especially for the water production. The cumulative production for the well H-12 is illustrated in Figures 4.12 and 4.13. Again the difference between using one or two layers in the model is important. For this well, the production shows a flat zone at approximately 750 days. This was caused by damaged (paraffin deposition) and consequently low production. Even though this was incorporated in the recurrent file assigning a low skin factor value, the program might not represent this problem very accurately. 


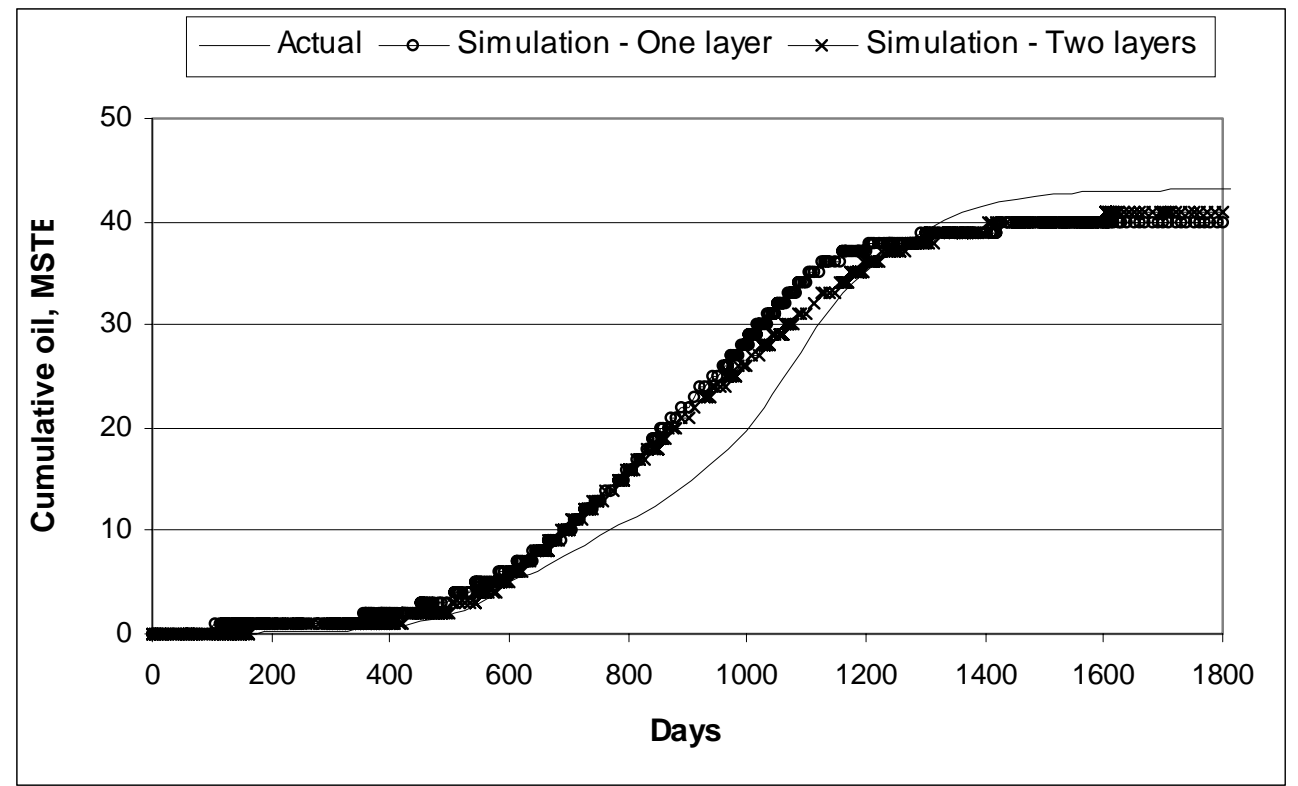

Figure 4.8. Comparison of cumulative oil production from the pilot. Both producers

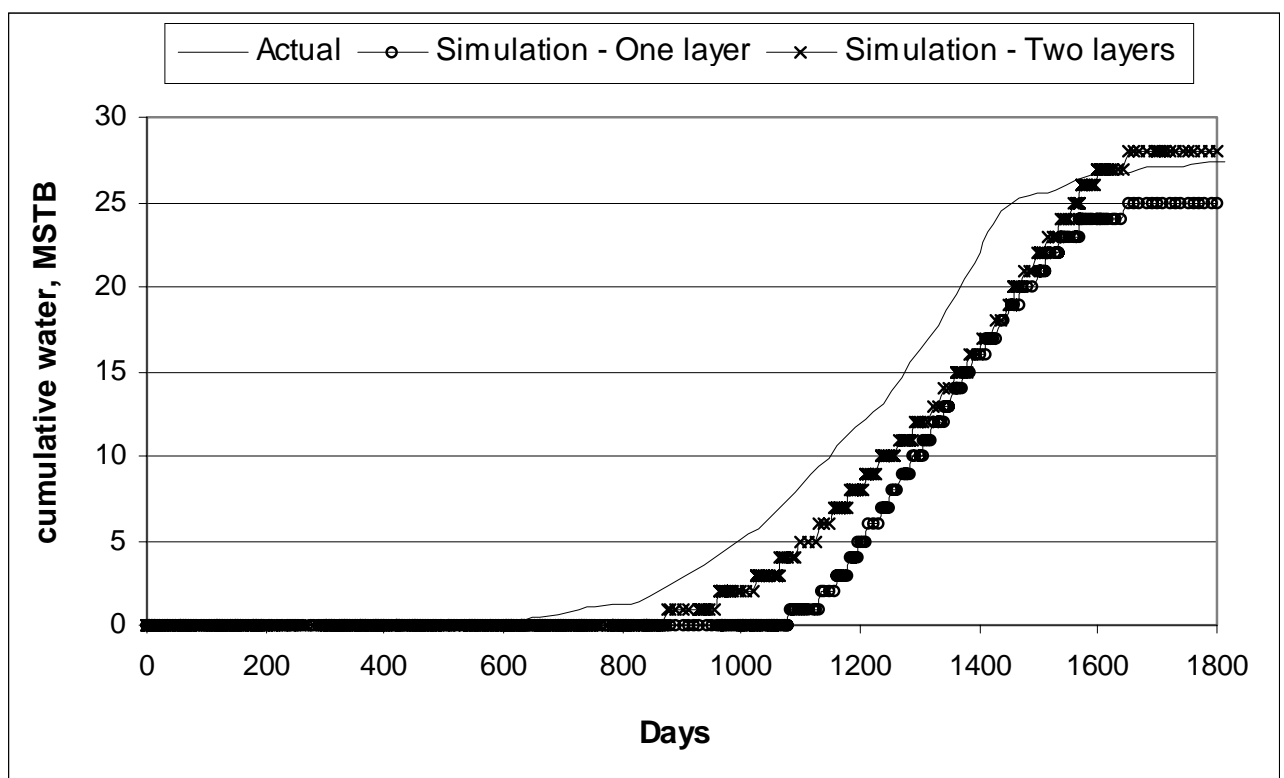

Figure 4.9. Comparison of cumulative water production from the pilot. Both producers 


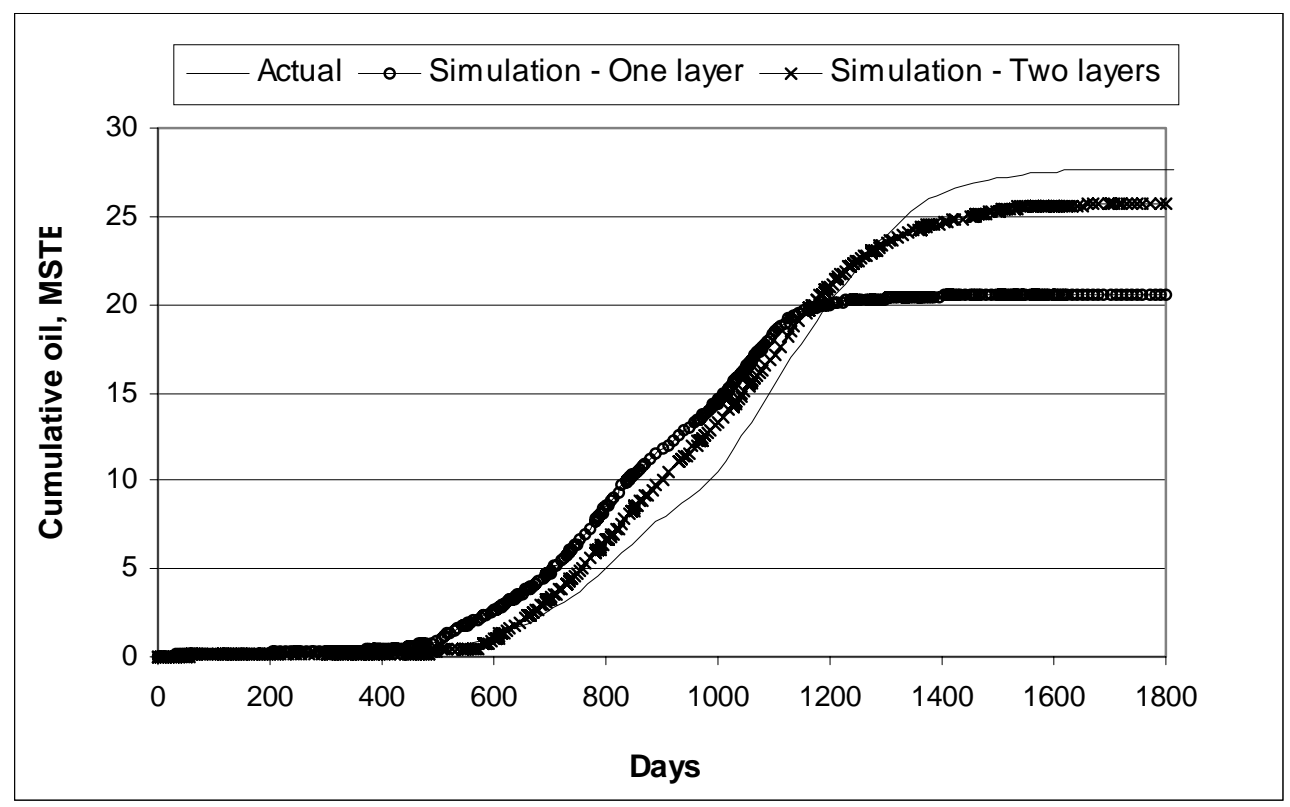

Figure 4.10. Comparison of cumulative oil production. Well M-1

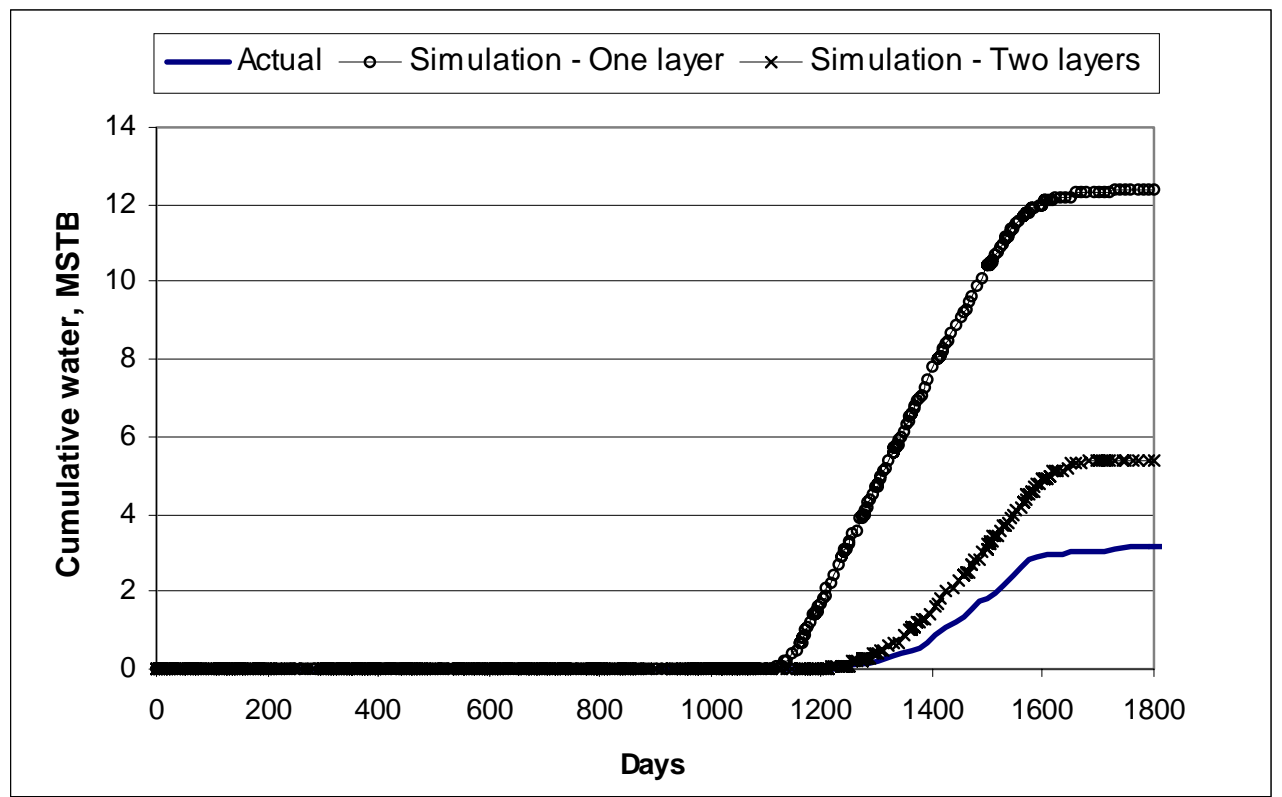

Figure 4.11. Comparison of cumulative water production. Well M-1 


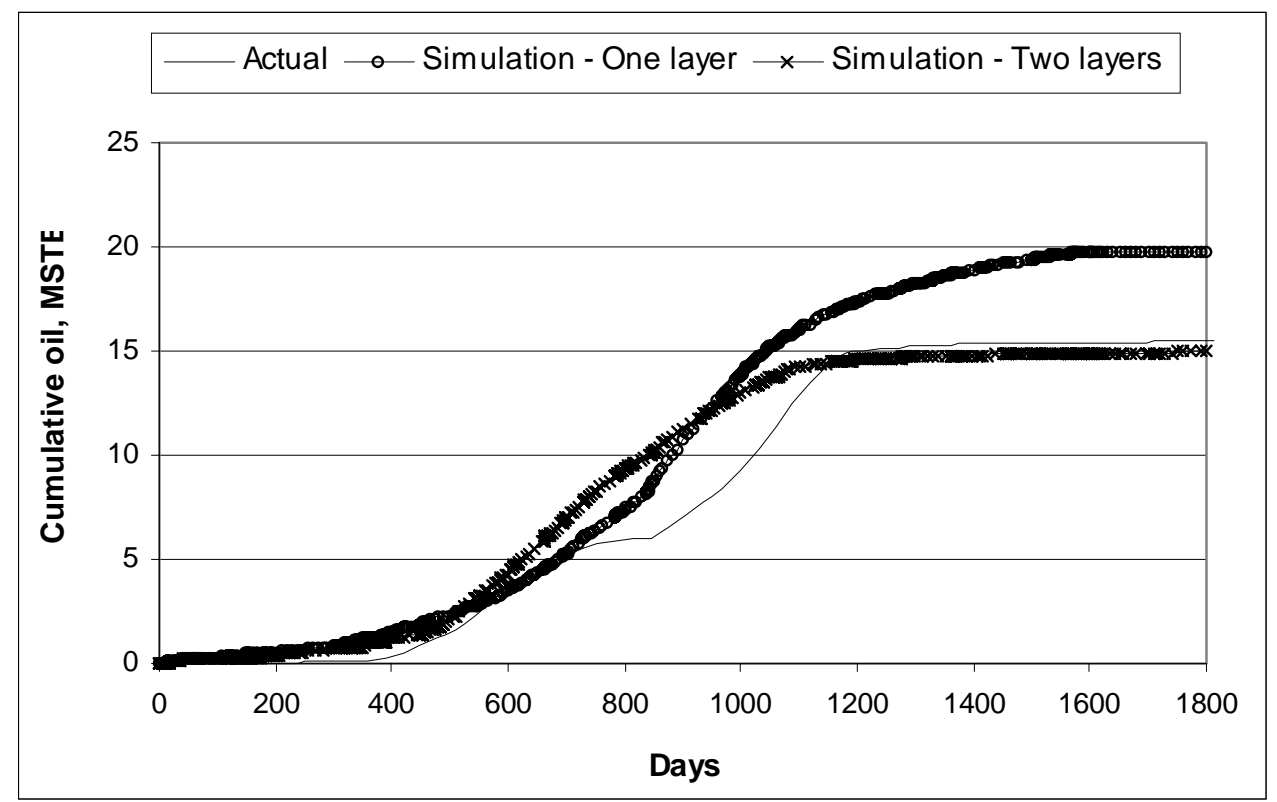

Figure 4.12. Comparison of cumulative oil production. Well H-12

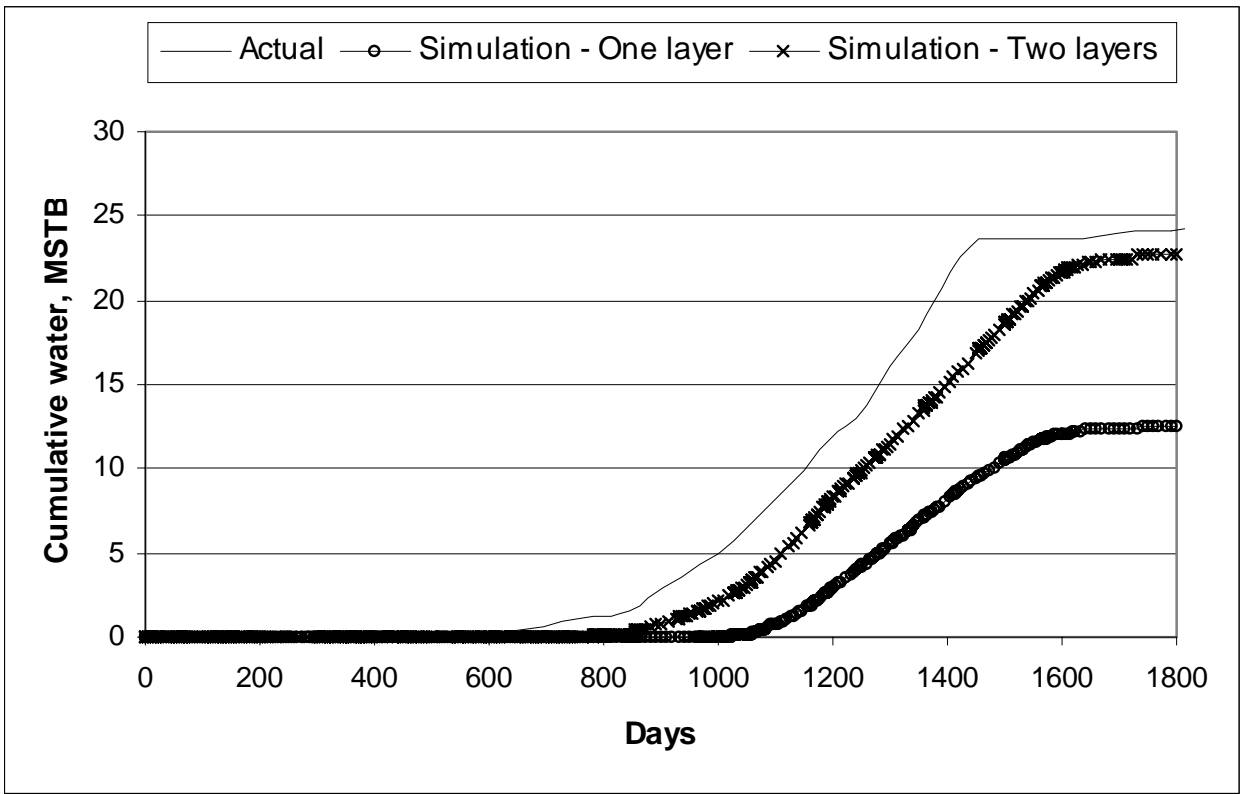

Figure 4.13. Comparison of cumulative water production. Well H-12 


\section{CHAPTER 5.}

\section{CONCLUSIONS.}

1. Two Artificial Neural Networks were successfully developed for prediction of porosity and permeability in a heterogeneous reservoir.

2. The prediction of porosity and permeability with A.N.N.s improved the description of the reservoir and helped to identify the main flow units for the formation in the pilot area.

3. Lithology was not a critical factor in the definition of the flow units for the pilot area. Flow units were selected based on porosity and permeability distribution.

4. The flow units identified in the pilot area enhanced the simulation of the waterflooding performance.

5. After attempting different architectures, the Backpropagation network, with three slabs in the middle layer and different activation functions, gave better results for prediction of porosity and permeability.

6. The use of derivatives in the training and test sets helped in the development of the A.N.N.s, reducing the inherent noise in the inputs. 
7. Density and Gamma Ray slope were the input parameters with higher contribution factors in the A.N.N.s developed in this study.

8. The numerical simulator used, Boast 98 , proved to be very user-friendly. The graphical interface allows for quick evaluation of the reservoir performance at run-time. Nevertheless, there is a problem with the cumulative material-balance calculation. Every time a new case is run, the previous cumulative material balance value is added to the new one. 


\section{CHAPTER 6.}

\section{RECOMMENDATIONS}

1. Three stratigraphic units were observed in the Gordon formation, defined as units A, B and C. In the pilot area, core and log analysis showed that only unit A was present. In other wells like B-18, L-13 and B-19, outside the pilot area, both units A and B were present. As a result, in order to define the flow units with more accuracy for the entire field, a similar study should be conducted in those areas where more than one unit is observed.

2. Further research is recommended in order to predict the flow units within the formation using A.N.N. In this case, input parameters such us stratigraphic units could be included to have a more accurate reservoir description. 


\section{REFERENCES.}

1. Craig, F.F. Jr. The Reservoir Engineering Aspects of Waterflooding. SPE Monograph Series, SPE, Dallas. 1971.

2. Slatt, R.M., and Hopkins, G.L. "Scales Geologic Reservoir Description to Engineering Needs", JPT, February 1990. pp. 202-210.

3. Molnar, D., Aminian, K., and Ameri, S.: "The Use of Well Log Data for Permeability Estimation in a Heterogeneous Reservoir”, SPE 29175, Proceedings of SPE Eastern Regional Conference, pp 167-180, 1994.

4. Aminian, K., Ameri, S., Avary, K.L., Bilgesu, H.I., Hohn, M.E., McDowell, R.R., and Matchen, D.L. "Reservoir Characterization of Upper Devonian Gordon Sanstone”, Jacksonburg, Stringtown Oilfield, Northwestern West Virginia. SemiAnnual Report. West Virginia University, October 1999.

5. Satter, A. and Thakur, G.C. Integrated Petroleum Reservoir Management. A Team Approach. PennWell Books, Tulsa OK. 1994.

6. Willhite, G.P. Waterflooding. SPE Textbook Series, Volume 3. SPE, Richardson, TX. 1986.

7. Extracted from NeuroShell 2 Help, (C) Ward Systems Group, Inc.

8. Fausett, L. Fundamentals of Neural Networks: Architectures, Algorithms and Applications. Prentice Hall, 1994.

9. Mohaghegh, S. Virtual-Intelligence Applications in Petroleum Engineering: Part I- Artificial Neural Networks. JPT, September 2000. pp. 64-73. 
10. Mattax, C.C. and Dalton, R.L. Reservoir Simulation, SPE Monograph Volume 13. SPE, Richardson, TX. 1990.

11. Fanchi, J.R. Principles of Applied Reservoir Simulation. Gulf Publishing Co., Houston, TX, 1997.

12. Heemstra, Ray. BOAST98 and EDBoast. User's Guide and Documentation Manual. BDM-Federal, Inc. for the U.S. Department of Energy.. December, 1998.

13. Tiab, D. and Donaldson, E.C. Petrophysics. Gulf Publishing Co., Houston, TX, 1996. pp. 255.

14. Vasquez, M. and Beggs, H.D. Correlations for Fluid Physical Property Prediction. JPT, June 1980. pp 968-970. 


\section{APPENDIX A.}

Porosity, permeability and lithology distribution in cored wells. 


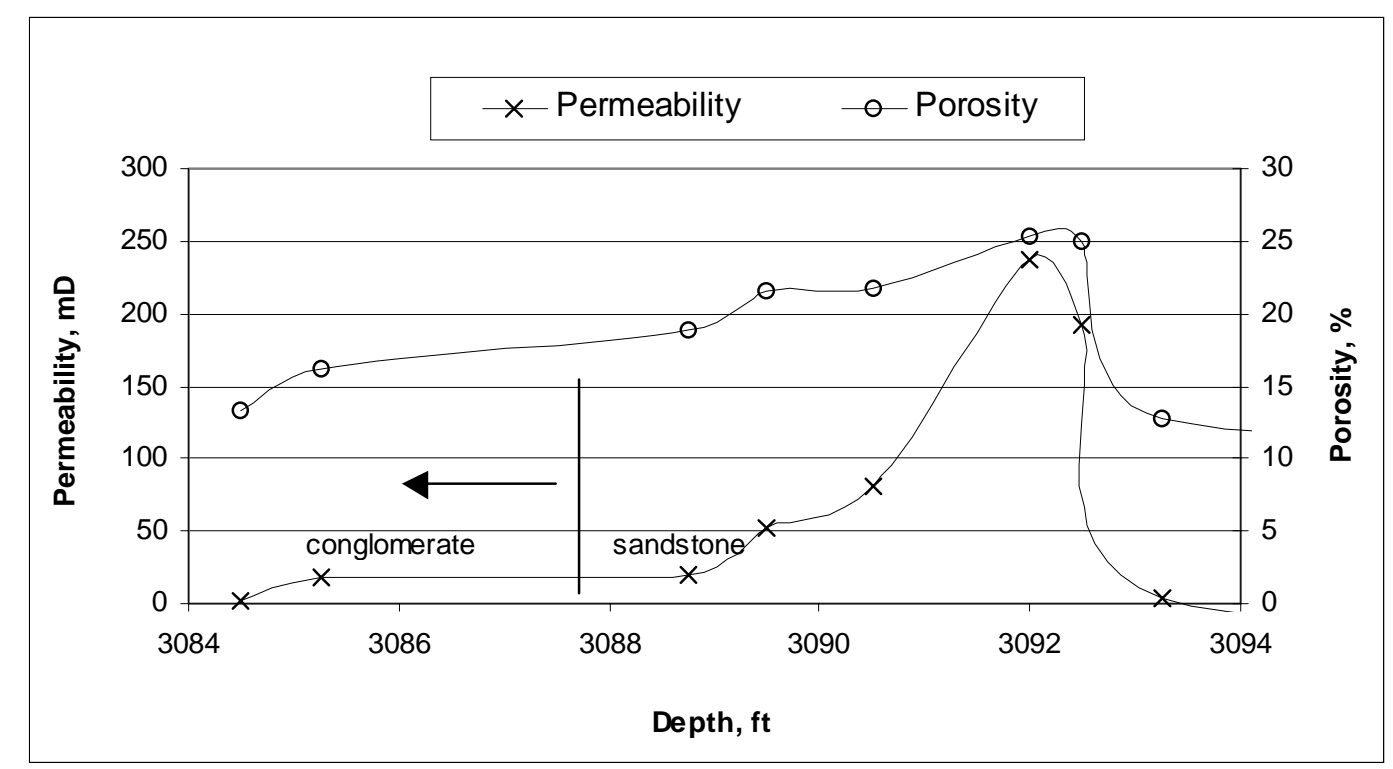

Figure A.1 Porosity, permeability and lithology distribution from core data.

Well H-11.

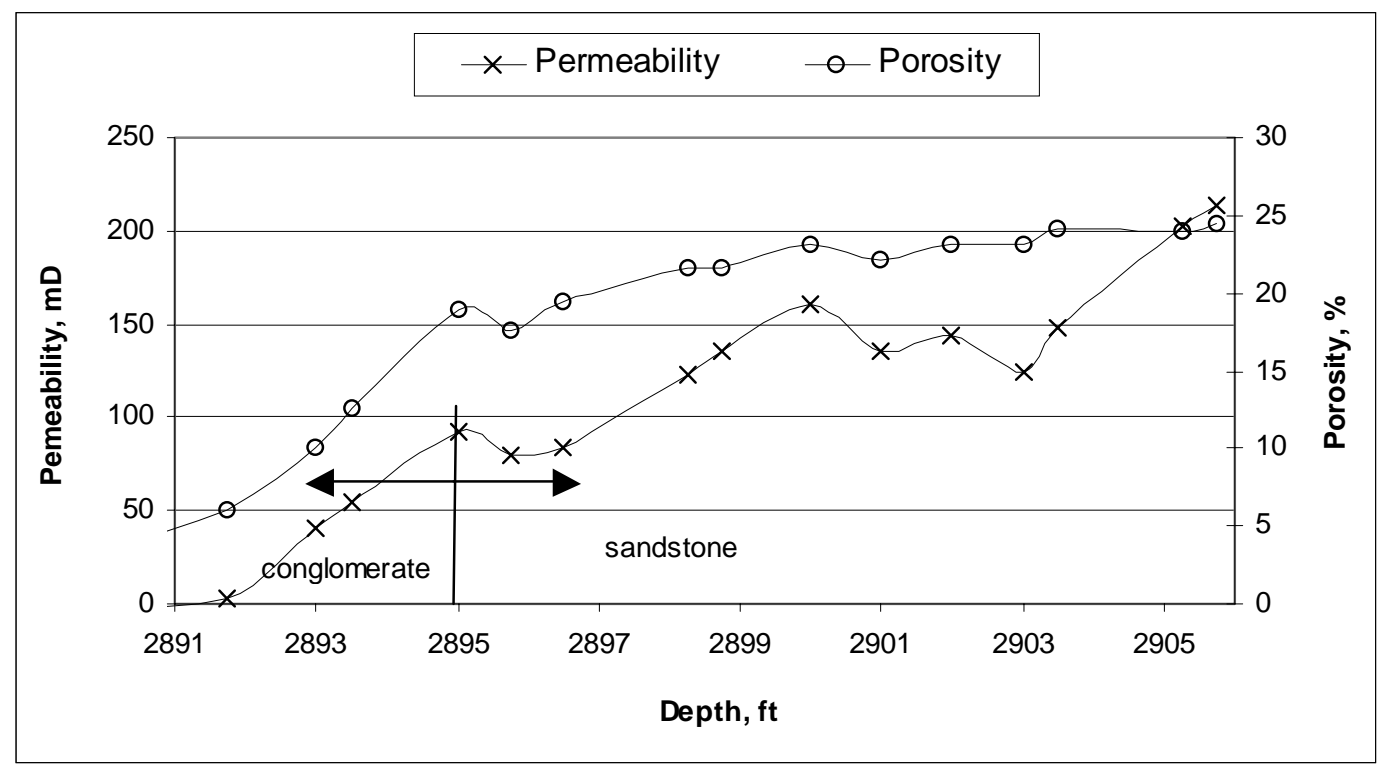

Figure A.2 Porosity, permeability and lithology distribution from core data.

Well H-9 


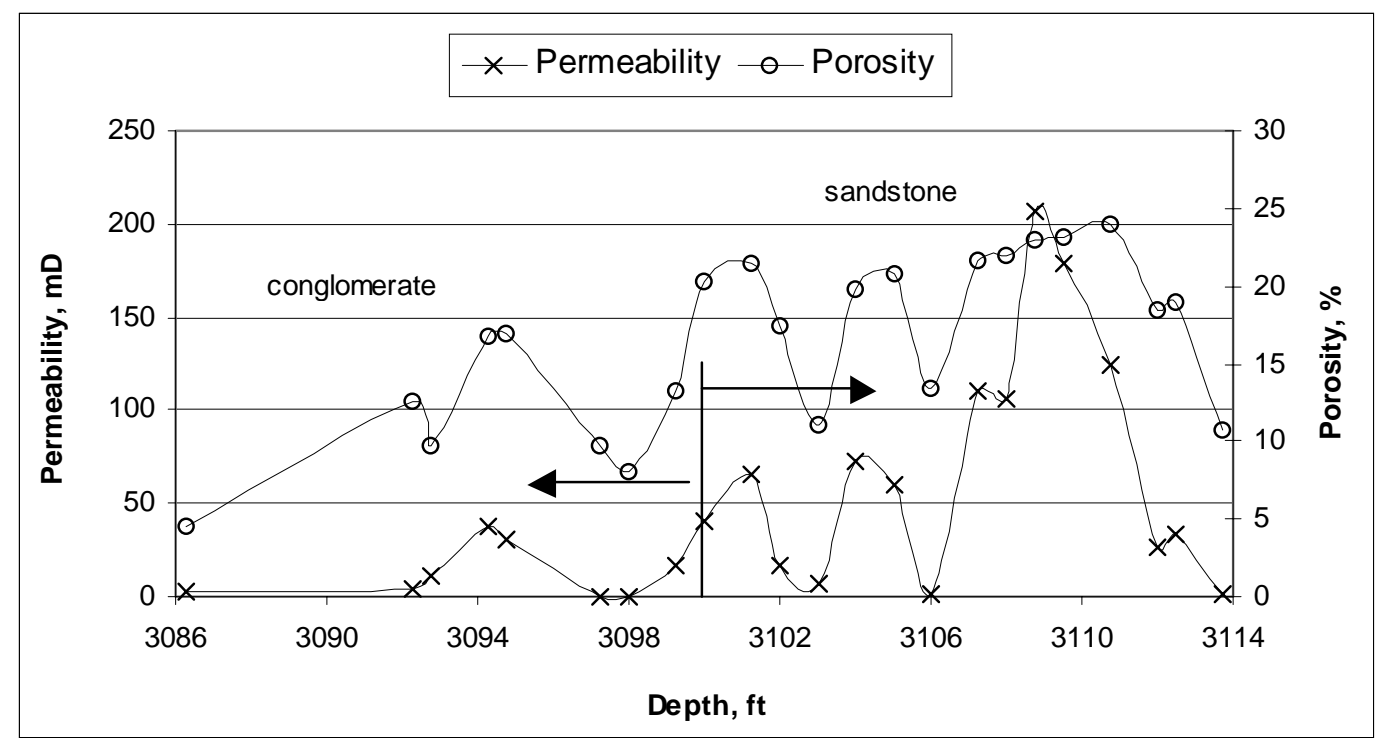

Figure A.3 Porosity, permeability and lithology distribution from core data.

Well B-19

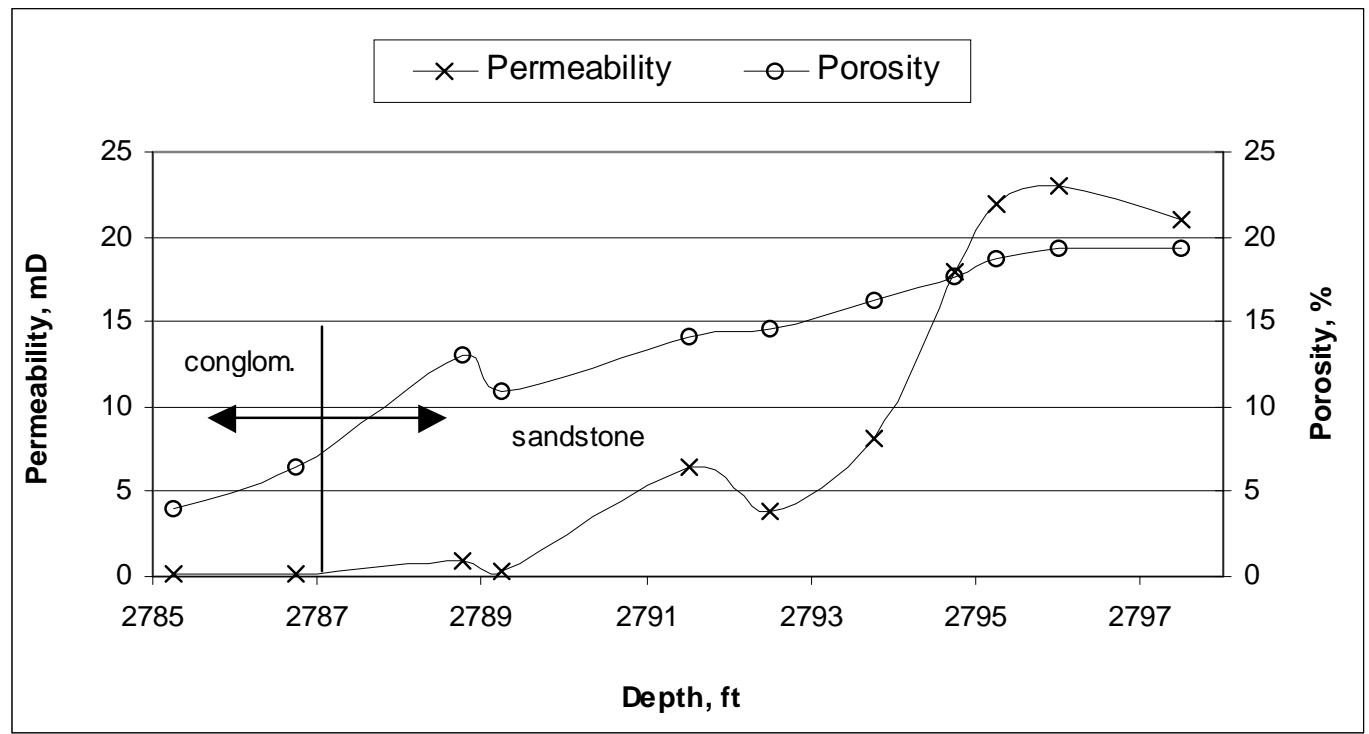

Figure A.4 Porosity, permeability and lithology distribution from core data.

Well T-8 


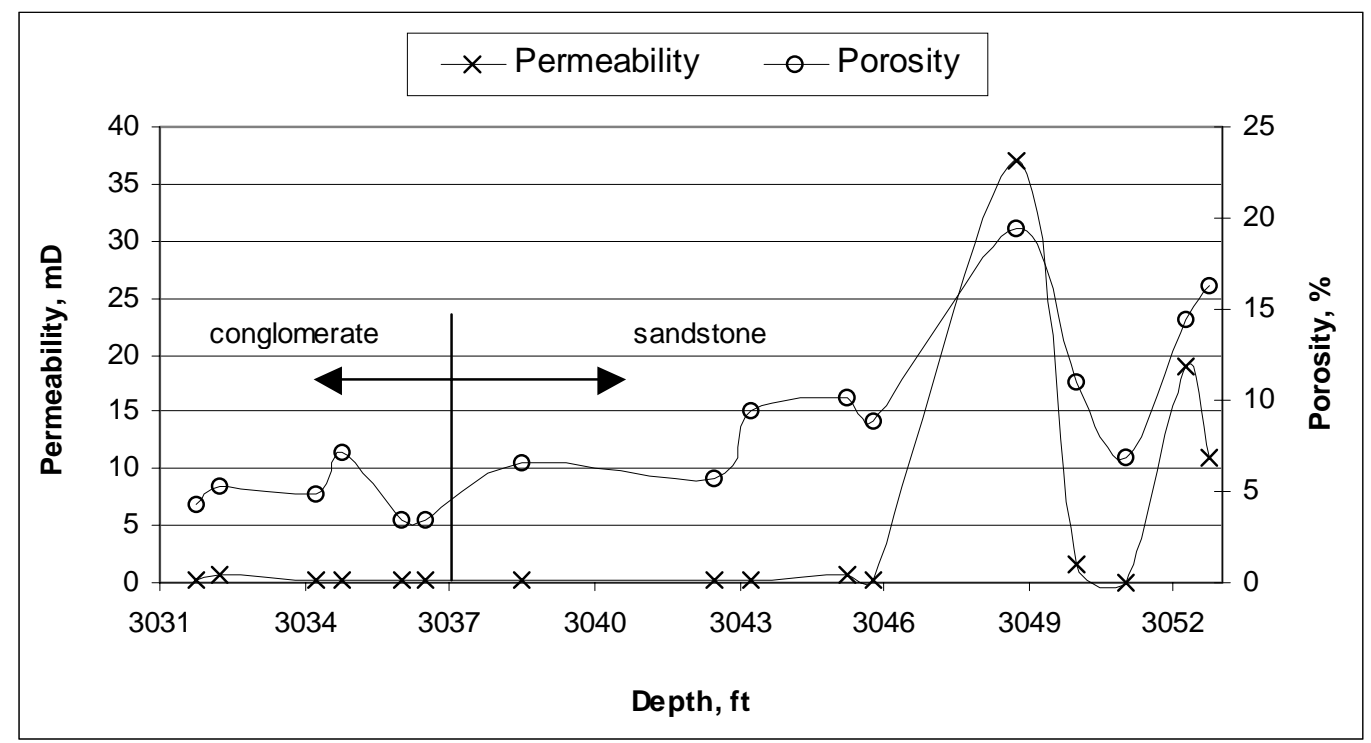

Figure A.5 Porosity, permeability and lithology distribution from core data.

Well L-13

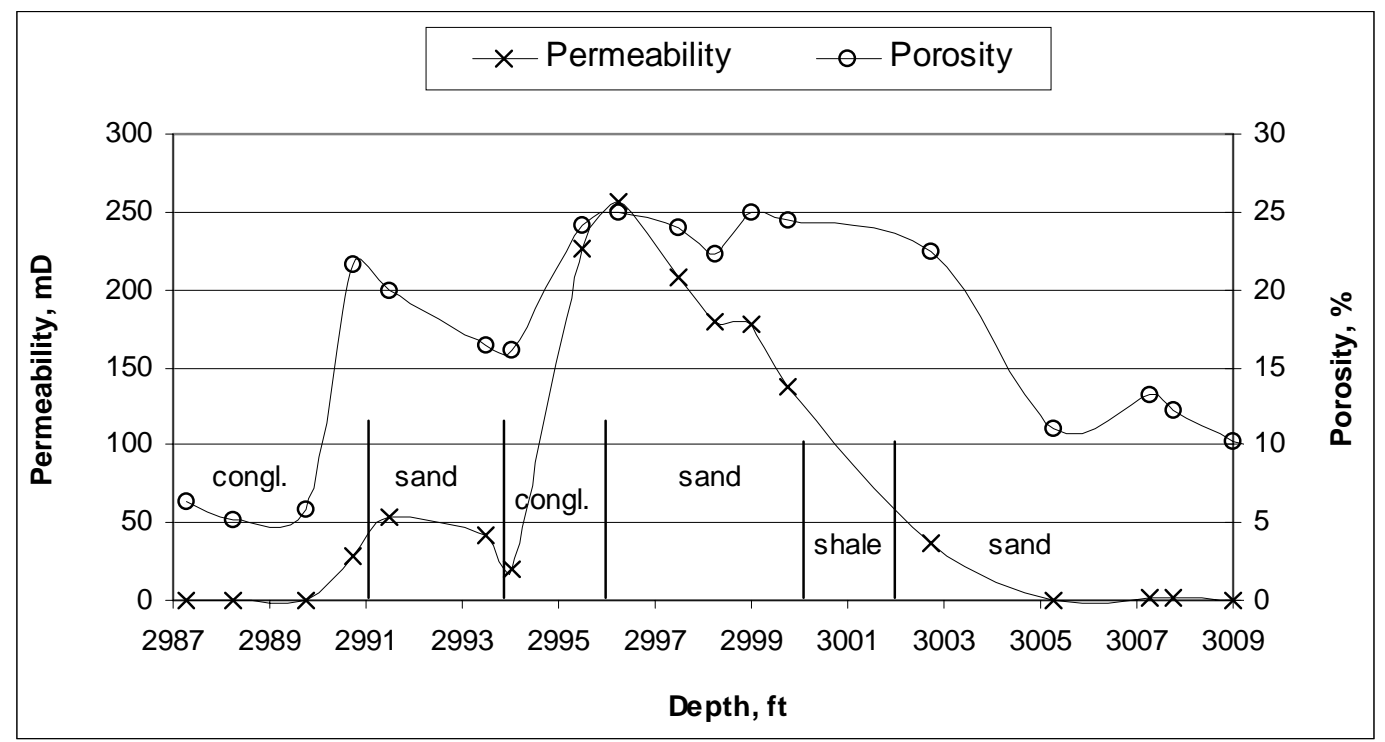

Figure A.6 Porosity, permeability and lithology distribution from core data.

Well B-18 


\section{APPENDIX B.}

Porosity predictions in cored wells. 


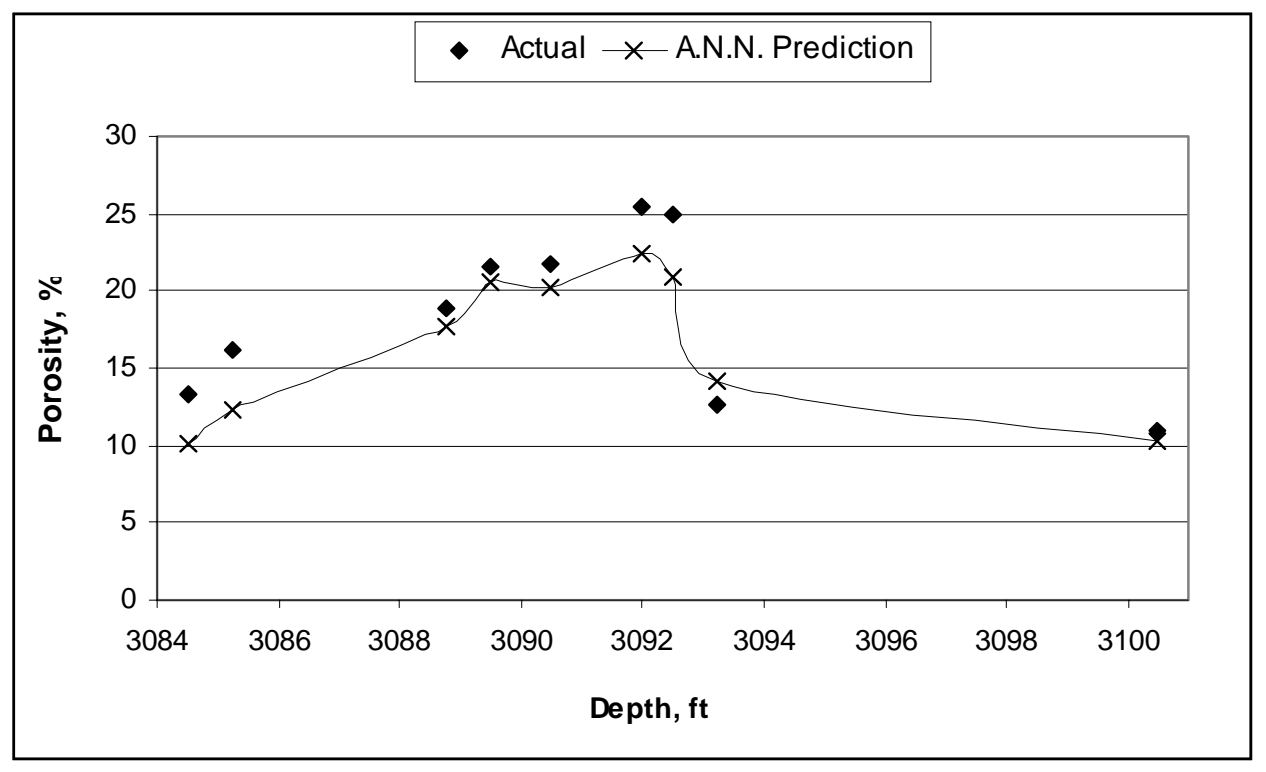

Figure B.1. Porosity Prediction with A.N.N. Well H-11

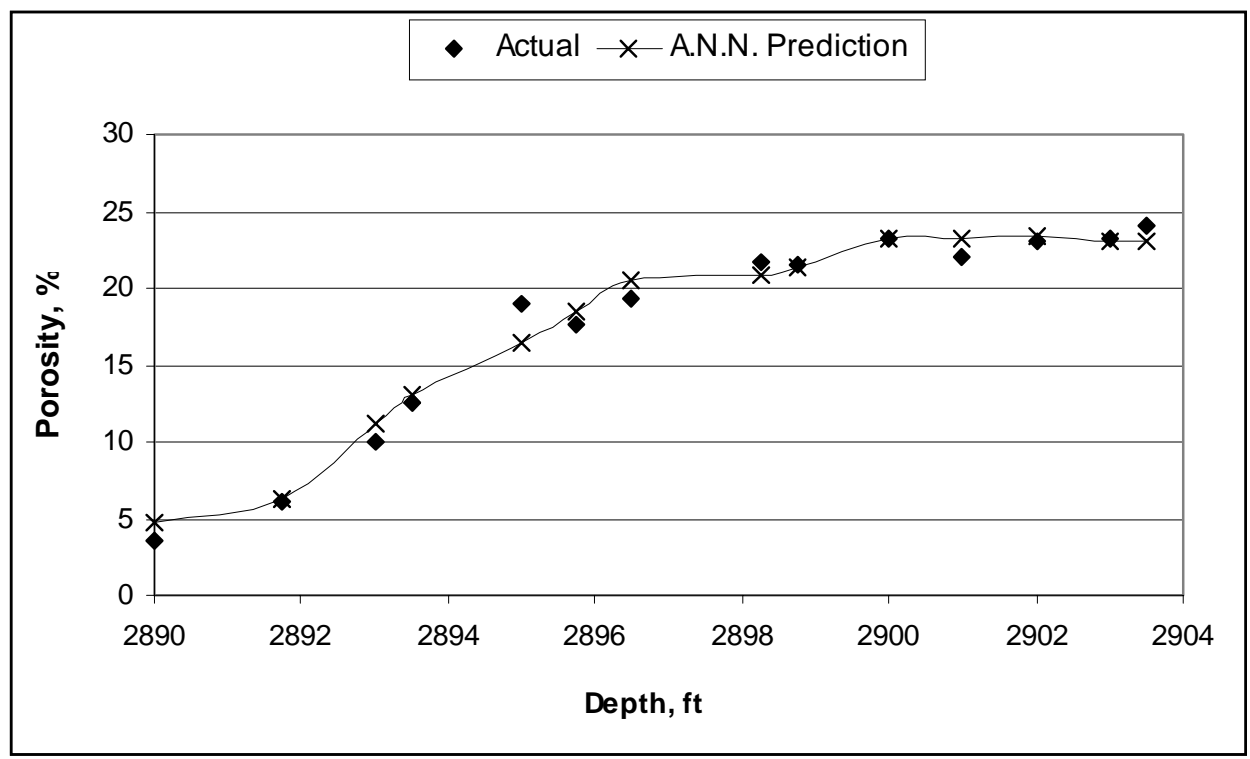

Figure B.2 Porosity Prediction with A.N.N. Well H-9 


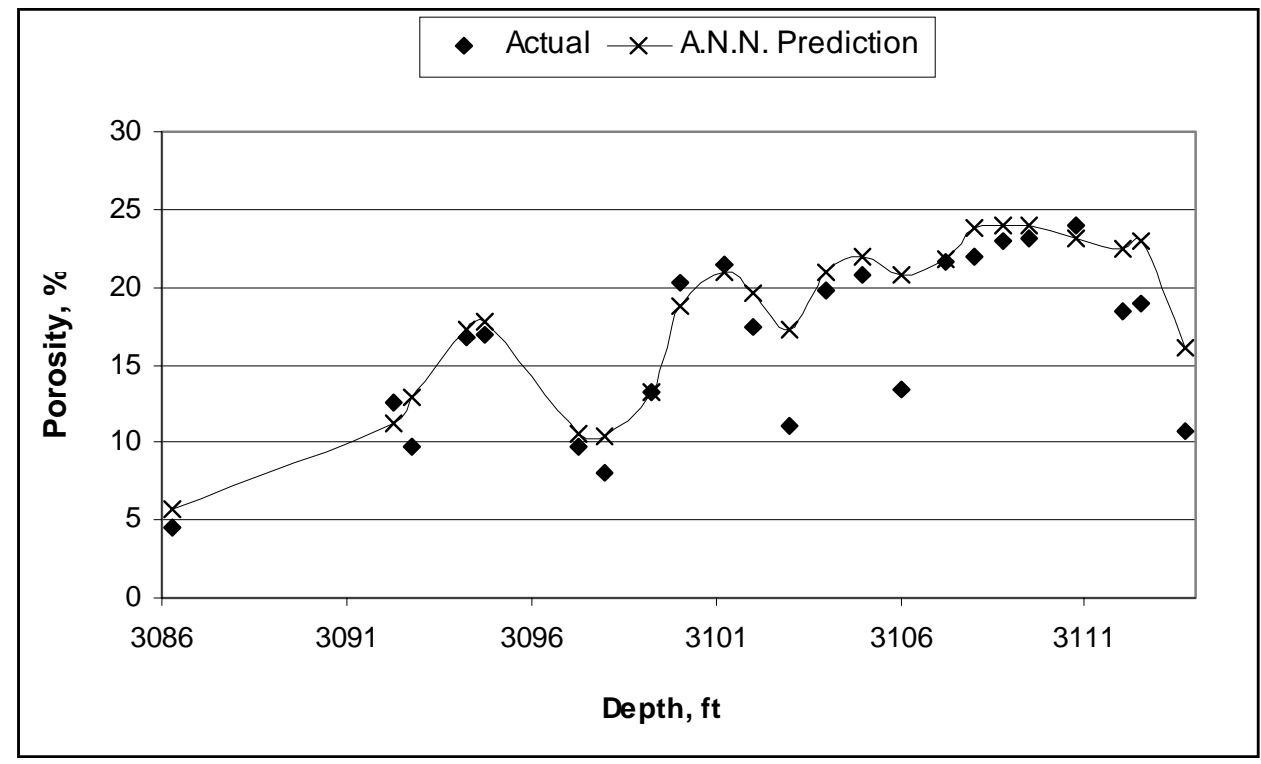

Figure B.3 Porosity Prediction with A.N.N. Well B-19

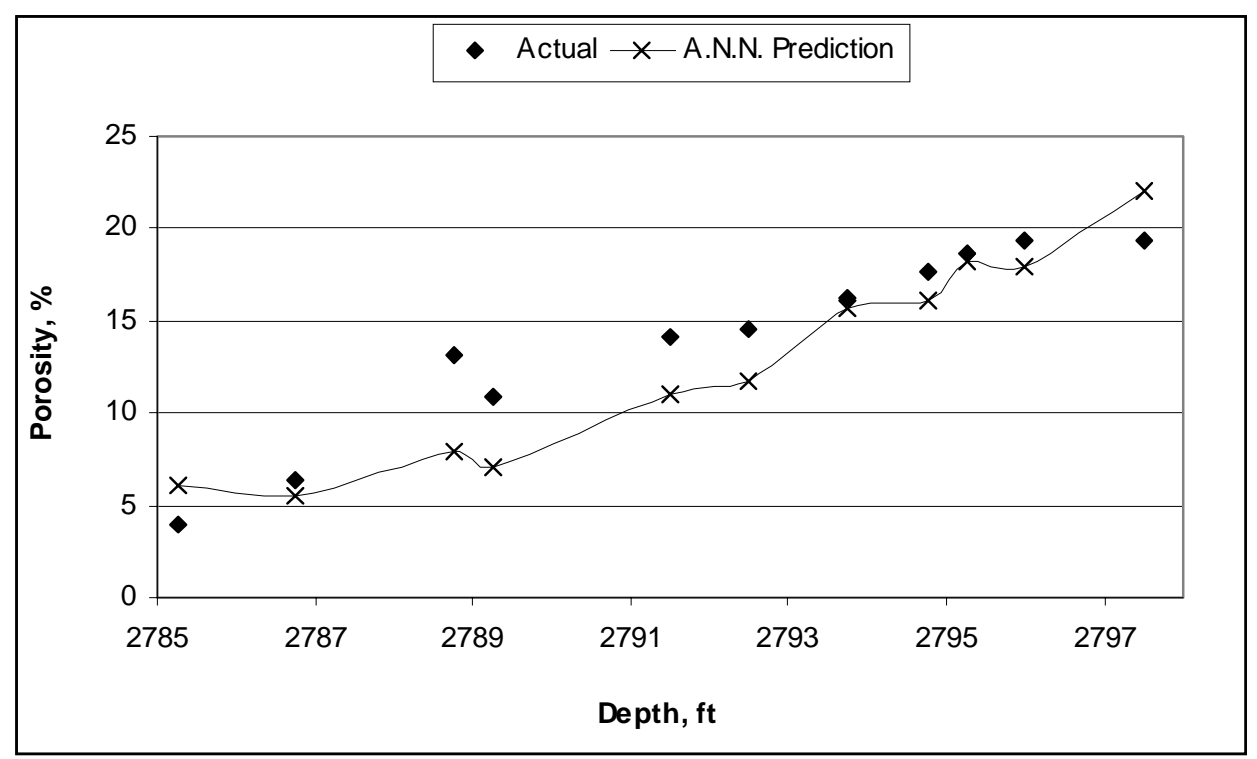

Figure B.4 Porosity Prediction with A.N.N. Well T-8 


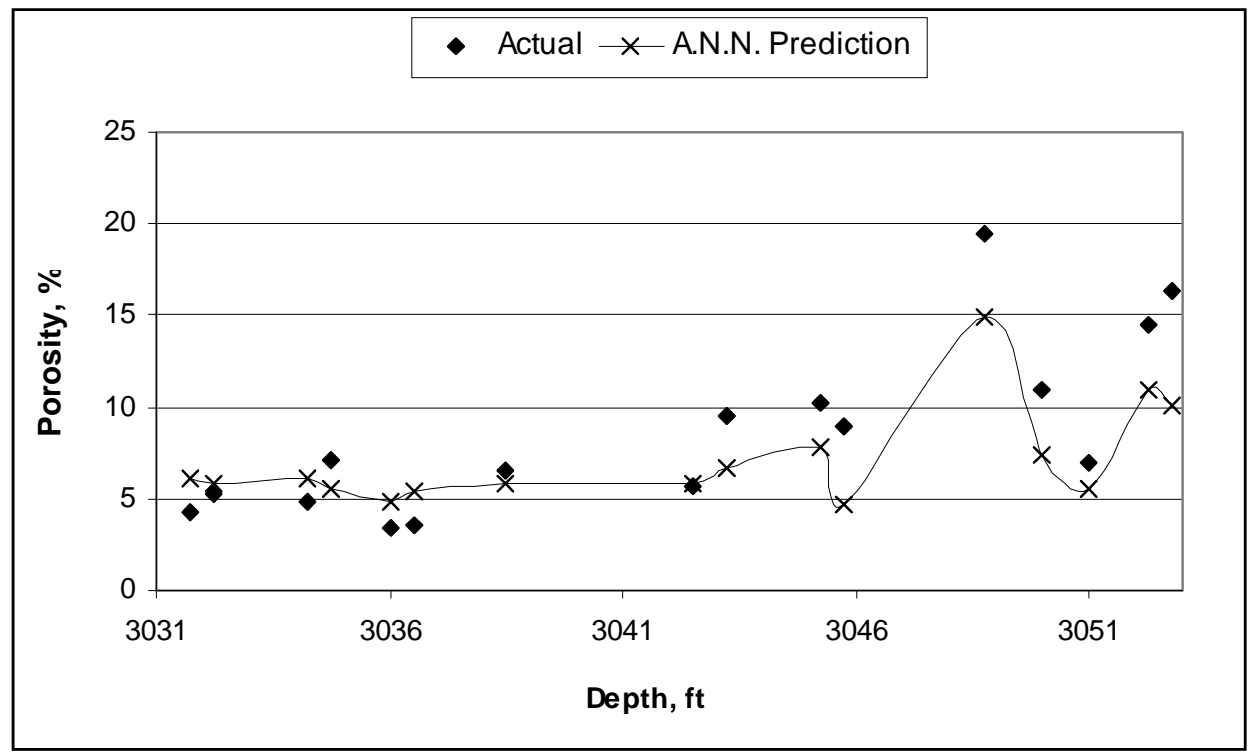

Figure B.5 Porosity Prediction with A.N.N. Well L-13

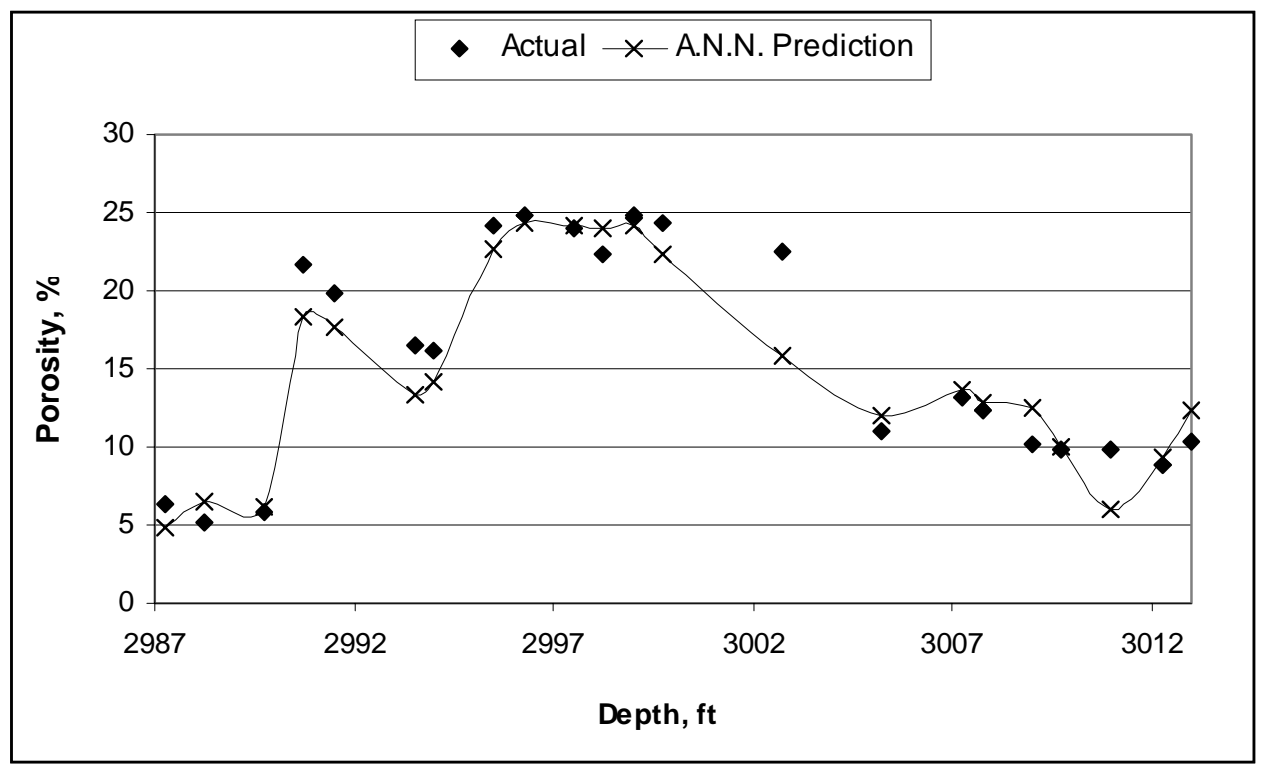

Figure B.6 Porosity Prediction with A.N.N. Well B-18 


\section{APPENDIX C.}

Permeability predictions in cored wells. 


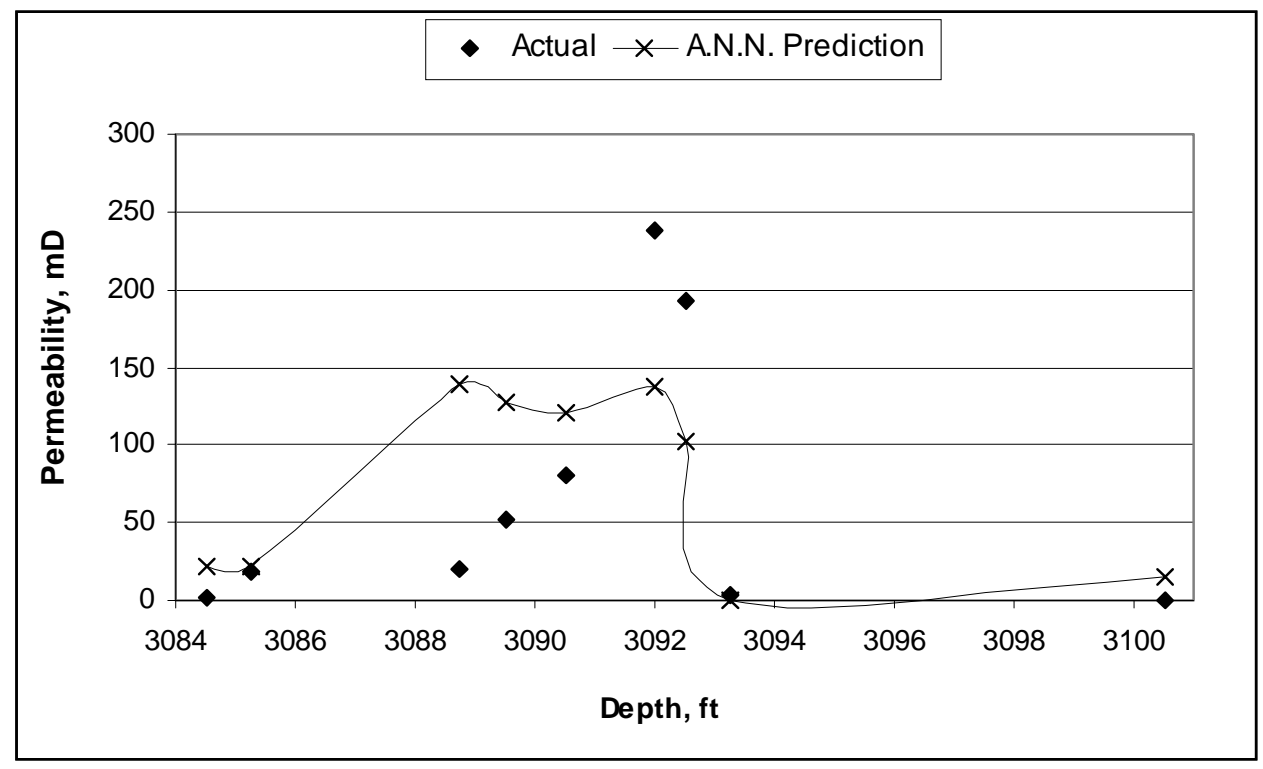

Figure C.1 Permeability Prediction with A.N.N. Well H-11

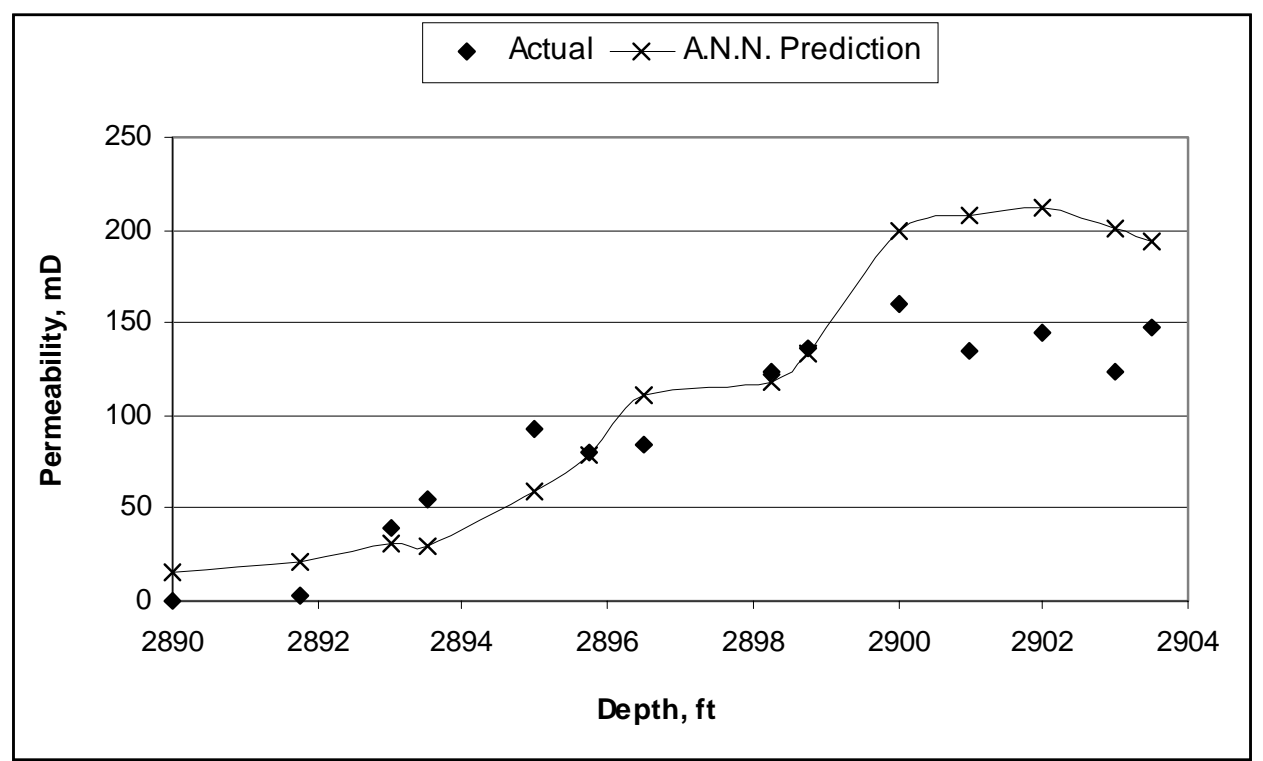

Figure C.2 Porosity Prediction with A.N.N. Well H-9 


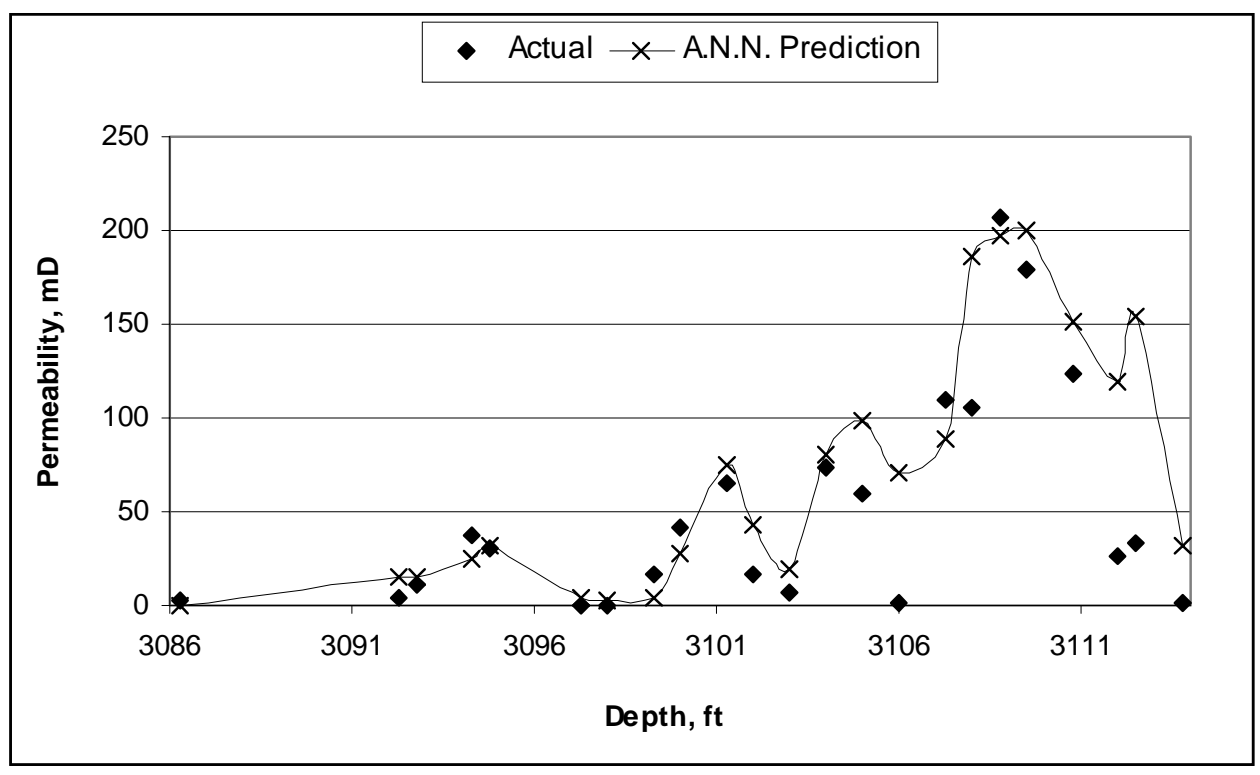

Figure C.3 Porosity Prediction with A.N.N. Well B-19

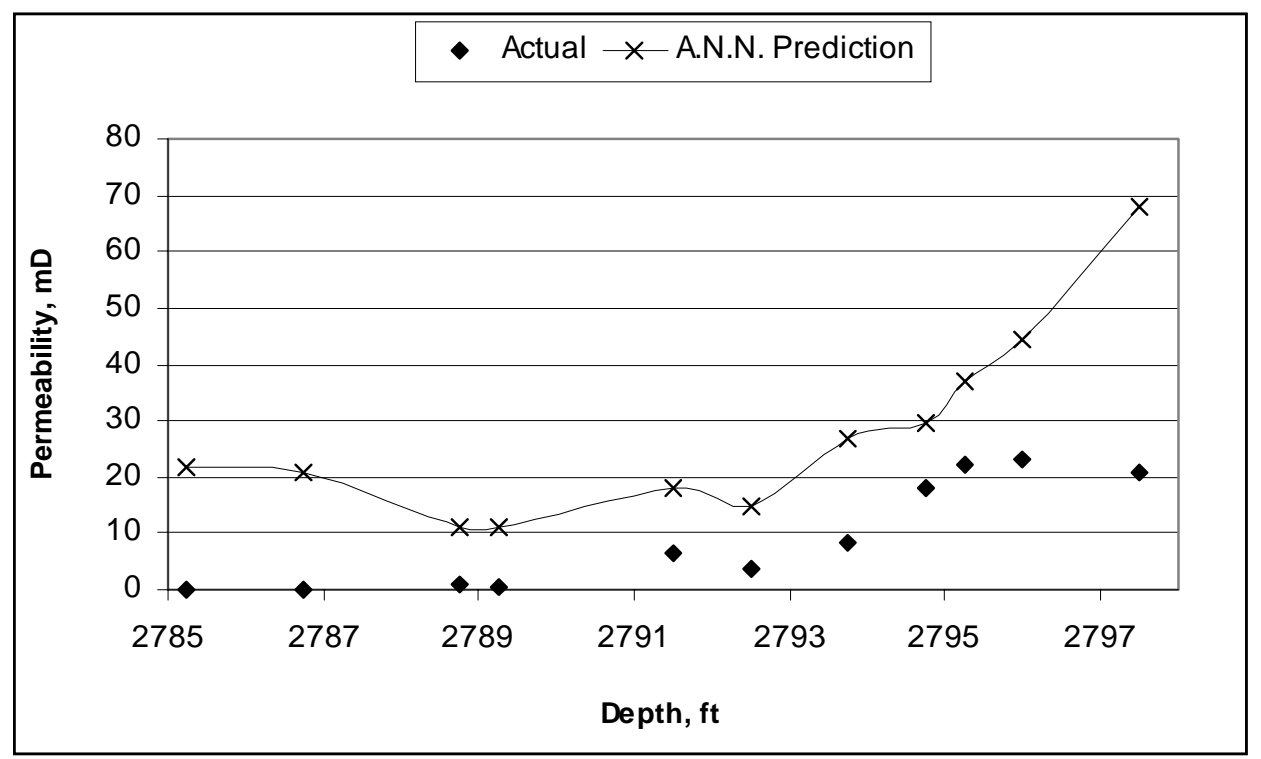

Figure C.4 Porosity Prediction with A.N.N. Well T- 8 


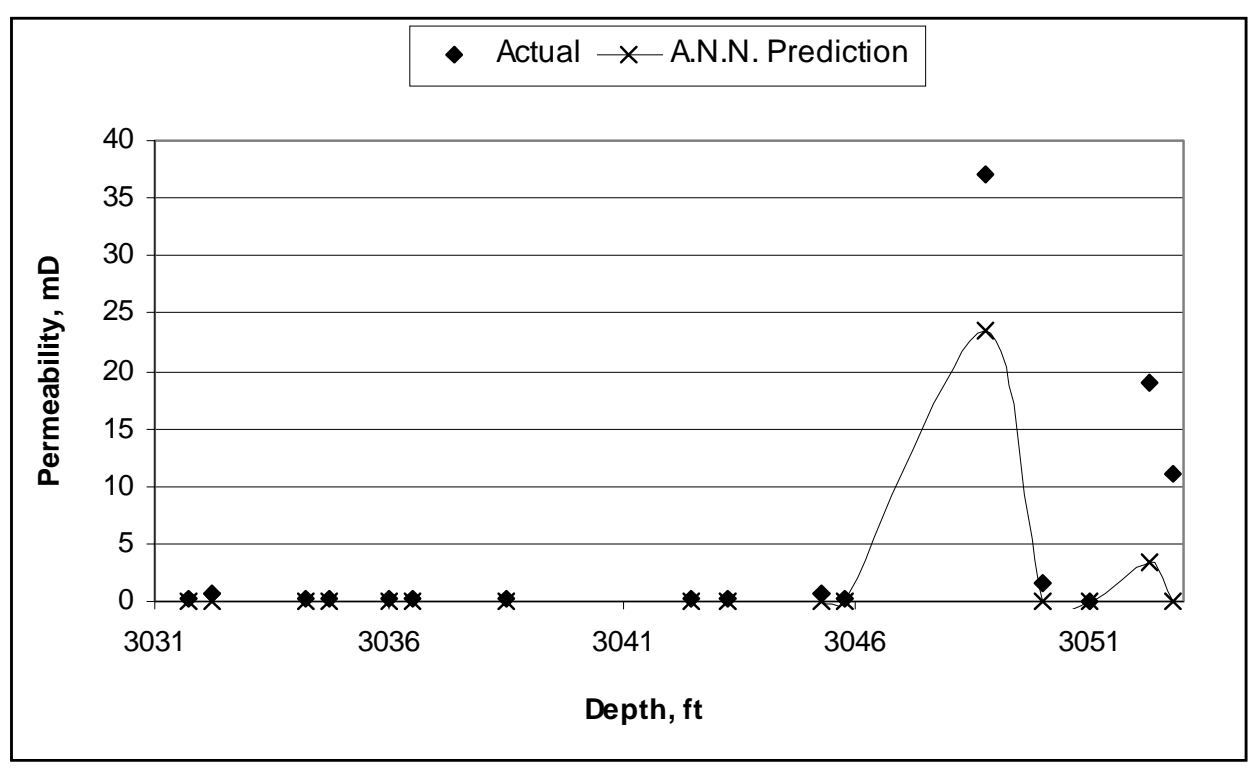

Figure C.5 Porosity Prediction with A.N.N. Well L-13

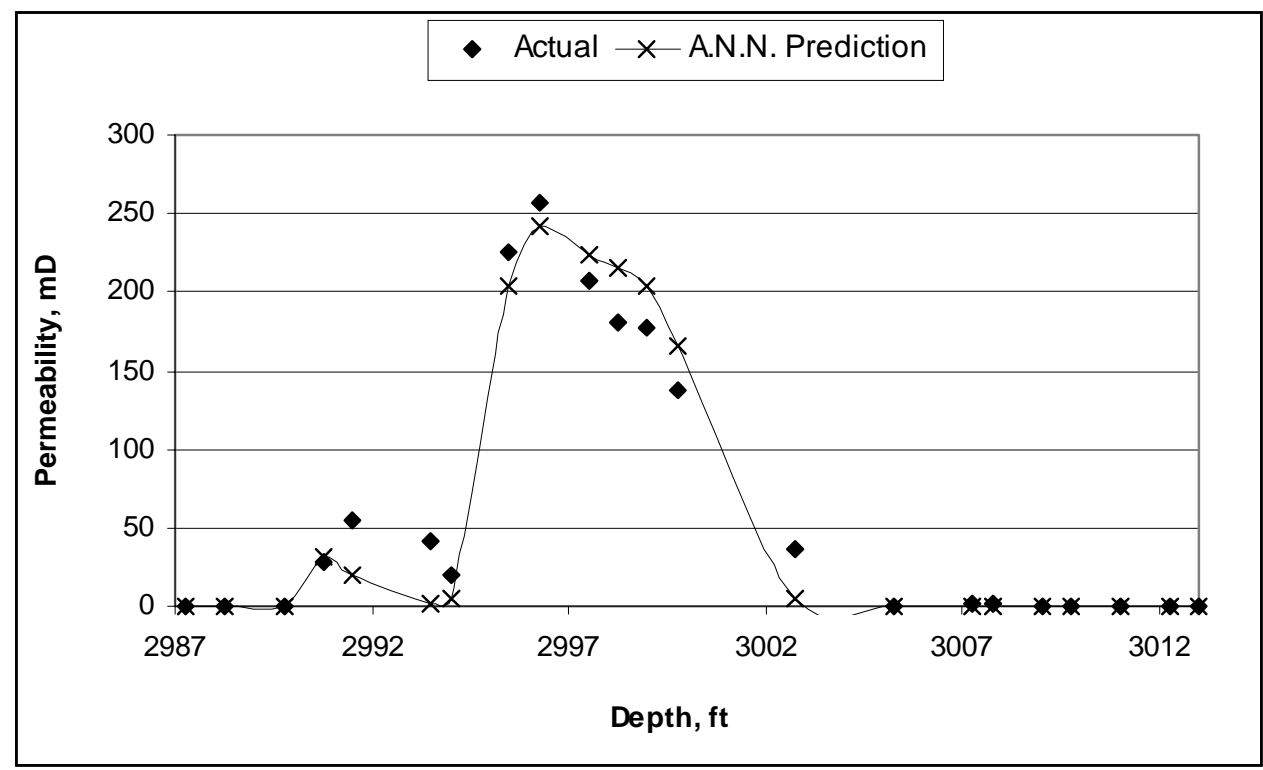

Figure C.6 Porosity Prediction with A.N.N. Well B-18 


\section{APPENDIX D.}

Porosity and permeability predictions with A.N.N. for wells in pilot area. 


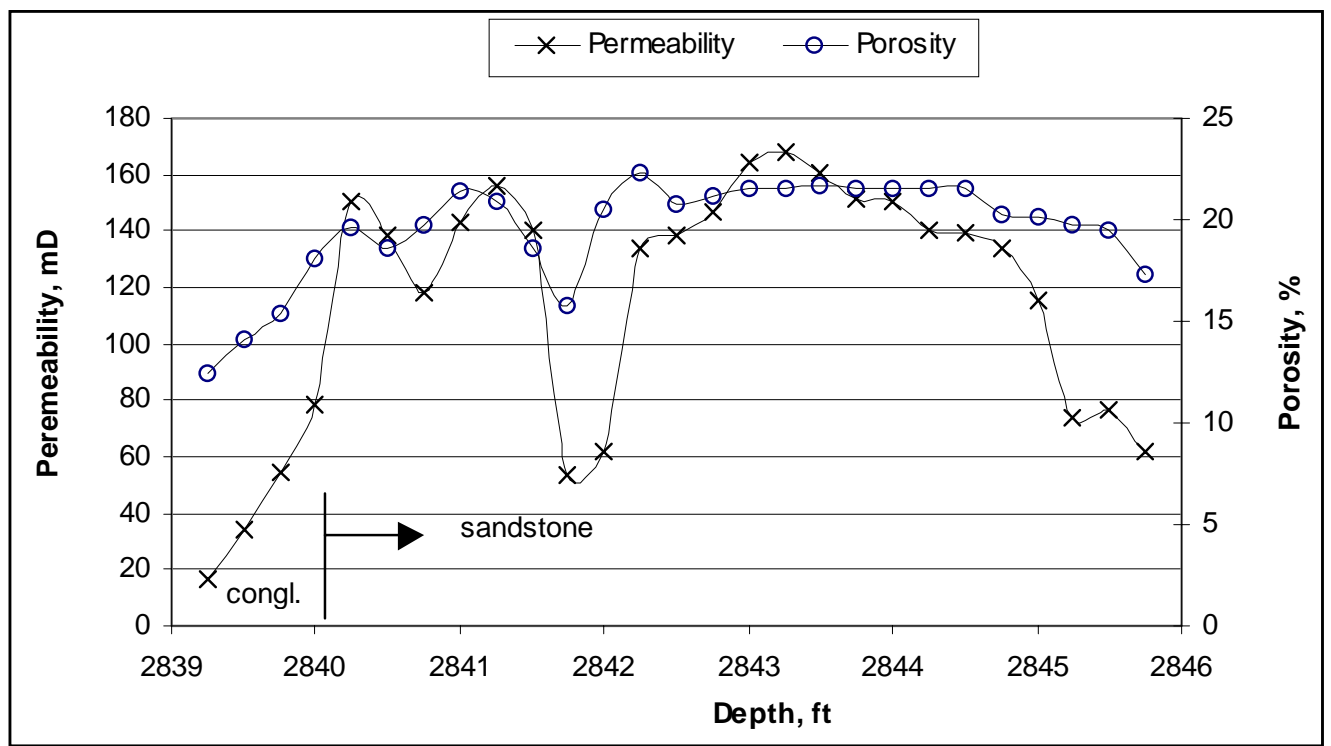

Figure D.1 Porosity and permeability distribution from A.N.N.

\section{Well P-7}

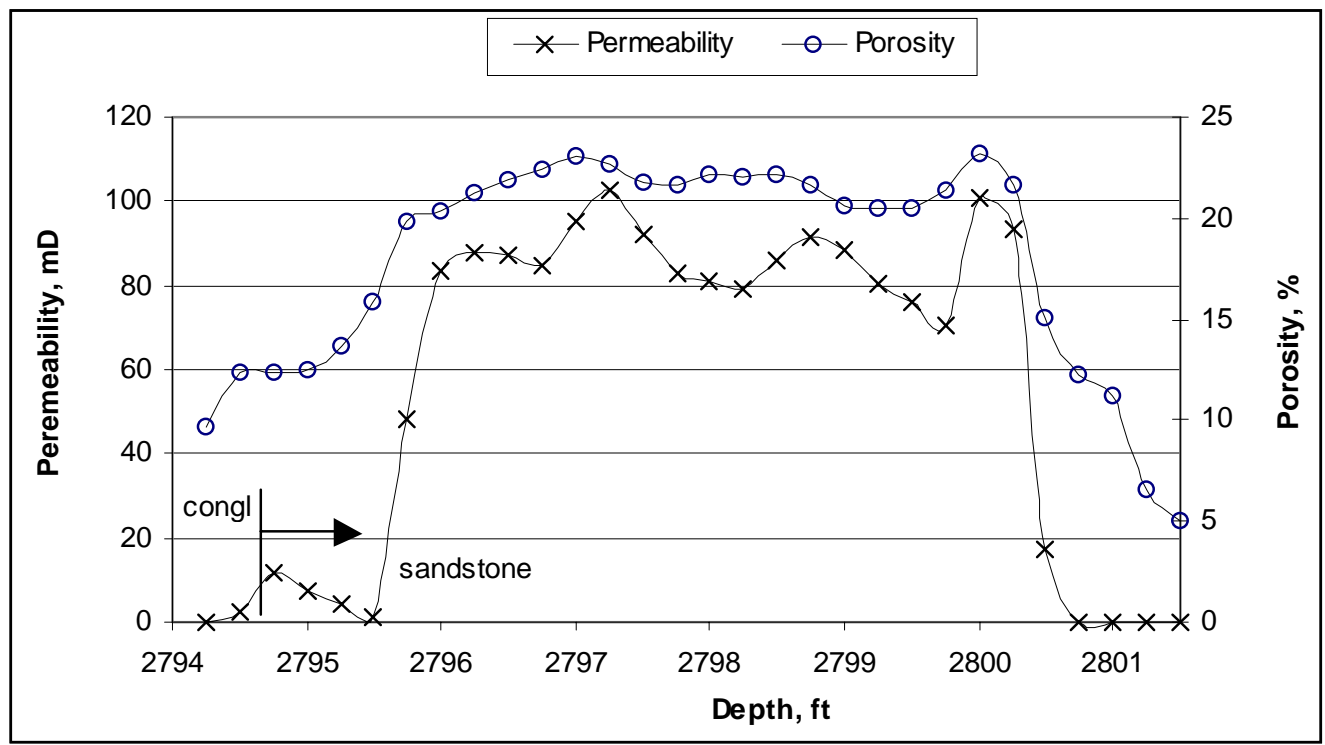

Figure D.2 Porosity and permeability distribution from A.N.N.

\section{Well L-9}




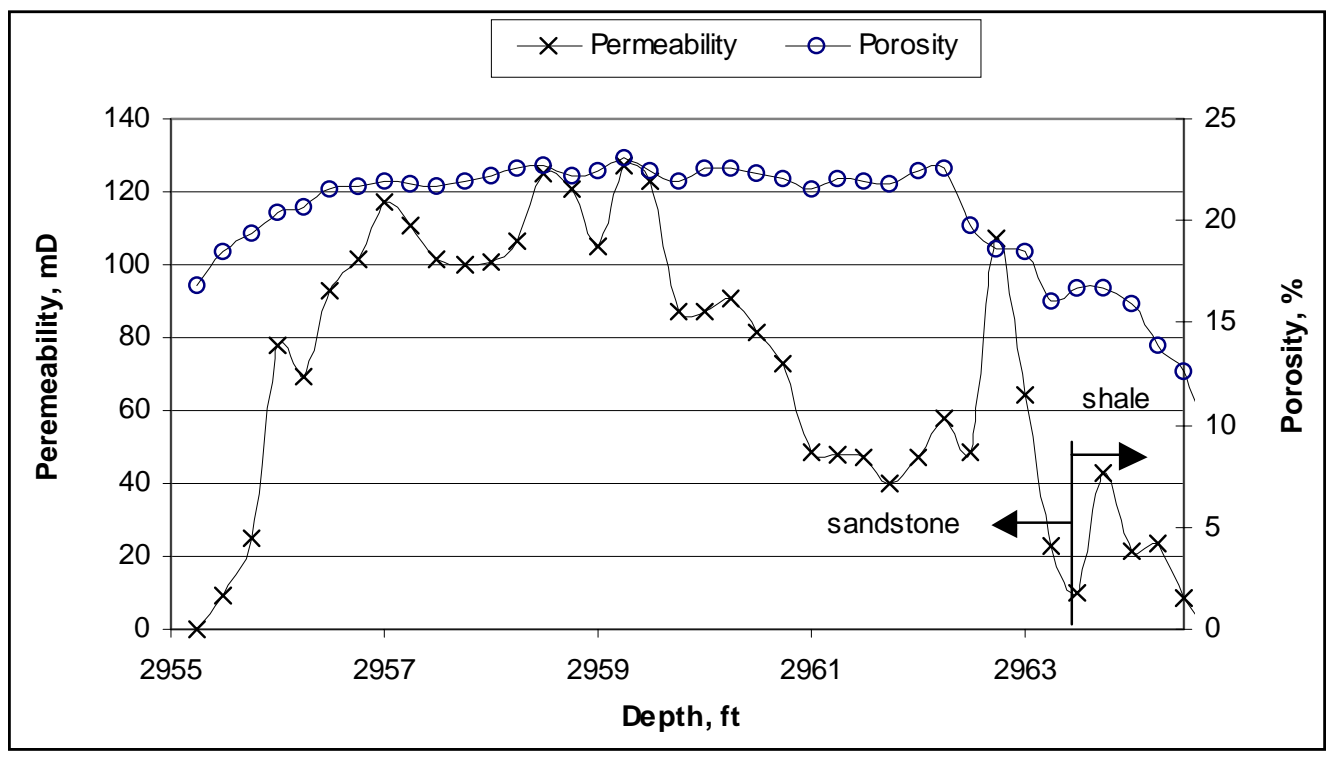

Figure D.3 Porosity and permeability distribution from A.N.N.

Well H-10

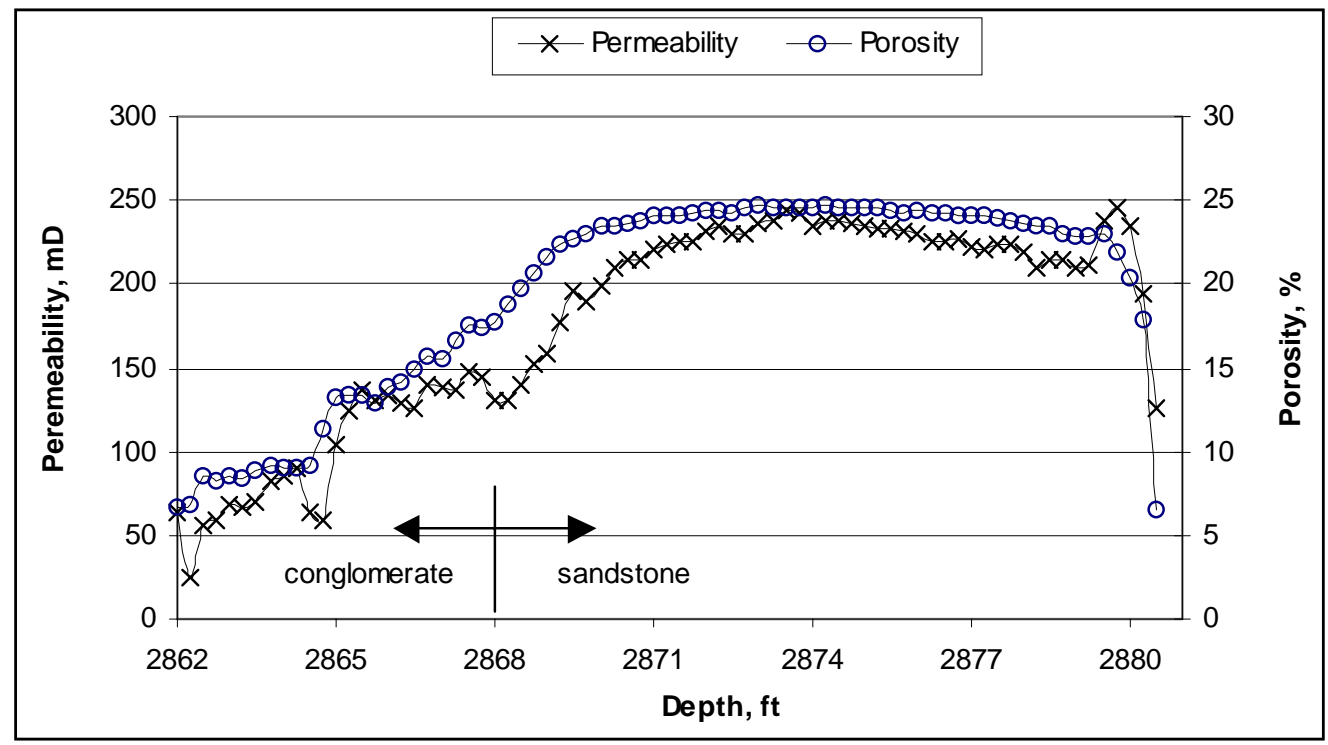

Figure D.4 Porosity and permeability distribution from A.N.N.

Well A-5 


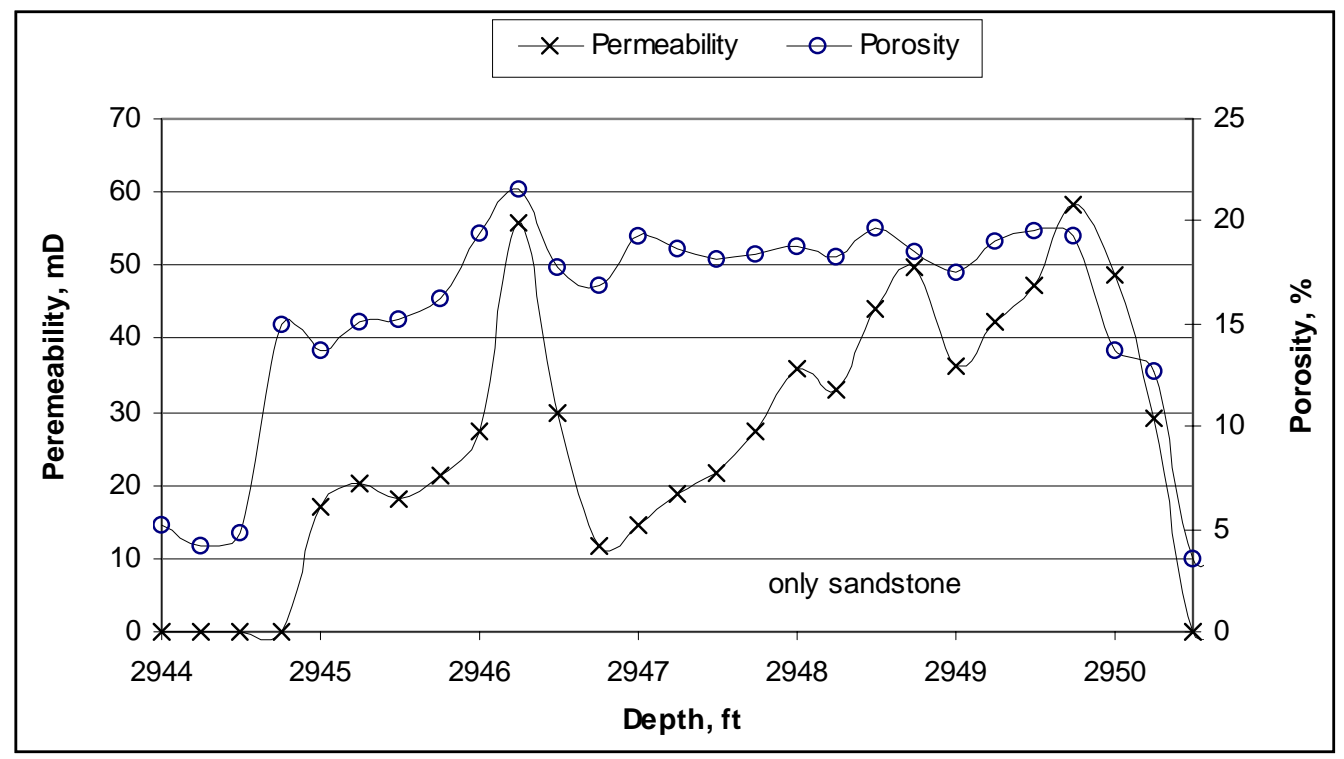

Figure D.5 Porosity and permeability distribution from A.N.N.

Well H-12 


\section{APPENDIX E.}

Description of Edboast and Boast98 simulator 


\section{EDBOAST.}

This is an editor used for data input. The main window, shown in Figure C.1, presents seven horizontal menu items. These items are File Name, Directory, Extension, Options, Help, Quit, and About. The reservoir, fluid, solution method and other pertinent information are edited in "Options".

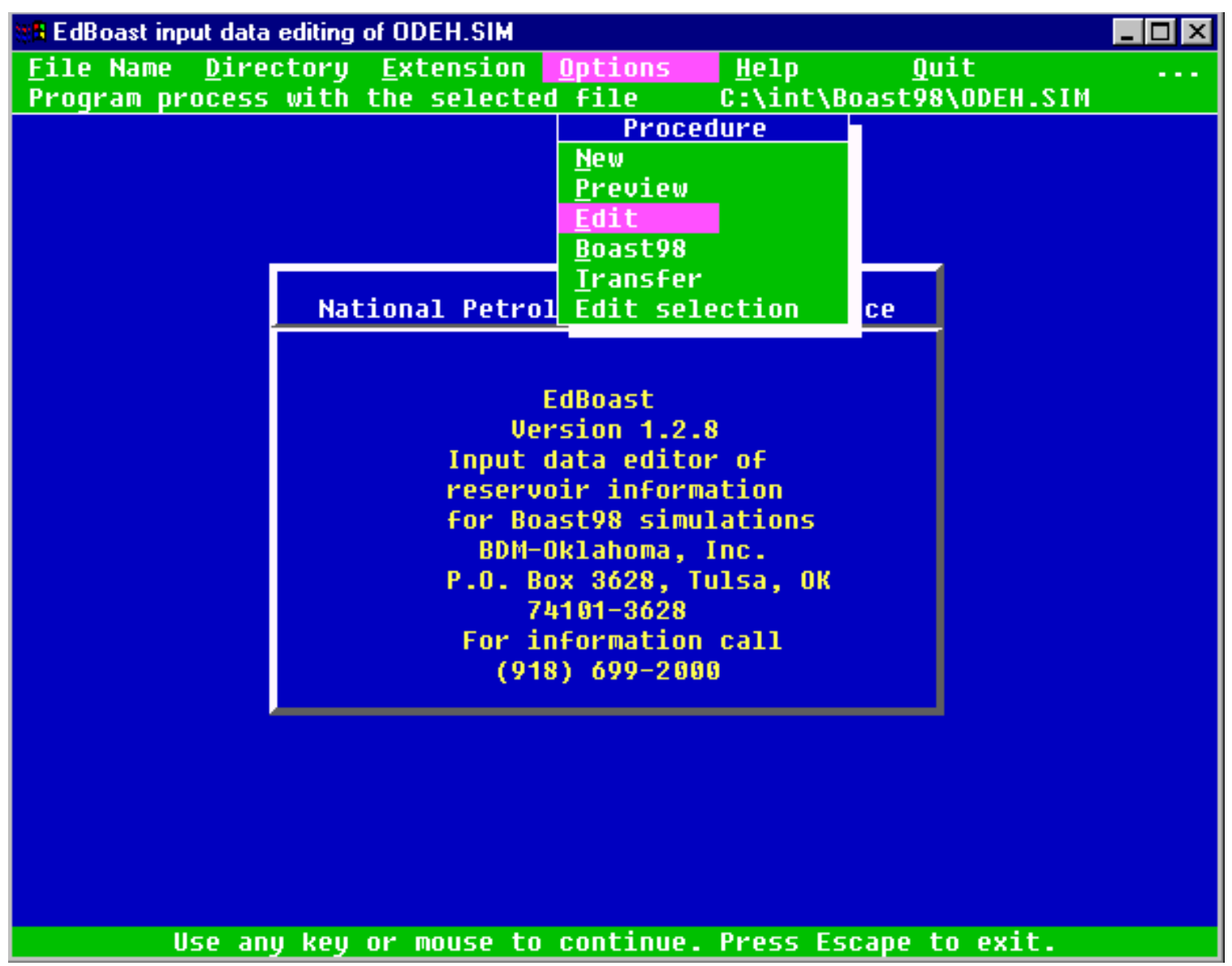

Figure E.1. EDBOAST Main Menu Window.

Selecting "Edit" under the "Options" item of the main menu brings up this EdBoast Home Page dialog window. The EdBoast Home Page consists of 14 home page 
buttons. These 14 buttons are Begin, Grid, Porperm, Transm, Table, Initial, Codes, Aqui, Wells, Recurr, Default, Next, Accept, and Abort. This window is depicted in Figure E.2

Button 1. BEGIN. This first button introduces the dialog frame, which contains five lines of reservoir description called "Header". The first line of the "Header" will be the title card. The other four lines are run identification records. The next two boxes in the frame contain two integers representing switches for restart initialization or restart run, and another for writing a post-run Table.

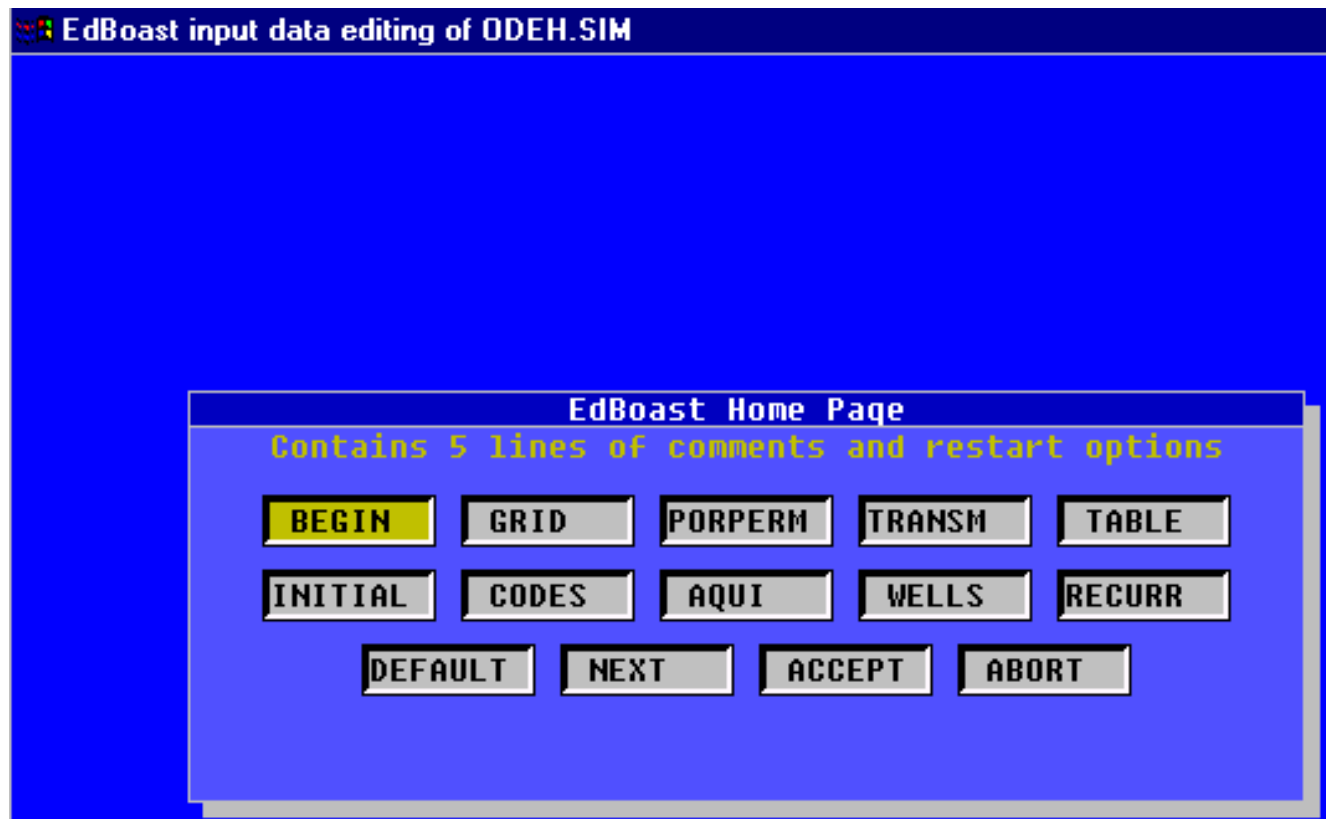

Figure E.2. Main input data menu in EdBoast. 
Button 2. GRID. This button brings up five or more dialogs or spreadsheets for entering reservoir model grid dimensions (I, J, and K) and geometry data (grid size). Before each spreadsheet of values is presented, a page of instructions is shown which describes the invisible commands or various key shortcuts, which can be used to command the spreadsheet.

Button 3. PORPERM. PORPERM button brings up five or more dialogs or spreadsheets for entering reservoir porosity and permeability data. Also a special dialog box is presented for each region modified for porosity or permeability.

Button 4. TRANSM. Presents options for transmissibility modifications.

Button 5. TABLE. Requests information for Rock and PVT regions and their respective relative permeability and capillary pressure tables. The first dialog from this button, allows entry for the number of distinct rock regions is to be changed and the number of regions where the PVT default region value of one is to be changed. The rock region is a saturation dependent data set for relative permeability. The PVT region is a pressure dependent data set, including oil, water, and gas PVT tables. At least one rock region and one saturation region is required.

Button 6. INITIAL. This button introduces a set of two dialogs plus one more dialogs for each layer and rock region of data containing the pressure and saturation initializations. 
Button 7. CODES. This button introduces debug and diagnostic controls options and solution method specifications. The data can be entered in a series of two dialogs

Button 8. AQUI. This button introduces the installation of the aquifer data.

Button 9. WELLS. This button introduces well data, such us total number of wells that will be used in the entire simulation, well number, the number of well nodes, and the well name for each well are entered. This is followed by X, Y, Z locations of each well node being entered.

Button 10. RECURR. This button introduces a set of six dialogs for each data set for entering recurrent data. The total number of data sets entered (up to 200) is displayed in the first window(s) presented. Up to 21 data sets with associated information are allowed in the first page and 22 data sets on each succeeding page. This allows a preview of the number of elapsed times days and also a break down on the number of NEW and OLD (modified) wells are in each data set.

Button 11. DEFAULT. This button will initiate a set of pre-selected input data, which will allow the beginner a quick step forward. 
Button 12. NEXT. This button will advance to the next button in the line up. This is the same as the Tab plus the Enter key being hit. The Up and Down arrow keys will advance or reverse the highlighted button selections.

Button 13. ACCEPT. This button will allow the saving of the edited input data under the same or a different file name.

Button 14. ABORT. Returns to the original main menu. The same file name is in the buffer and another command such as Preview or Boast98 can apply to file name previously selected.

\section{BOAST98.}

Boast98 evaluates reservoir performance based on finite-difference, implicit pressure, and explicit saturation, with options for both direct and iterative methods of solution. The reservoir is described by three dimensional grid blocks and by three fluid phases. Other options include steeply dipping structures, multiple rock and PVT regions, bubble point tracking, automatic time step control, material balance checking for solution stability, multiple wells per grid block, and rate or pressure constraints on well performance.

The Boast98 application will have been started indirectly by the selecting "Transfer" or "Boast98" under the "Options" menu of the EdBoast application, or 
directly by typing the name under a DOS prompt, or by clicking on the icon in a directory window of the computer operating system.

The primary items in the main menu bar are File Name, Directory, Extension, Option, Help, Quit, and About. These menu items have essentially the same function as in the EdBoast application described earlier. Figure E.3 presents a normal view of the Menu items before the run is started.

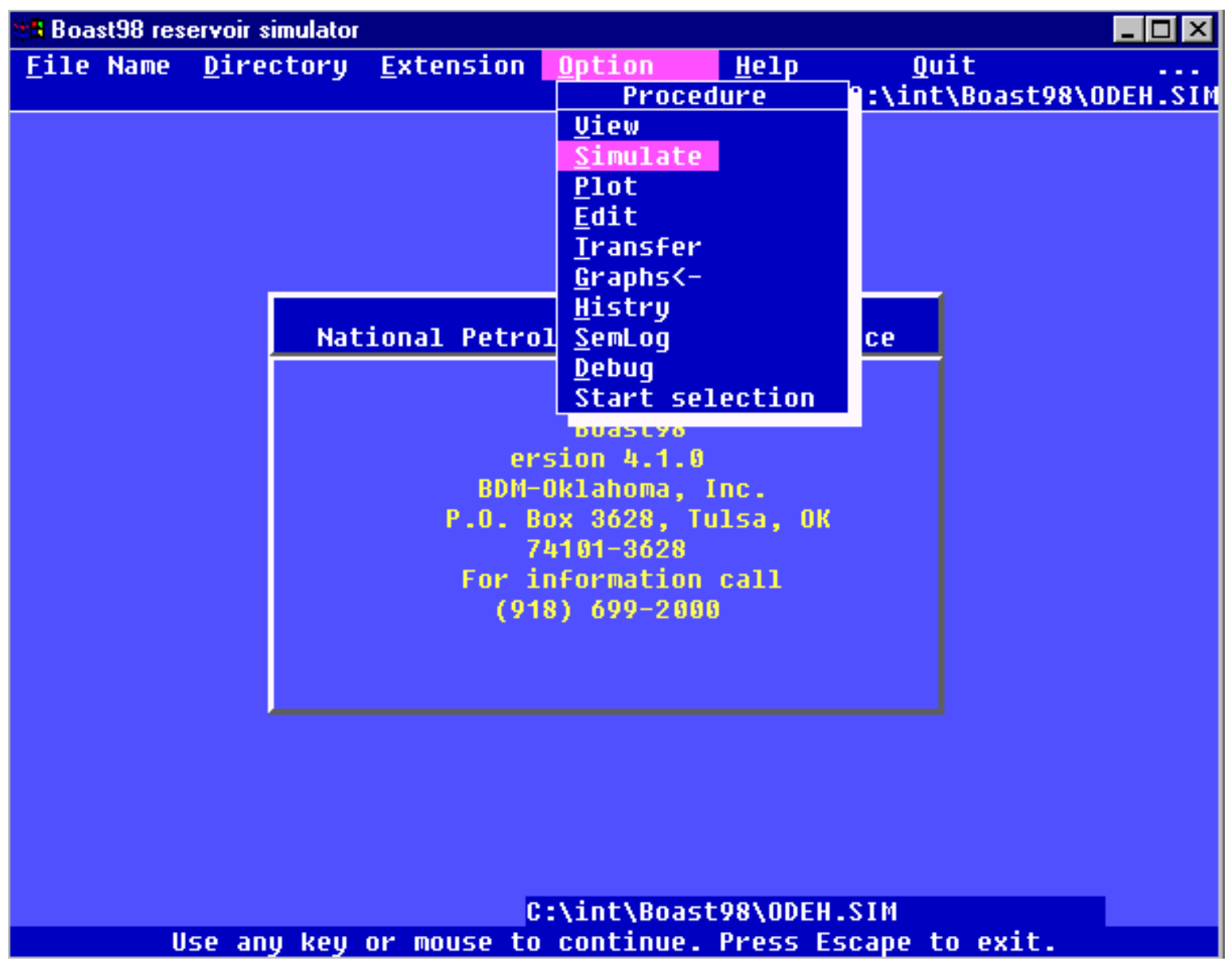

Figure E.3. Primary Menu Display of BOAST98. 
View. View the input data file contents chosen under the menu item File Name. This is a read only choice and the data cannot be altered under this view.

Simulate. This selection will begin the Boast98 run with live time graphics in effect.

Plot. Plot the results of the last time step of the last simulation run.

Edit. The current file name selection is handed over to the EDBOAST application. If EDBOAST is in the current directory, the Home Page Button dialog will be presented containing the input data from the current file selection of BOAST98. If EDBOAST is not in the current directory, the program, BOAST98, will ask for help in finding the file. In that case, use the Directory and File Name menu items alternately, together.

Transfer. Transfer to any executable application by selecting the proper directory-using Directory and the Transfer will show a list of executables.

Graphs. Default is turned on. The selection of live graphics will slow the total simulation time down somewhat, especially for larger grid sizes.

Histry. Default for history matching is turned off. Turning on Histry will allow the matching of historical production information with the simulated performance values. This switch can be turned on either before or after simulation begins. The switch is 
found under the Option menu or under the Explore menu. This comparison is only seen under the Explore selection during suspension of the run.

Debug. Used to debug the flowing well pressure (PWFC) calculations. This turns on special dialog boxes, which point out excess pressures building up around wells.

In order to take control from the Boast 98 simulation, all simulation activity may be stopped clicking on the right hand mouse button. The original menu at the top of the window will disappear and a secondary 7-item menu will be displayed. The secondary items are Grid map, Layer, Flow, Explore, Capture, Resume, and Abort. Figure E.4 show the Menu displayed after run suspension using the right mouse button.

Choosing secondary items "Grid map", "Layer", and "Flow" allow changes to the graphic presentations during the active simulation run. When "Explore" is chosen, a series of graphic probes is permitted in order to inspect the various reservoir simulation categories. "Capture" produces a captured image of the desktop, including the graphic windows of Boast98, shown at the time. The menu item "Resume" will allow the reservoir simulation run to continue from the time step where it was when suspension was called with the right mouse button. By choosing "Abort", the Run Complete notice box with come up containing the elapsed time, including any suspension time. 


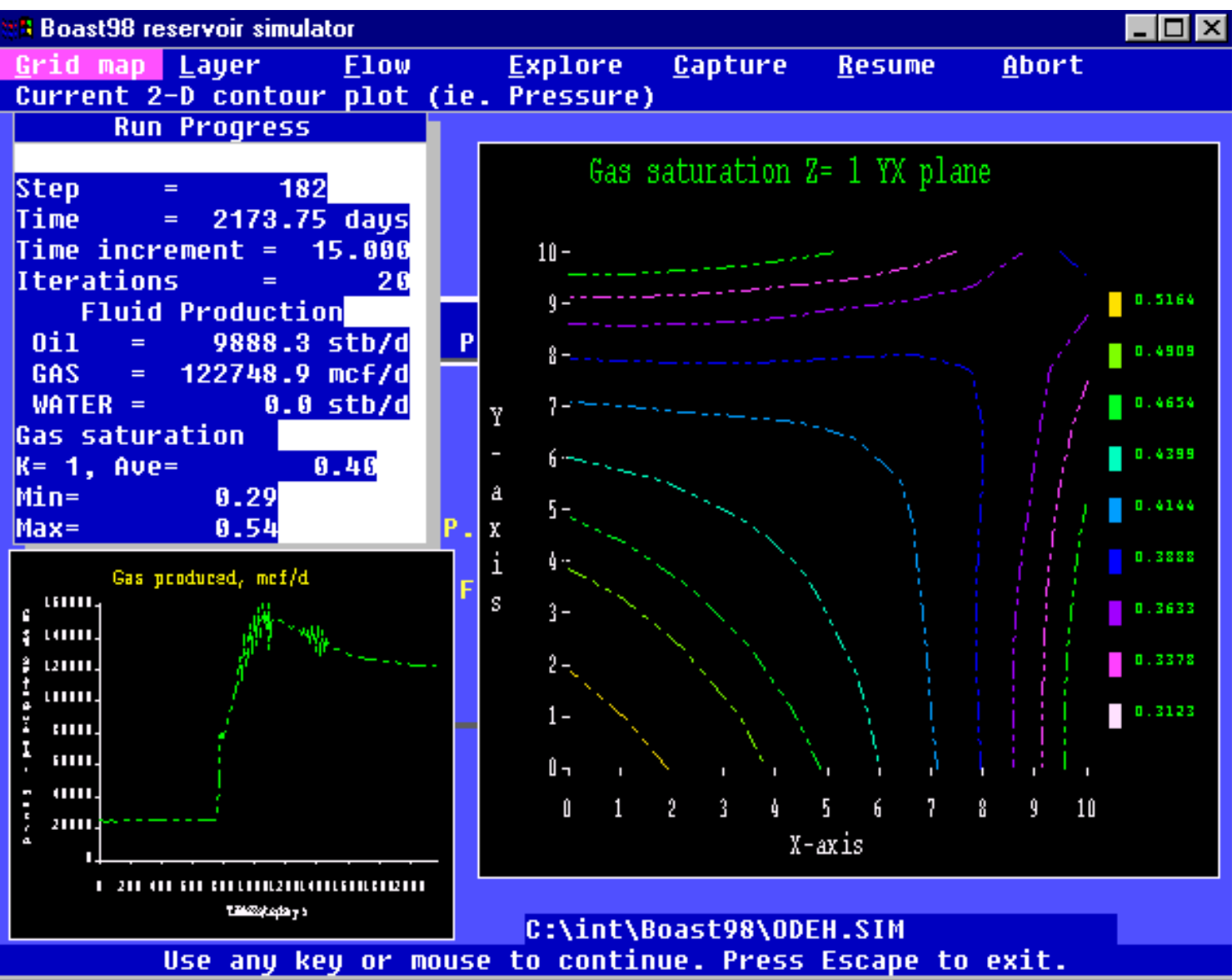

Figure E.4. Boast98 Secondary Menu shown during simulation. 


\section{APPENDIX F.}

History matching using lithologic zones as flow units. 


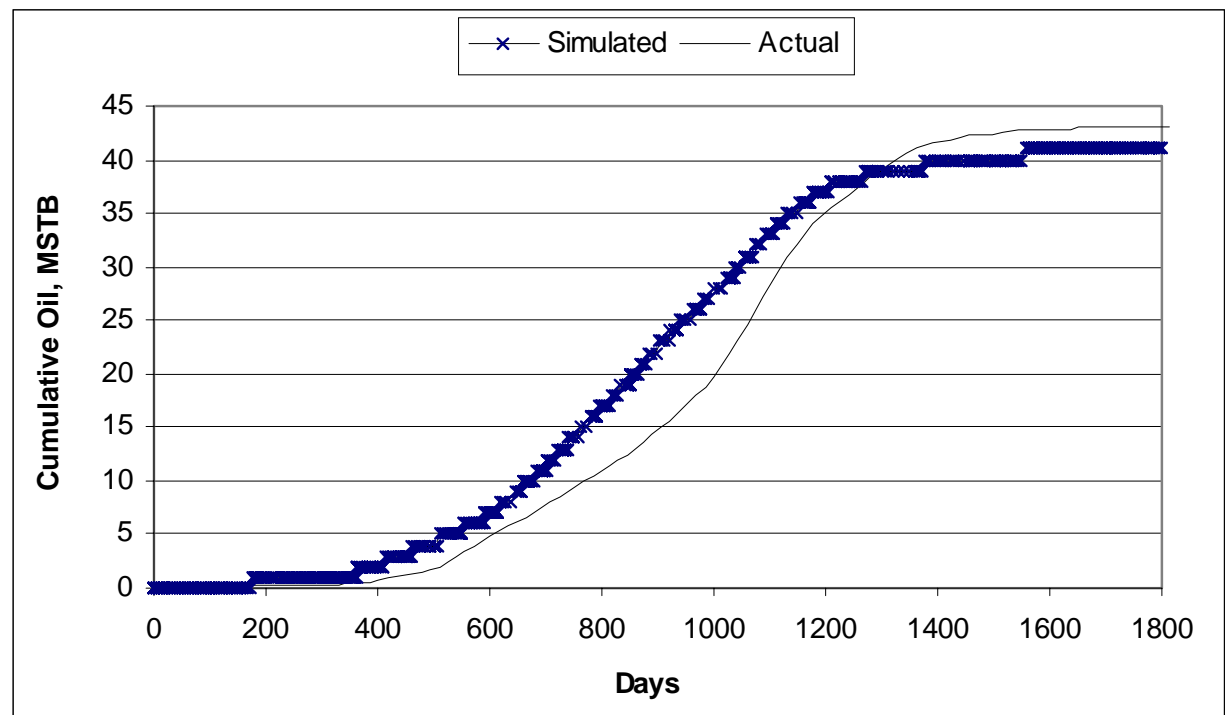

Figure F.1. Cumulative oil production for both producers. Lithologic zones taken as flow units.

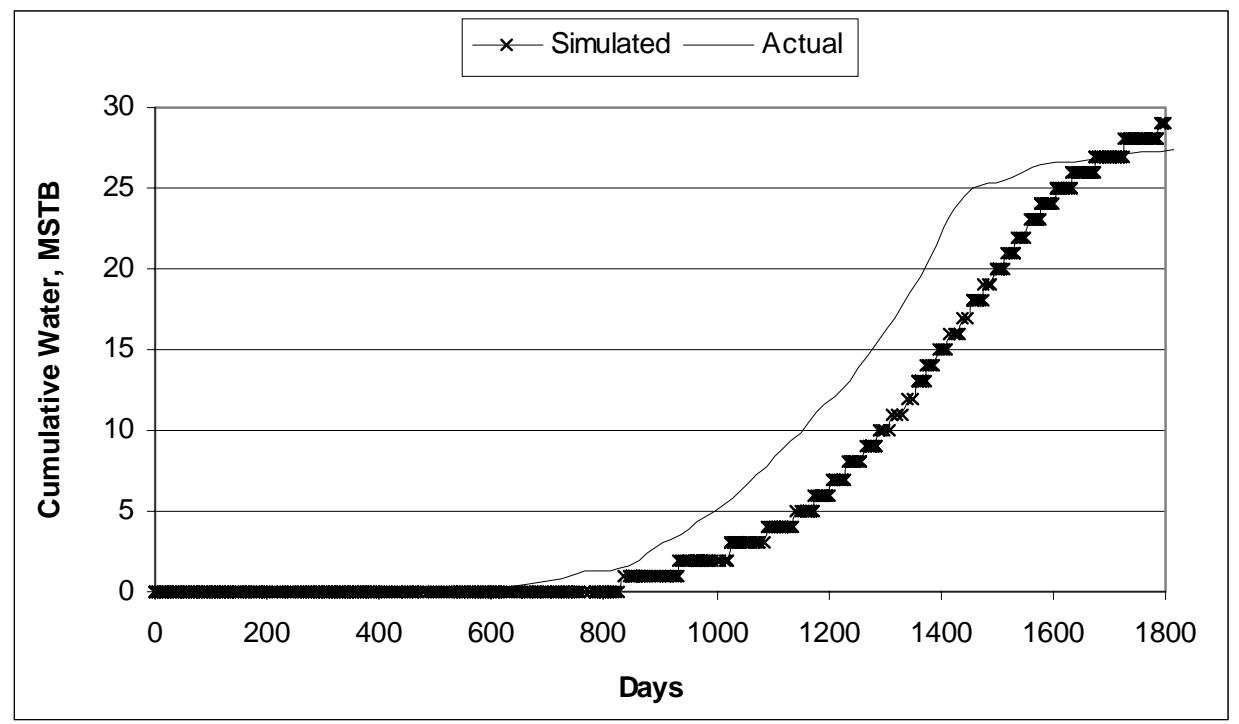

Figure F.2. Cumulative water production for both producers. Lithologic zones taken as flow units. 


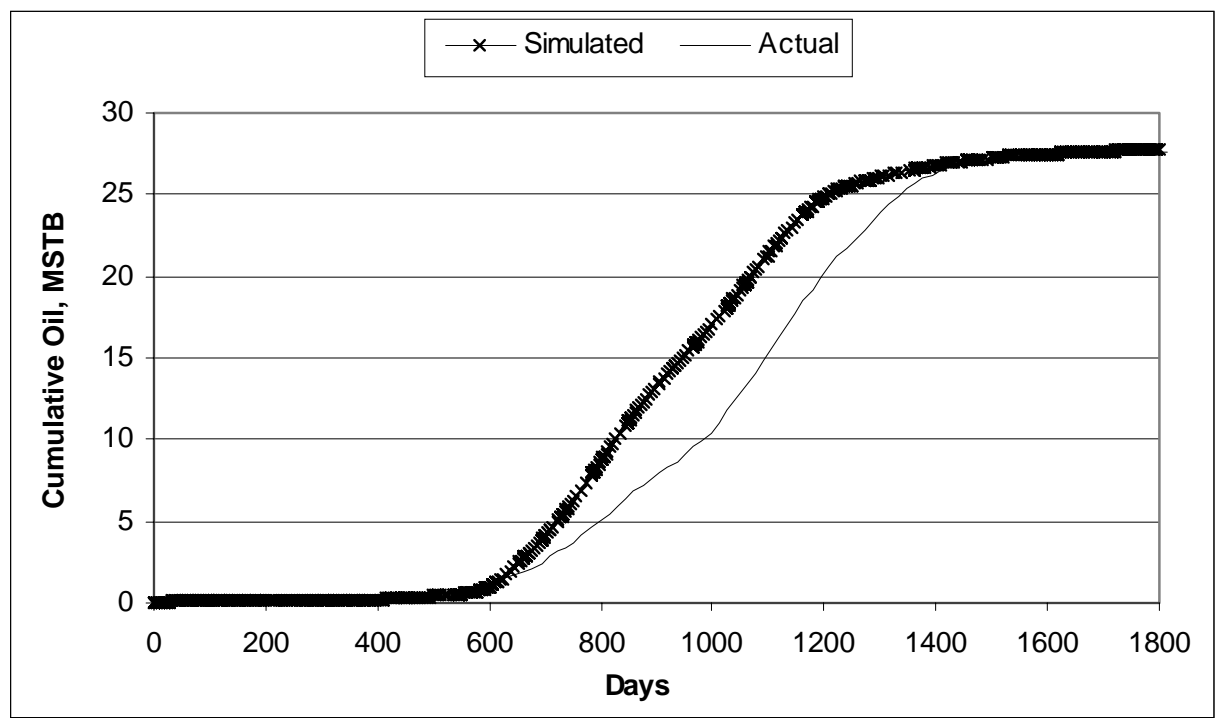

Figure F.3. Cumulative oil production, well M-1. Lithologic zones taken as flow units.

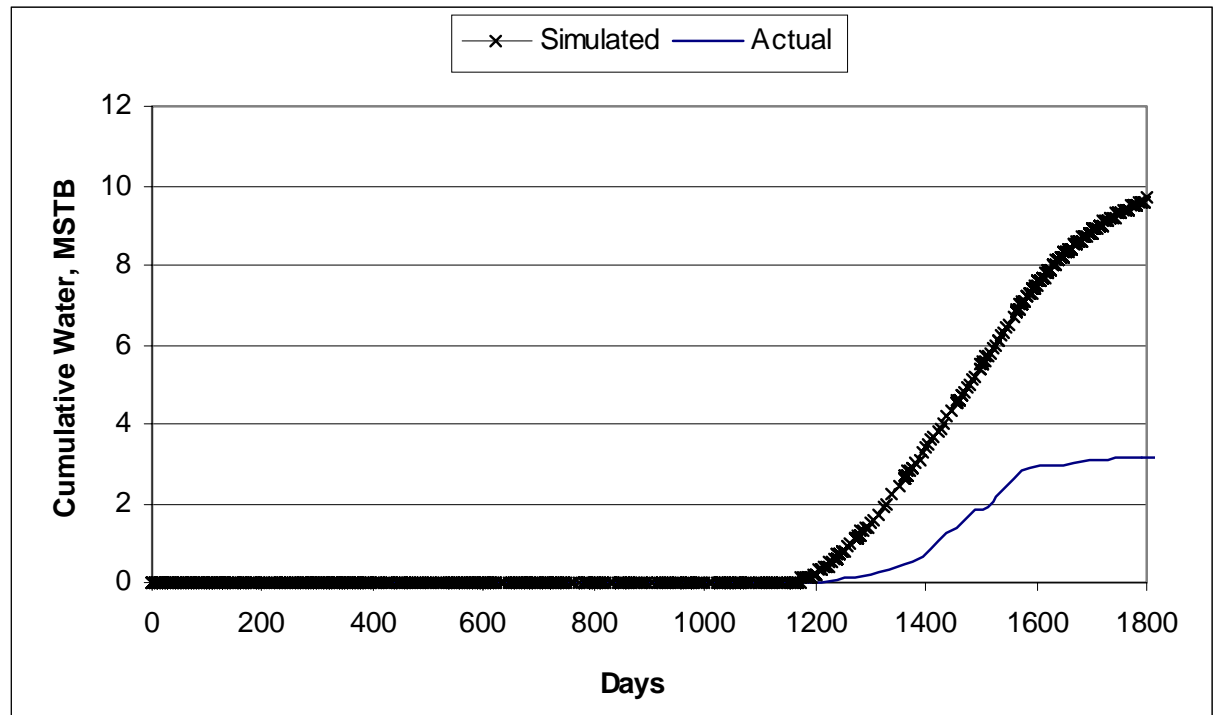

Figure F.4. Cumulative water production, well M-1. Lithologic zones taken as flow units. 


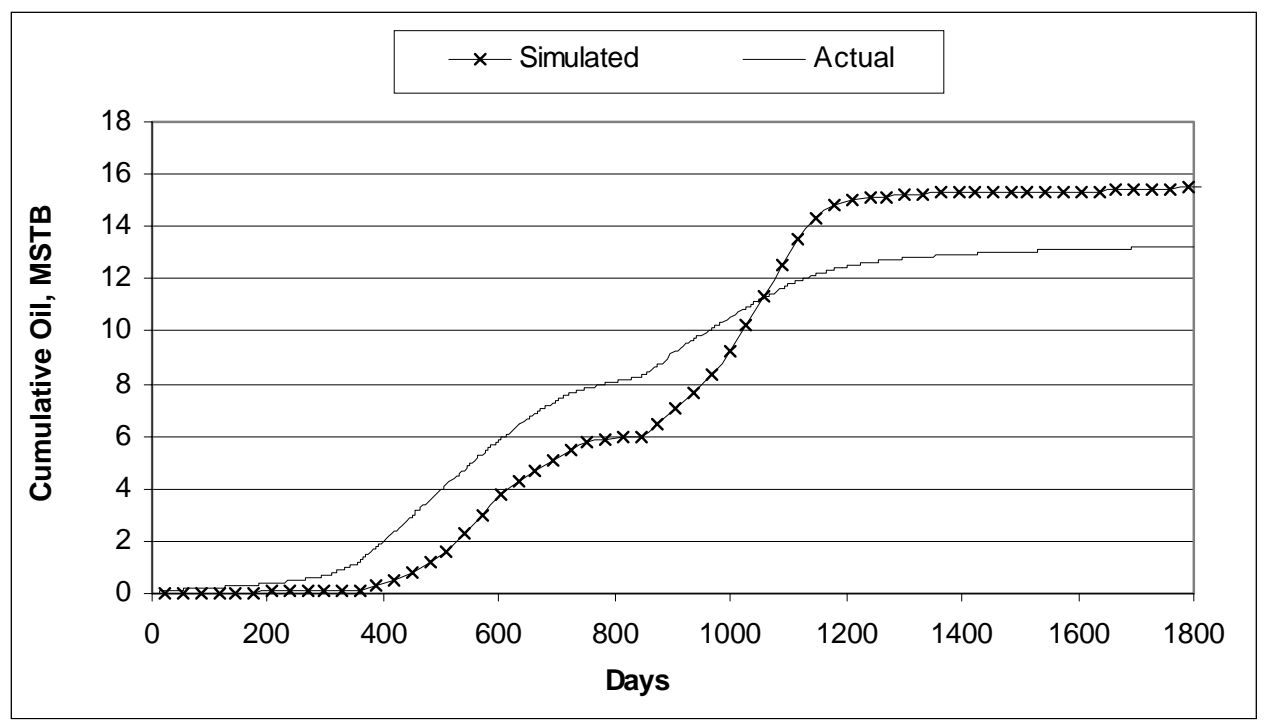

Figure F.5. Cumulative oil production, well H-12.

Lithologic zones taken as flow units.

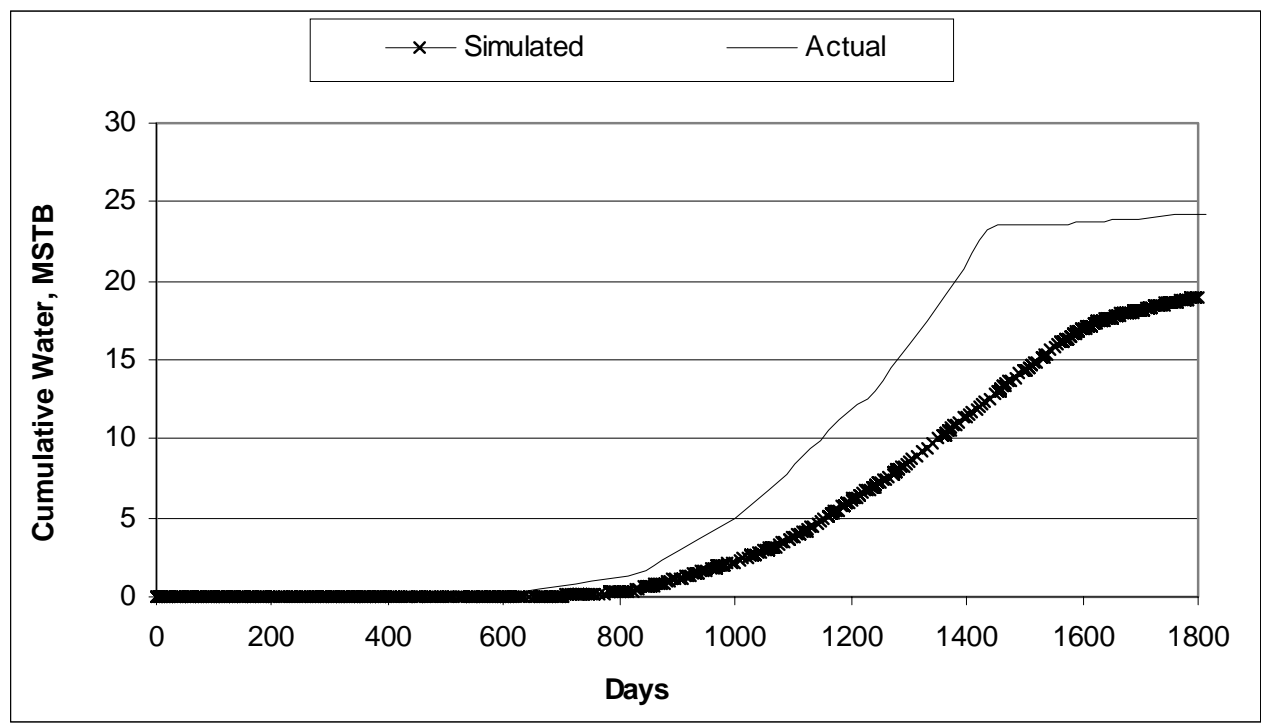

Figure F.6. Comparison of cumulative water production. Well H-12. Lithologic zones taken as flow units. 